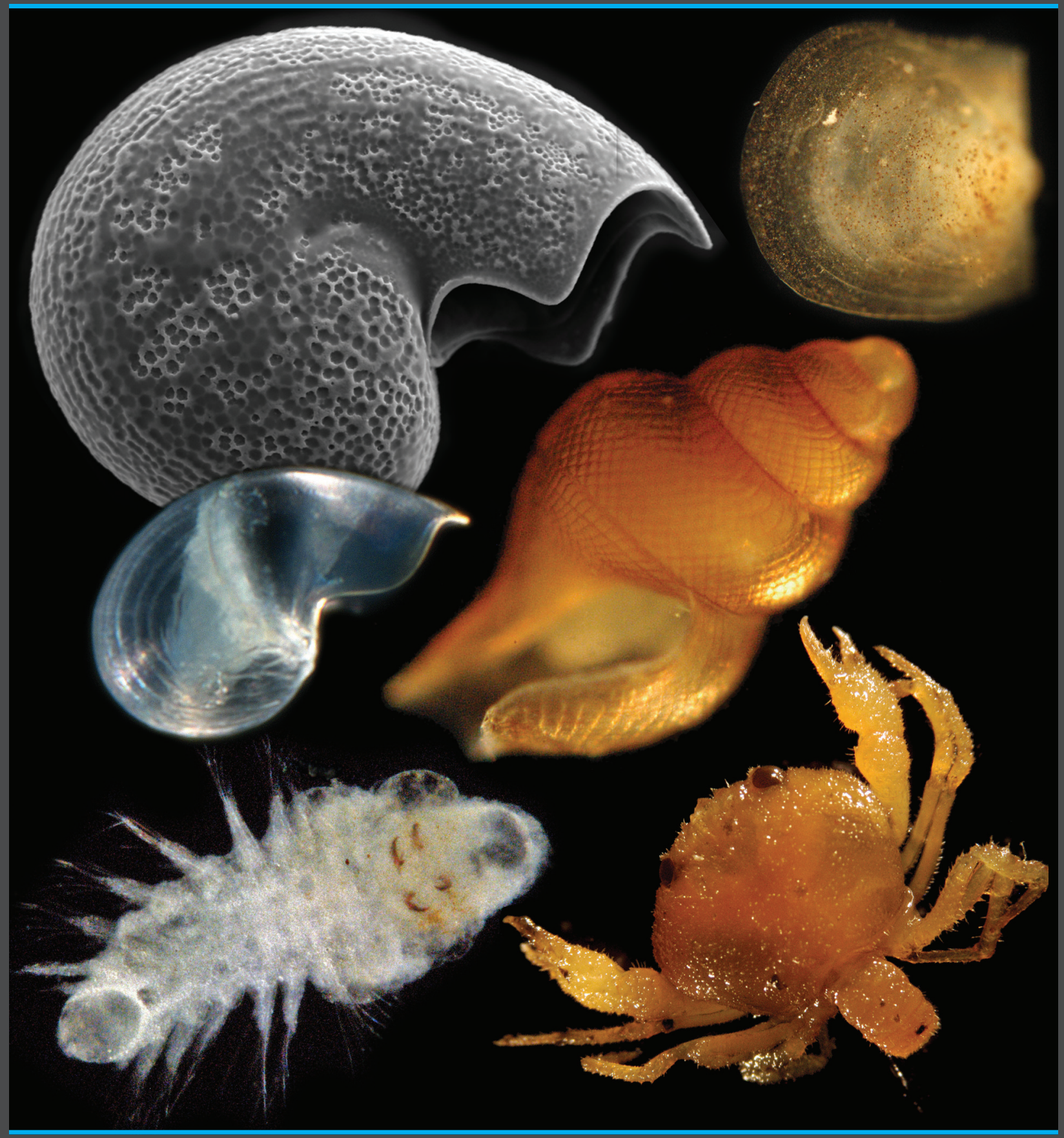

\title{
Photographic identification guide to larvae at hydrothermal vents
}

by Susan W. Mills, Stace E. Beaulieu and Lauren S. Mullineaux Woods Hole Oceanographic Institution

Funding provided by NSF grants OCE-9619605, OCE-9712233, OCE- 0424593 and ATM-0428122 and ChEss Grant \#WHOI 1334800.

Approved for public release; distribution unlimited. 


\section{WHOI-2009-05}

\section{Photographic identification guide to larvae at hydrothermal vents}

by

Susan W. Mills, Stace E. Beaulieu and Lauren S. Mullineaux

June 2009

\section{Technical Report}

Funding was provided by the National Science Foundation under Grant Nos. OCE-9619605, OCE-9712233, OCE-0424593 and ATM-0428122 and ChEss Grant No. WHOI 1334800.

Reproduction in whole or in part is permitted for any purpose of the United States Government. This report should be cited as Woods Hole Oceanog. Inst. Tech. Rept., WHOI-2009-05.

Approved for public release; distribution unlimited.

Approved for Distribution:

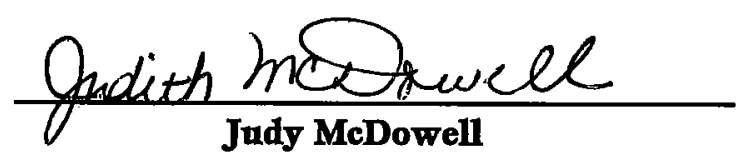

Department of Biology 
This page intentionally left blank 
Foreward $\ldots \ldots \ldots \ldots \ldots \ldots \ldots \ldots \ldots \ldots \ldots \ldots \ldots \ldots$

Acknowledgements ...............

Introduction. . . . . . . . . . . .

Methods.......................3

Using This Guide. . . . . . . . . . . . . . 5

Terminology. .................6

Gastropoda .....................

Gorgoleptis spiralis. . . . . . . . . . . . 9

"Pointy apex" .................. 11

Unknown benthic sp. A. . . . . . . . . 13

Unknown neomphalid $5 \ldots \ldots \ldots$

Lepetodrilus spp... . . . . . . . . . . . . . . . 17

Clypeosectus delectus . . . . . . . . . . . . 19

Gorgoleptis emarginatus...............21

Gorgoleptis sp. 3...............23

Unknown 7.. ...............25

Lepetodrilus-like protoconchs . . . . . . . . 27

Unknown 8.. .................29

Unknown 9. ................... 31

Echinopelta fistulosa. . . . . . . . . . . . 33

Peltospiraspp....................... 35

Lirapex granularis . . . . . . . . . . . . . 37

Unknown peltospirid $240 \mu \mathrm{m}$. . . . . . . . . 39

Unknown neomphalid B...........441

Cyathermia naticoides . . . . . . . . . . . . 43

Neomphalus fretterae . . . . . . . . . . . . . . 45

Melanodrymia ?galeronae ............47

Neolepetopsis spp.. ..................... 49

Pachydermia laevis ...............551

Eulepetopsis vitrea . . . . . . . . . . . . 53
Unknown neomphalid W. ............55

Melanodrymia aurantiaca . . . . . . . . . . 57

Unknown ?neomphalid $290 \mu \mathrm{m}$. . . . . . . . 59

Rhynchopelta concentrica ...........661

Ctenopelta porifera ..............663

Bathymargarites symplector . . . . . . . . . 65 65

Laeviphitus sp.. . . . . . . . . . . . . . . 67

Phymorhynchus sp. ................69

Bivalvia . . . . . . . . . . . . . . 71

Bathymodiolus thermophilus ..........71

Bathypecten vulcani. . . . . . . . . . . . 73

Polychaeta ........................75

Amphisamytha galapagensis . . . . . . . . . . 75

Archinome rosacea . . . . . . . . . . . . . . 77

"Chaetosphaerids" . . . . . . . . . . . . . .79

Glycera sp....................81

Nectochaetes....................83

Nereis sp.....................85

Ophryotrocha sp.................87

Polynoids... . . . . . . . . . . . . . . . .899

Unknown polychaete A. ..........91

Unknown polychaete B...........93

Crustacea ....................95

Barnacle cyprids. . . . . . . . . . . . . 95

Bythograea microps. . . . . . . . . . . . . 997

Bythograea thermydron ..............999

Foraminifera ................... 101

?Tretomphalus sp................. 101

Literature Cited . . . . . . . . . . . . . . . 102

Taxonomic Index . . . . . . . . . . . . . . . . 104 


\section{Foreward}

The purpose of this guide is to assist researchers in the identification of larvae of benthic invertebrates at hydrothermal vents. Our work is based on plankton sampling at the East Pacific Rise $9-10^{\circ} \mathrm{N}$ vent field from 1991-2007, supplemented by benthic collections of juveniles. In addition to images and descriptions of the species, we included frequency data from largevolume plankton pump samples taken between 1998 and 2004 and time-series sediment trap samples from 2004-2005.

This guide is divided into five sections: Gastropoda, Bivalvia, Polychaeta, Arthropoda and other miscellaneous taxa. All except the gastropods are in alphabetical order within a section. Since size is an important characteristic in species determinations in gastropod protoconchs, we have put them in order of ascending size. An alphabetical index is included at the end of the guide. Except where otherwise stated, light microscope

\section{Acknowledgements}

We are indebted to the taxonomists who described these species, whose papers appear in the Literature Cited section. In the case of the gastropods, they often included SEM's of the larval shells, which greatly assisted us in assembling this guide. In particular, we would like to thank Anders Warén for assistance with identifications of larval and juvenile gastropods and for advice on mounting specimens for SEM. In addition, we thank Stacy Kim, Pat McMillan, Anne Beaudreau, Andrew Sweetman, and Diane Adams for help in learning how to distinguish larval gastropods.

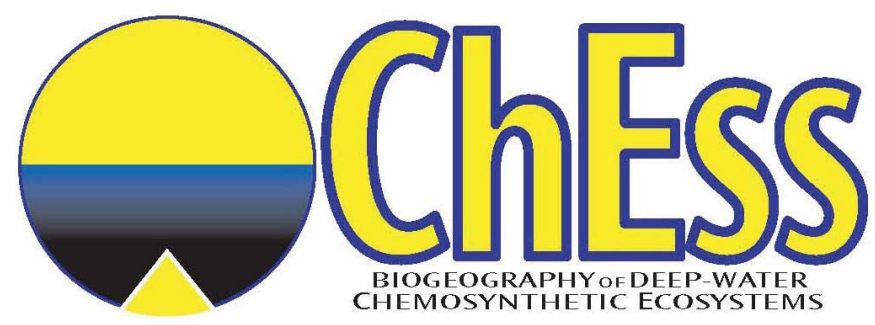

pictures were taken by Stace Beaulieu and SEM's by Susan Mills and Diane Adams.

Although our own samples are limited to the EPR $9-10^{\circ} \mathrm{N}$ site, we would like to expand this guide by including additional species from other areas. This guide is also available online at:

\section{http://www.whoi.edu/vent-larval-id/}

The online version includes links to ChEssBase and the Ocean Biogeographic Information System (OBIS). Please contact Susan Mills (smills@whoi.edu) or Stace Beaulieu (stace@whoi.edu) if you have photos you would like to have included on the website.

This guide is intended to serve as a companion to the Handbook of Deep-Sea Hydrothermal Vent Fauna (Desbruyeres, et al., 2006), which provides photographs and descriptions of the adult forms.

This work was funded by NSF grants OCE-9619605 to L. Mullineaux, D. Manahan and C. Young, OCE9712233 to L. Mullineaux, C. Fisher and C. Peterson, OCE-0424593 to L. Mullineaux, A. Thurnherr, J. Ledwell, D. McGillicuddy and W. Lavelle, ATM0428122 to H. Singh, T. Shank, L. Mullineaux, M. Neubert and others, by a WHOI Deep Ocean Exploration Institute grant to L. Mullineaux and S. Beaulieu and by a grant from the ChEss project of the Census of Marine Life to L. Mullineaux, S. Beaulieu and S. Mills.
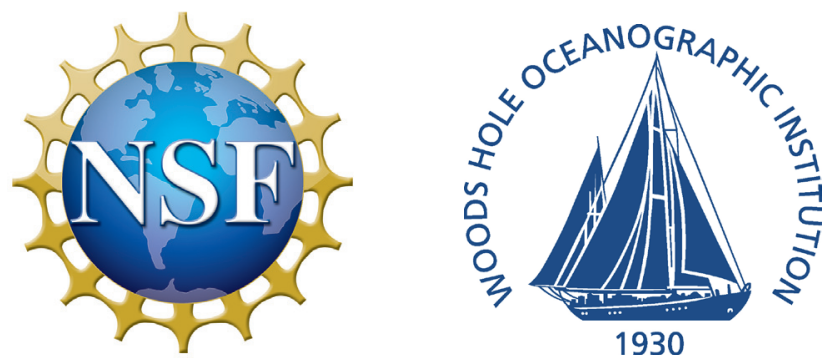


\section{Introduction}

For animals living on the seafloor, a planktonic larval stage is a critical phase of the life cycle. Larval dispersal provides ecological and genetic connections among communities in patchy habitats such as hydrothermal vents. Temporal variation in larval supply to benthic communities can lead to fluctuations in the size and genetic composition of adult populations. On long time scales, barriers to dispersal can lead to speciation and are thought to be fundamental factors in generating biogeographic patterns and regional biodiversity. Despite the importance of the larval phase, very little is known about larval dispersal in the deep sea, even at hydrothermal vents where the habitat is patchy and transient, and larval exchange critical to the survival of endemic species.

General difficulties of larval identification for deepsea studies include the scarcity of larvae in plankton samples, the fact that the adults may be unknown, and the difficulty of matching larval morphotypes to adult forms. However, some hydrothermal vent habitats have well-characterized benthic communities with relatively low species diversity and relatively high biomass and fecundity, resulting in large numbers of larvae in the

\section{Collection and preservation of larvae}

For this first edition of the identification guide, larvae were collected near hydrothermal vents at the East Pacific Rise (EPR) $9^{\circ} \mathrm{N}$ site. Specimens were obtained over a 15 -yr period, beginning with collection by nets and pumps with small-volume samples from 1991 1995 (Kim and Mullineaux, 1998), pumps with largevolume samples from 1998 - 2007 (Mullineaux et al., 2005; Beaulieu et al., 2009), and time-series sediment traps from 2004 - 2007 (Adams, 2007; Adams and Mullineaux, 2008). Net tows, plankton pumps, and sediment traps do not sample larvae in equal proportions - some are better collected by one method or another and a combination of methods is likely to give a more complete description of the larval species composition of a particular site (Beaulieu et al., 2009).

For our recent studies at the EPR, large-volume pumps were used to collect discrete plankton samples over plankton compared to typical deep-sea habitats. In addition, a large portion of hydrothermal vent communities can be comprised of gastropods, which can, in many cases, be identified by protoconch morphology. For example, gastropod larvae collected near hydrothermal vents in the eastern Pacific have been identified morphologically under light and electron microscopy (Mullineaux et al., 1996).

Since the discovery of hydrothermal vents thirty years ago, researchers have been collecting larvae in studies to explain the colonization of these oases in the deep (e.g. Lutz et al. 1984, Turner et al. 1985, Kim and Mullineaux 1998). Recent emphasis has been placed on time-series collections of larvae in multi-disciplinary studies of larval dispersal and supply to vent communities, such as the LADDER project at the East Pacific Rise (http://www.whoi.edu/projects/LADDER/). The purpose of this photographic identification guide is to serve researchers studying hydrothermal vent larvae in previously collected and future samples. The photographs may also be useful to those studying newly settled colonists.

\section{Methods}

1-day periods (McLane Large Volume Water Transfer System WTS-LV50; McLane Research Laboratories, Inc., Falmouth, MA, USA). We pumped $30 \mathrm{~L} \mathrm{~min}^{-1}$ $\left(500 \mathrm{~cm}^{3} \mathrm{~s}^{-1}\right)$ over a filter comprised of $63 \mu \mathrm{m}$ Nitex mesh, yielding $-40 \mathrm{~m}^{3}$ pumped per day. For time-series sampling we used a conical, time-series sediment trap with sampling aperture $0.5 \mathrm{~m}^{2}$ and 21 cups (McLane PARFLUX Mark 78H-21 Sediment Trap; McLane Research Laboratories, Inc., Falmouth, MA, USA). Prior to deployment, we filled the cups with a solution of $20 \%$ dimethylsulfoxide (DMSO) in ultrapure water saturated with $\mathrm{NaCl}$. We chose this preservative to allow for molecular genetic analyses of the collected specimens (e.g. Comtet et al., 2000). The pumps and sediment traps were deployed on autonomous subsurface moorings, with the samples collected between 2 and $175 \mathrm{~m}$ above bottom (mab) depending on each mooring configuration. Moorings were positioned within or near ( $<2 \mathrm{~km}$ off-axis) the axial summit trough. 


\section{Methods}

For the large-volume pump samples, after recovery on deck the filter holder was removed into a 20 -L bucket with chilled, filtered seawater. All subsequent handling of the sample occurred in a cold room ( $4^{\circ} \mathrm{C}$ ). Samples were carefully rinsed from the filter using a squirt bottle with chilled, filtered seawater. Many of the collected specimens were alive upon retrieval of the pump. We briefly examined the samples live under a dissecting microscope prior to collecting onto a $63 \mu \mathrm{m}$ sieve, rinsing with fresh water, then preserving in $95 \%$ ethanol for examination at our laboratory. For the sediment trap samples, after recovery of the mooring we photographed the cups and stored them at $4^{\circ} \mathrm{C}$ prior to shipment to our laboratory for examination.

\section{A. McLane Large Volume Water Transfer System WTS-LV50 Plankton Pump. \\ Photo by Carly Strasser, WHOI.}

\section{B. McLane PARFLUX Mark 78H-21 Sediment Trap. Photo by Skylar Bayer, WHOI.}

\section{Sorting and photographing larvae}

For sorting at our laboratory within a few months after each cruise, samples were poured over nested $300 \mu \mathrm{m}$ and $63 \mu \mathrm{m}$ sieves, and each fraction was rinsed with fresh water into a petri dish. We sorted larvae under a dissecting microscope at $25 \mathrm{X}$, with identification generally at 50X; some specimens required examination under a compound microscope at 100X. Individual larvae were manipulated with a fine paintbrush or short length $(-5 \mathrm{~mm})$ of human hair glued to the end of a wooden stick. Individuals were transferred with a pipette set to $-10 \mu \mathrm{L}$. For examining under the compound microscope, individuals were transferred to a welled slide filled with fresh water. We moved the cover slip gently side-to-side to roll the larva into an appropriate position for measuring and photographing. Larvae sorted from both sediment trap and pump samples were saved in 95\% ethanol and stored in Lauren Mullineaux's laboratory at Woods Hole Oceanographic Institution. We do not recommend transfer from DMSO solution to ethanol for future studies because it apparently caused tissue degradation for polychaete larvae.
A.

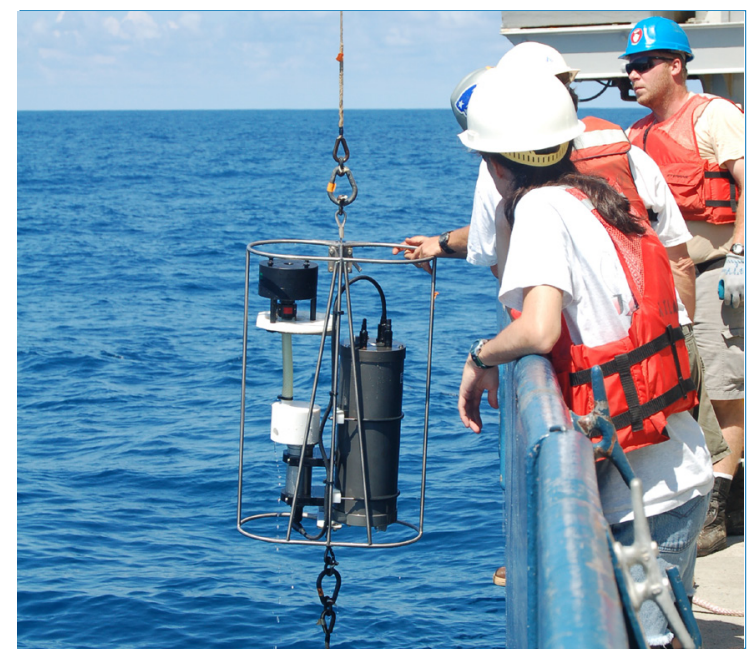

B.

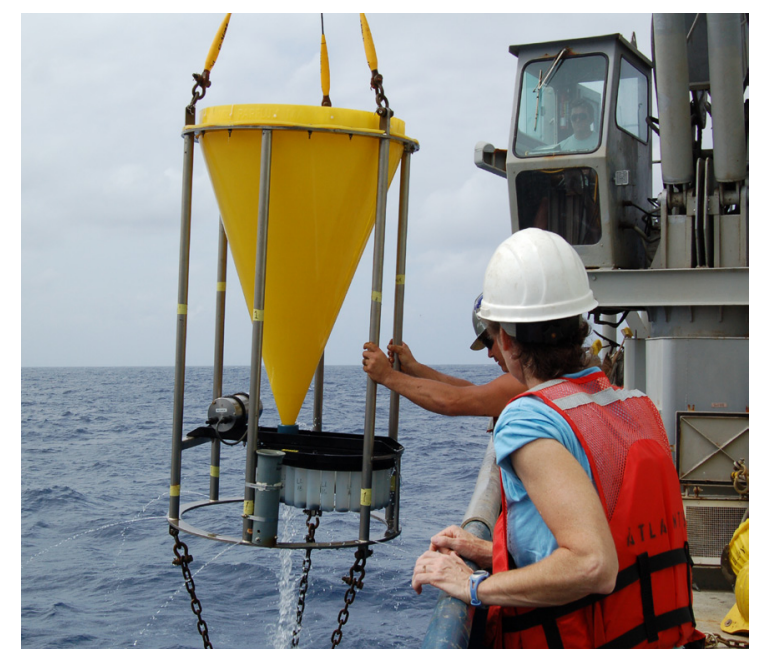

Some gastropod larvae were dried and imaged using scanning electron microscopy (SEM). These specimens were placed on $1.25 \mathrm{~cm}$ diameter circular cover slips which had been previously coated with a thin layer of white Elmer's glue, which was allowed to dry. The small amount of ethanol clinging to specimens dissolved the glue enough to stick them in place. The cover slip with the specimen was then attached to a SEM stub and sputter-coated for $1 \mathrm{~min}$ using Samsputter. These were examined using the JEOL 840 scanning electron microscope at the Marine Biological Laboratory (MBL).

Species identifications were made using a variety of sources. For gastropod protoconchs we relied heavily on the literature, which contains detailed SEM photographs of protoconchs for many species from the EPR $9^{\circ} \mathrm{N}$ site. For species for which the protoconch is unknown, we occasionally would image the protoconch of an identified juvenile for comparison (e.g., Gorgoleptis spiralis). For the identification of Bythograea sp. zoea, we are indebted to Ana Dittel (University of 
Delaware), who examined one of our specimens. Our mussel larvae were all at a stage near to settling and could be directly compared to the shells of settled juveniles. For polychaete larvae, we were forced to use comparisons with newly settled juveniles or similarity to larvae of other, related species; thus, most of these could not be identified to species. Assignment of deepsea polychaete larvae to species awaits development of molecular genetic probes (e.g., Pradillon et al., 2007).

Most of the photographs in this guide were taken through a Zeiss Axiostar compound microscope under brightfield, usually at $100 \mathrm{X}$ and occasionally only at 50X for larger specimens. For most of the photographs we used a Nikon D100 SLR digital camera with resolu-

This guide is intended to serve as a reference for the morphological identification of larvae collected near hydrothermal vents. In this first edition, the species are restricted to those found at EPR $9^{\circ} \mathrm{N}$. However, in future editions of this guide, we would like to include hydrothermal vent larvae from other regions, and we encourage contributions to our website. To use this guide to identify larvae, we recommend using both a dissecting and compound microscope, each with a calibrated micrometer in the eyepiece.

\section{Standard Description Format}

Top line: Species name (or morphotype), family, and original reference for description of the species.

Photo panels: Light microscopy, followed by SEM for gastropod protoconchs and, often, dark field for polychaete larvae.

Additional references with photographs: listed below the photo panels.

Size: Provided for calibrated dissecting and compound microscopes.

Morphology: Gastropod protoconchs and polychaete larvae are described using standard terminology (see Terminology on next page). If the morphotype is not tion $3008 \times 2000$ pixels and twelve bit dynamic range. We used an AF Zoom-NIKKOR 28-200mm lens and obtained the best images with F-stop 8, at shutter speed $-1 / 125 \mathrm{sec}$. Some photographs were taken with the same camera and a Zeiss Stemi 2000-C dissecting microscope. A few photographs were taken using a Zeiss Discovery.V12 Axiovision system dissecting microscope and Zeiss Axiocam MRc5 camera with Axiovision software at the MBL. The original images were adjusted using Adobe Photoshop software to enhance details.

For those who would like more information about methods of preserving, handling and storing small gastropods, we highly recommend Geiger et al. (2007).

\section{Using This Guide}

identified to species, this section lists references to similar-looking species.

Frequency: For frequency designations, we used larval abundance data at EPR $9^{\circ} \mathrm{N}$ for on-axis, near-bottom pump samples from 1998-2000 (4 cruises, 4 locations, 12 samples; subset of data in Mullineaux et al., 2005) and 2004 (1 cruise, 1 location, 5 samples; Beaulieu et al., 2009), and one on-axis, near-bottom deployment of a time-series sediment trap from Nov. 2004 - Apr. 2005 (Adams, 2007). Trap frequency data are not available for polychaetes, as they are generally poorly preserved in the DMSO solution used in the traps.

We used four categories to describe the frequency of each species (or morphotype):

Common: Present in majority of samples, at relatively high abundance overall (i.e., >5\%)

Frequent: Present in majority of samples, at relatively low abundance overall (i.e., $<5 \%$ )

Occasional: Present in $<1 / 2$ samples, at variable (usually low) relative abundance per sample

Rare: Present in very few samples, with only a single individual per sample.

"Can be confused with": This section provides thumbnail photos of similar-looking species (or morphotypes), with comparisons of morphological features. 


\section{Terminology}

\section{Gastropod terminology}

With a few exceptions, we photographed the protoconchs in the apical view, with the aperture on the bottom right-hand side of the picture, as illustrated in the diagram below. This is the side that remains visible after the larva settles and begins post-larval growth, so the photos can be directly compared to juveniles and adults that have retained their protoconchs. The more proximal ("posterior") portions are to the left in the diagram, the more distal ("anterior") to the right. The axis of coiling is the point around which the coil of the shell rotates. Most of these larvae are planispiral, or nearly so, meaning that their coiling is more or less in one plane. This gives them a sort of pseudo-bilateral symmetry and we will sometimes refer loosely to the "base" (at the bottom left-hand side of the diagram) and the "height" of the shell, as well as to the "right" side (facing out of the page in the diagram), the "left" side (facing into the page in the diagram), the "bottom" (the view with the aperture facing out of the page) and the "top" (the view with the aperture facing into the page). Many of these protoconchs have an aperture rim; usually this is visible only with the light microscope.
Most of these larvae have some form of sculpture on their shells. In the planispiral species, there are three types, with some degree of overlap:

Pitted sculpture, which is typical of the Family Lepetodrilidae, consists of depressions in the surface of the shell. These may be small or large, shallow or deep and may be widely scattered or so close together that the entire surface of the shell is pitted. Sometimes the pits may follow the curve of the shell, so that the sculpture appears to form lines. Pitted sculpture often appears grainy under the light microscope.

Lineate sculpture, found in the Family Peltospiridae, is a series of regularly-spaced ridges that follow the curvature of the shell. The lines usually start at the axis of coiling, though there are exceptions, and extend most of the way to the aperture. There may be other forms of sculpture present as well, such as tubercles - raised bumps - as found in Lirapex granularis.

Reticulate sculpture is formed by raised ridges, but instead of following the curvature of the shell, they spread out to form a mesh. This network may be very regular and interconnected or consist of relatively few irregularly forking lines. Sometimes the mesh covers the entire shell; more commonly it is limited to the more proximal portions of the shell. This kind of sculpture is found in the Neomphalidae.

Terminology for planispiral forms, with protoconch I. Apical view.

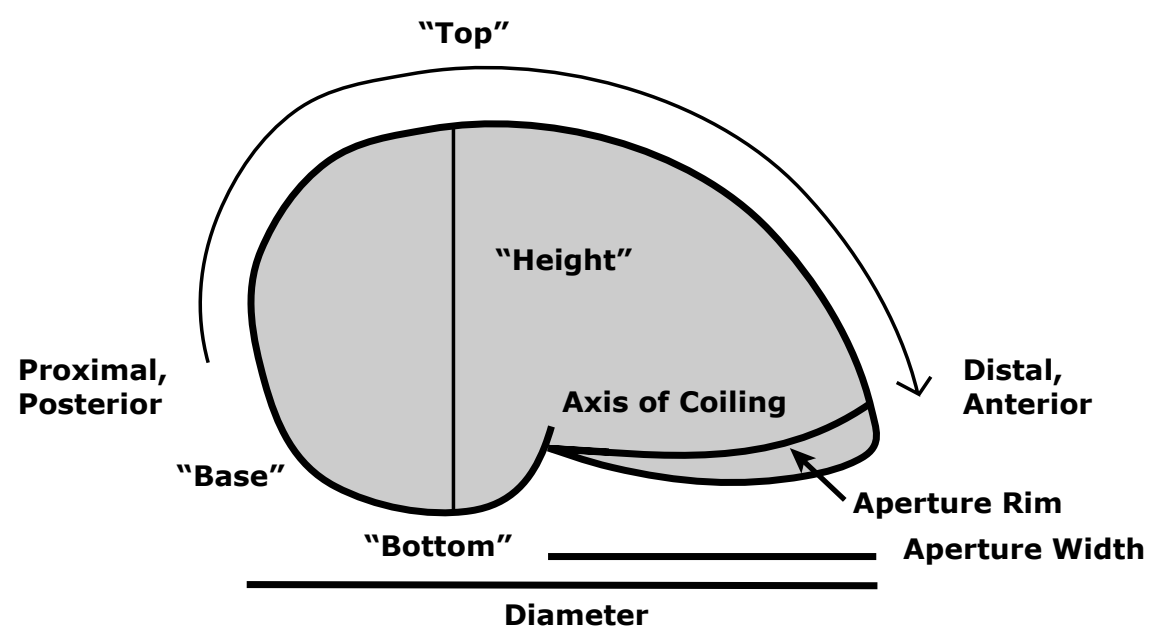

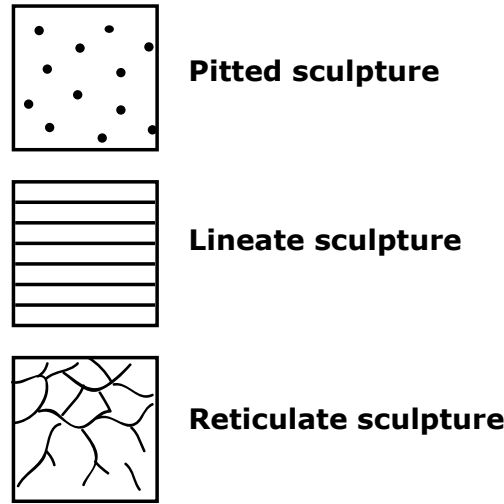




\section{Terminology}

For coiled forms we use slightly different terminology. These shells generally show two different growth stages, often with different types of sculpture. The earliest shell, protoconch I (PI), usually is formed while the larva is non-feeding, the second, protoconch II (PII) is formed after the larva begins feeding in the plankton. All of these shells are right-handed, meaning that when the shell is oriented with the apex at the top and the ap- erture opening facing out of the page, the aperture will be to the right. Our photographs usually show both the apical view, to illustrate PI, and the aperture view, which shows the larva as it is usually found in samples. In these species, we refer to sculpture that follows the curvature of the shell as spiral and sculpture that radiates out from the axis of coiling as axial.

Terminology for coiled forms, with both protoconchs I and II. Apical view.

Protoconch I

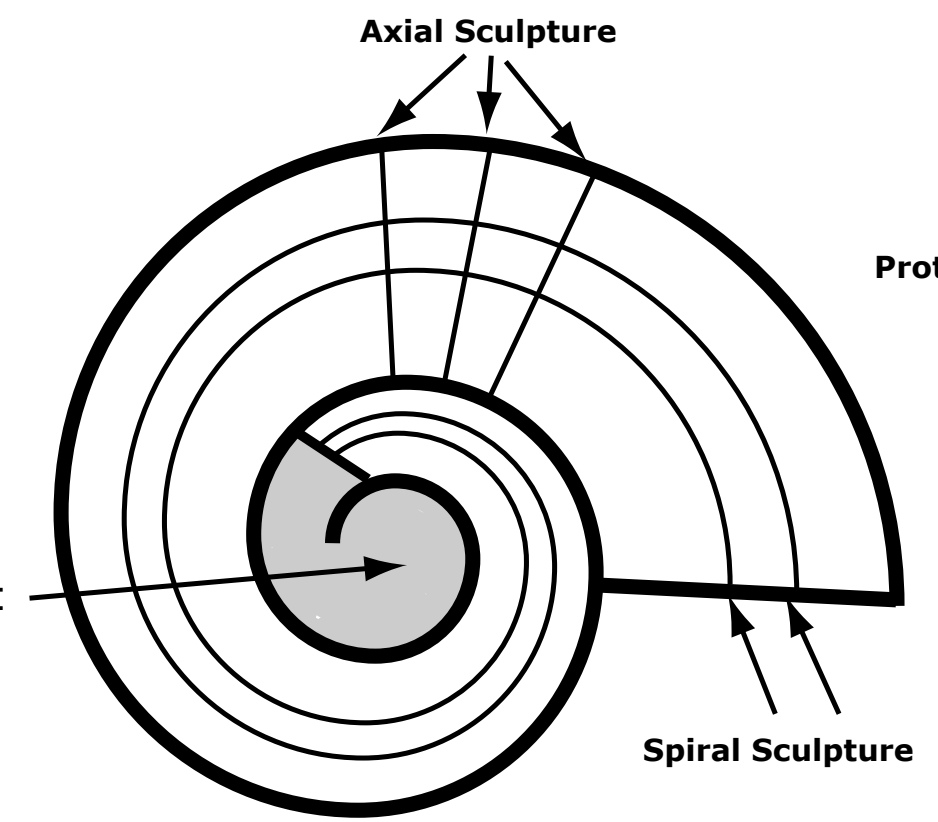

\section{Polychaete Terminology}

We are not qualified to give a detailed description of larval polychaete terminology, but for those unfamiliar with the group we have included definitions for a few of the standard terms. The first segment of a polychaete (the "head") is called the prostomium; the final segment ("tail") is the pygidium. The head may include appendages such as antennae (shown here) and palps and also one or more pairs of tentacular cirri, which are often on the second segment (the peristomium, not shown here). The pygidium may have anal cirri.
Terminology for polychaete larvae and juveniles.

Dorsal view.
The main body segments often have fleshy, paired "feet" (parapodia) protruding to the sides, which have bunches of bristles (chaetae) at the tips. A body segment with chaetae is referred to as a chaetiger. Chaetigers may have cirri or branchiae (gills) as well (not shown in this diagram).

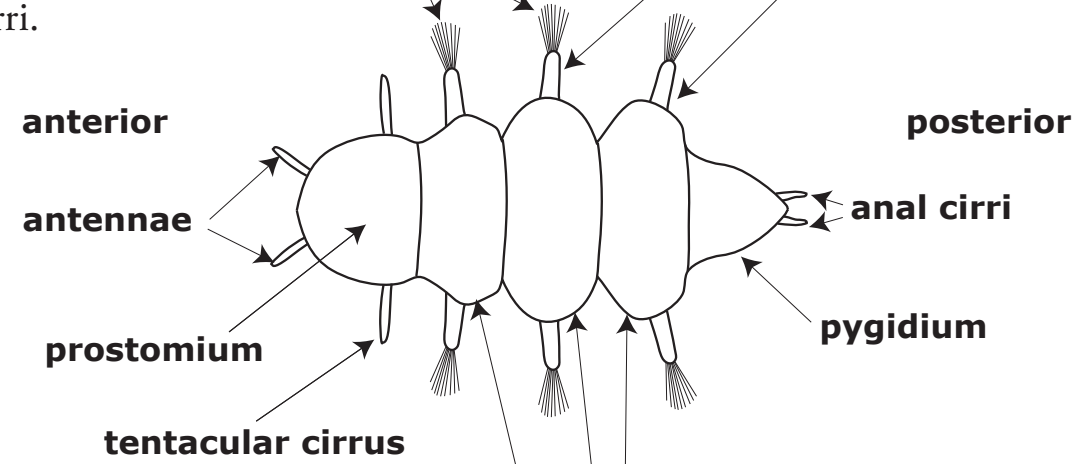

chaetigers 


\section{Can be confused with:}

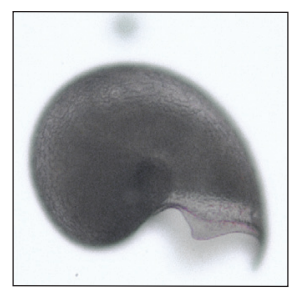

Gorgoleptis emarginatus strongly resembles $G$. spiralis in everything but size; G. spiralis is about $30 \mu \mathrm{m}$ smaller.

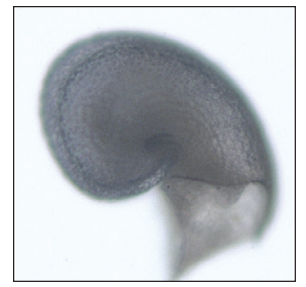

Gorgoleptis sp. 3. This presumed Gorgoleptis species is also about $30-35 \mu \mathrm{m}$ larger than $G$. spiralis. The point at the outer edge of the aperture is more pronounced in this group, it lacks the side points and is much less common. 


\section{GASTROPODA}

\section{Gorgoleptis spiralis McLean, 1988. Family Lepetodrilidae.}

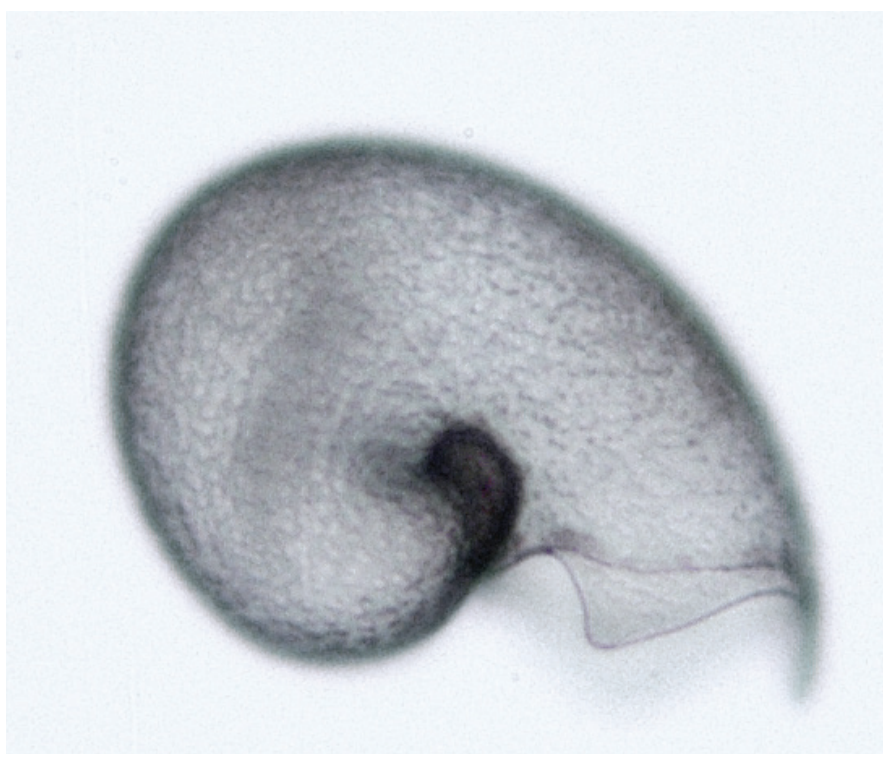

Size: $140-150 \mu \mathrm{m}$

\section{Morphology:}

Gorgoleptis spiralis is one of three presumed Gorgoleptis morphs we find in plankton samples at EPR $9^{\circ} \mathrm{N}$. It has coarse pitted sculpture in rows that follow the curve of the shell. The most distinctive feature of these protoconchs is the scalloped edges of the aperture, with sharp points at the anterior edge and on either side. There is a narrow aperture rim, tapering toward the posterior edge. The protoconch matches that of Gorgoleptis spiralis in size and sculpture, but the scallops are not preserved in post-larval specimens, making the identification somewhat tentative.

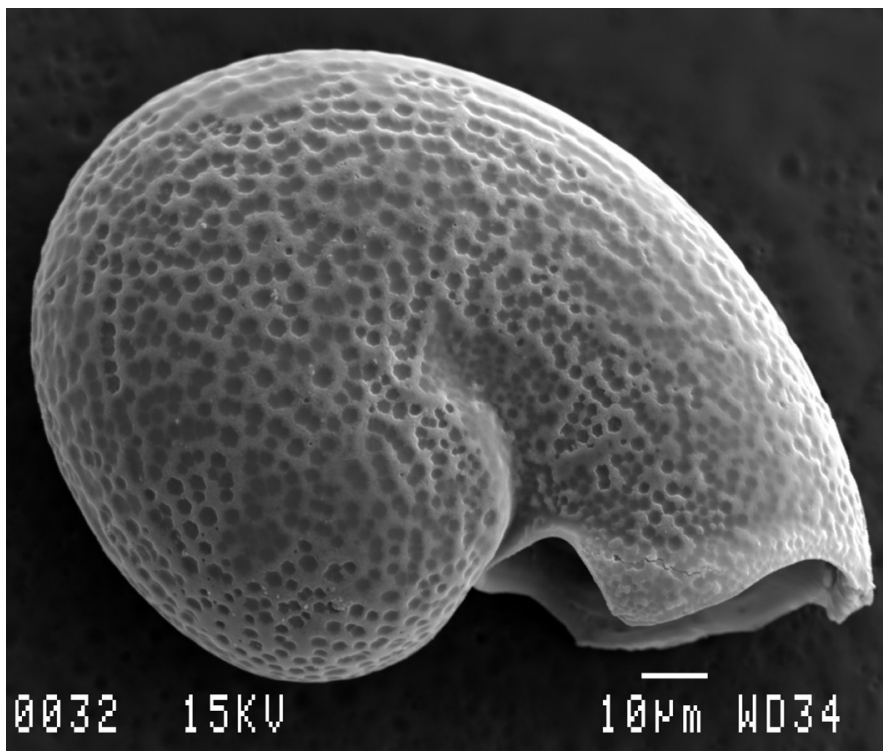

\section{Frequency:}

Pump EPR 1999-2000: Frequent

Pump EPR 2004: Frequent

Trap EPR 2004-2005: Frequent

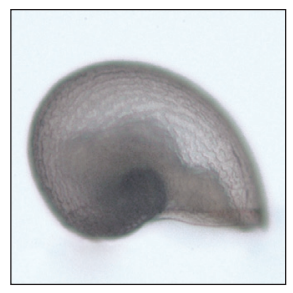

Clypeosectus delectus is about $25 \mu \mathrm{m}$ larger than G. spiralis. The sculpture is also very similar, but the aperture is nearly straight, rather than scalloped.

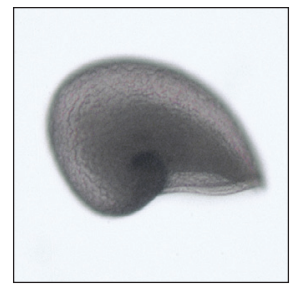

Pointy apex is about $10 \mu \mathrm{m}$ larger than $G$. spiralis. The sculpture is also very similar, but the aperture is nearly straight, rather than scalloped. 
GASTROPODA 


\section{"Pointy apex" (unknown slit limpet in Mullineaux et al., 2005).}

\section{Family ?Lepetodrilidae.}

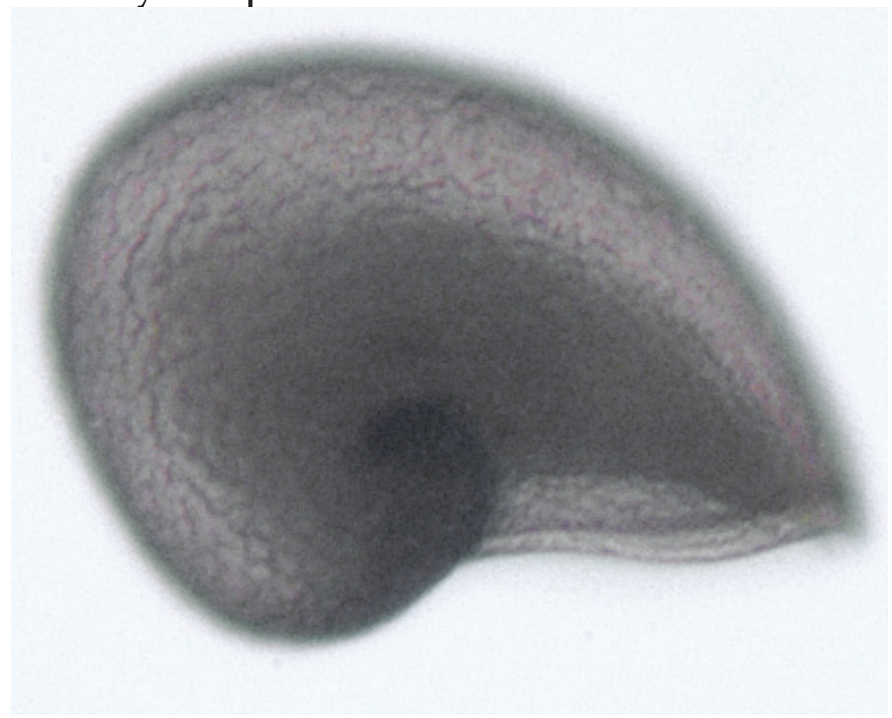

Size: $155-160 \mu \mathrm{m}$

\section{Morphology:}

These are small protoconchs with dense, shallow pitted sculpture over the entire shell, forming lines on the outer distal face. The shell itself is rather angular in overall appearance, with portions of the outline appearing almost flat. The aperture is slightly sinuous, with a narrow rim visible under the light microscope. The protoconch resembles Sutilizona theca, a slit limpet described from EPR $13^{\circ} \mathrm{N}$ in McLean (1989; SEM Fig. 4F).

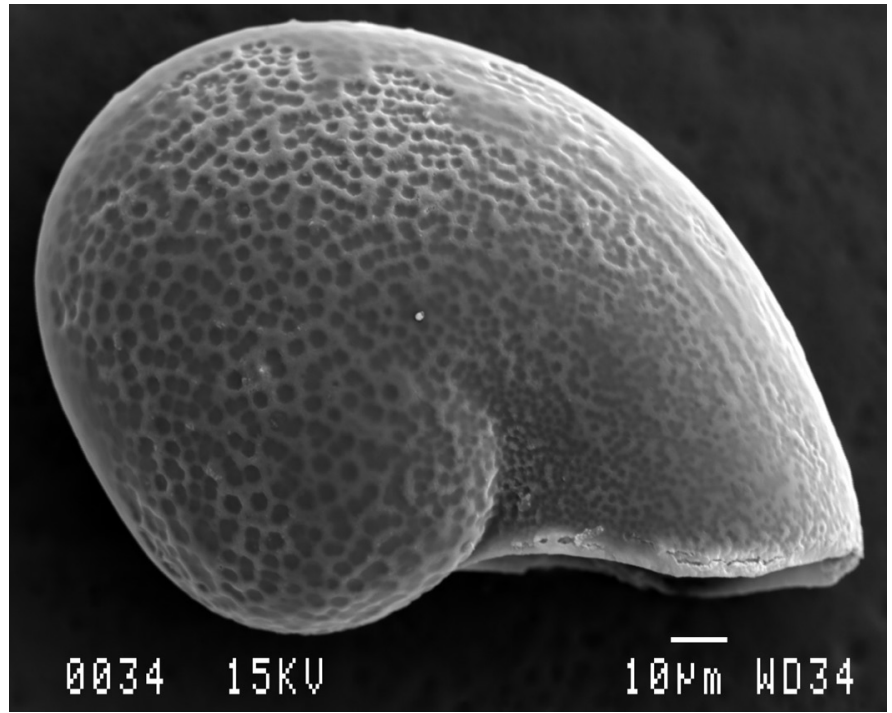

\section{Frequency:}

Pump EPR 1999-2000: Frequent

Pump EPR 2004: Frequent

Trap EPR 2004-2005: Frequent

\section{Can be confused with:}

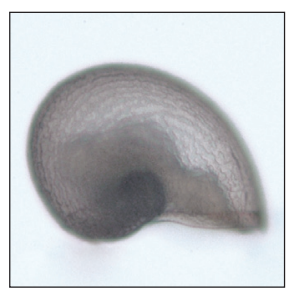

Clypeosectus delectus is very similar in size and appearance to pointy apex. It is possible that both protoconchs represent different forms of the same species (or possibly two species in the same genus), but because of consistent differences in their morphology, we have kept them separate for the present. Pointy apex can be distinguished by the more angular shape of this species, by its slightly smaller size $(160 \mu \mathrm{m}$ vs. $175 \mu \mathrm{m}$ for Clypeosectus) and by its narrower aperture rim.

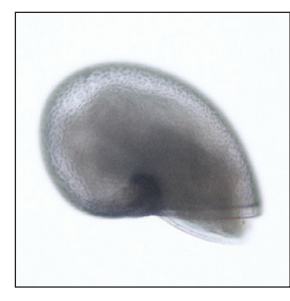

Lepetodrilus spp. Lepetodrilus spp. have finer pitted sculpture that doesn't usually show lineation. The base of the shell lines up with the aperture in these protoconchs, whereas in pointy apex it protrudes below. Pointy apex is about $15-20 \mu \mathrm{m}$ smaller.

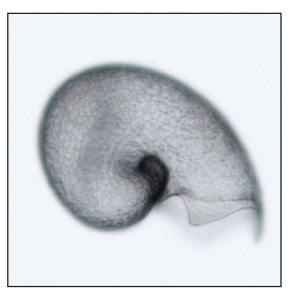

Gorgoleptis

spp., especially G. spiralis, pictured at left. All Gorgoleptis species have a sharp point at the outer edge of the aperture, and two have points at the sides as well. Gorgoleptis spiralis is slightly smaller than pointy apex; the other two Gorgoleptis species are about $20 \mu \mathrm{m}$ larger. 
GASTROPODA 


\section{GASTROPODA}

\section{Unknown benthic sp. A Family ?Neomphalidae.}
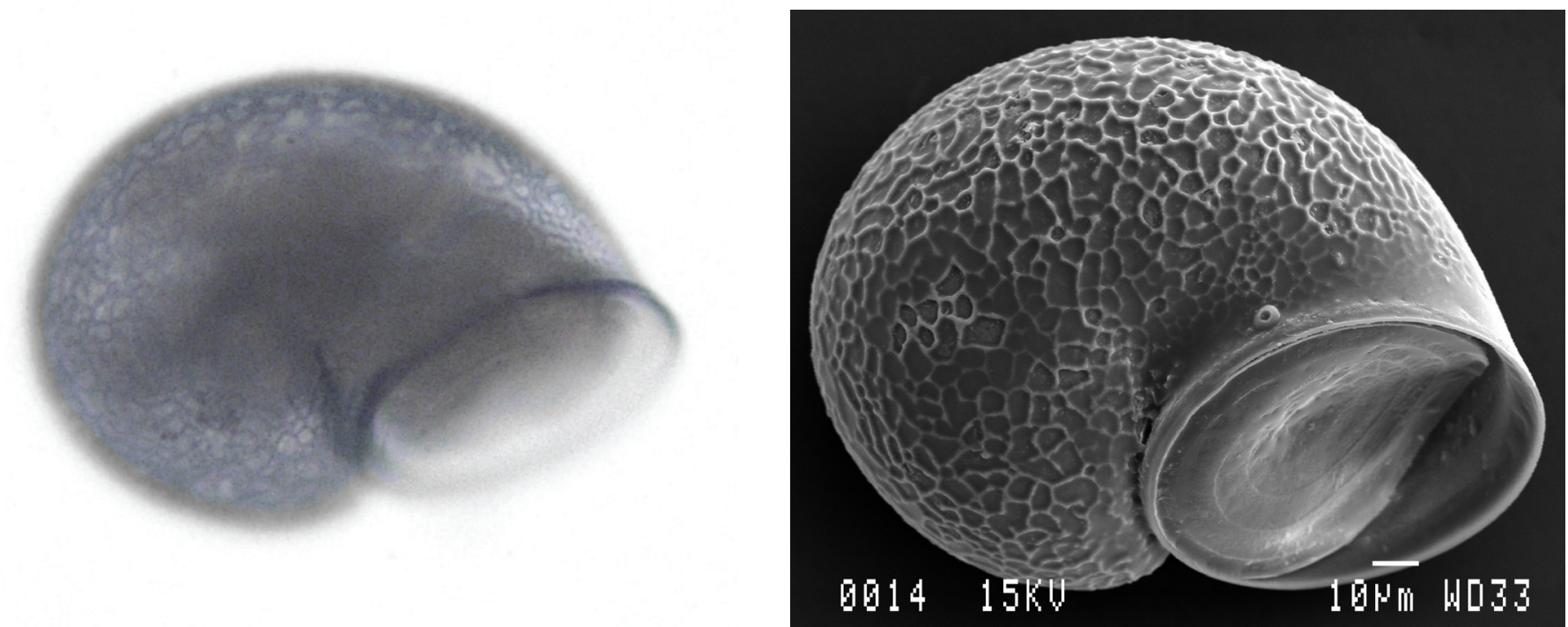

Size: $160-170 \mu \mathrm{m}$

\section{Morphology:}

This is a small distinctive protoconch. Nearly all the vent protoconchs are planispiral, with a very slight right-hand twist. This one, however, has a distinct left-hand twist, so that if you try to set it on its left side in our standard orientation for photographing the protoconchs, it will roll to show the aperture, as in the SEM above. It has overall regular reticulate sculpture and may be a neomphalid.

\section{Frequency:}

Pump EPR 1999-2000: Common

Pump EPR 2004: Common

Trap EPR 2004-2005: Common

\section{Can be confused with:}

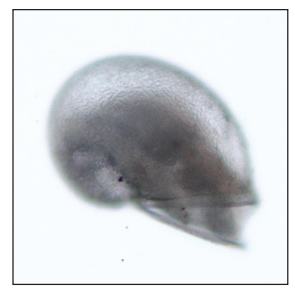

Unknown 5 looks very much like Unknown A, though it is about $10 \mu \mathrm{m}$ larger. It has a distinct flare to the aperture rim, which is wider than that of Unknown A. The easiest way to distinguish them quickly is to roll them; Unknown A will generally roll to expose the aperture, while Unknown 5 is stable on its side, as shown at left.

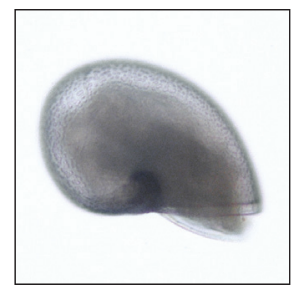

Lepetodrilus spp. is about $10 \mu \mathrm{m}$ larger than Unknown A. Lepetodrilus spp. has pitted sculpture rather than reticulate and is also stable on its side. 
GASTROPODA 


\section{GASTROPODA}

\section{Unknown neomphalid 5 Family ?Neomphalidae.}

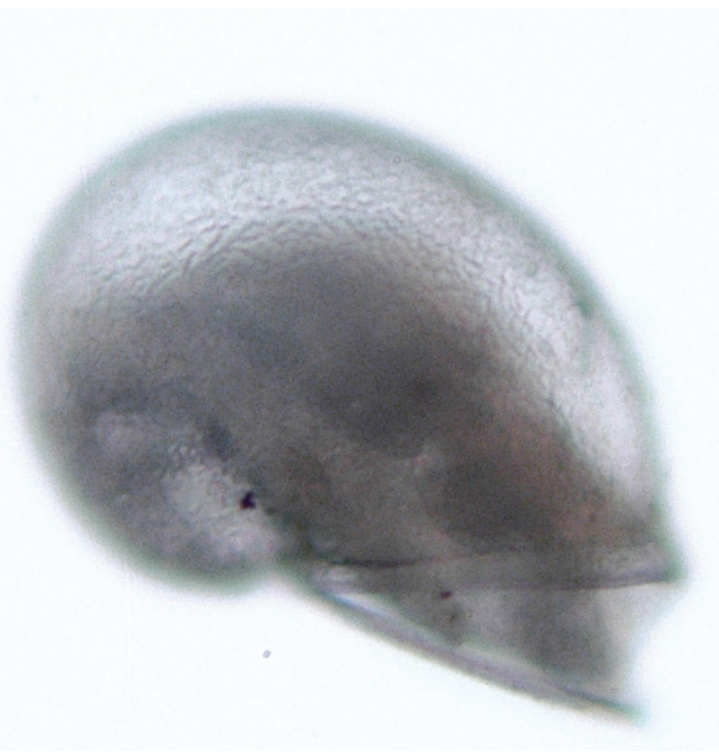

Size: $170-180 \mu \mathrm{m}$

\section{Morphology:}

This is a small bulbous protoconch with overall fine reticulate sculpture. It has a straight aperture with a narrow rim which flares out all around. Seen from the side, the aperture and the lowest part of the base line up. From this angle the aperture measures about $2 / 3$ of the total diameter of the shell. It resembles some of the Lacunoides protoconchs in the literature (especially L. vitreus from Juan de Fuca; Warén and Bouchet, 2001, p.167, Figure 29e), but neither of the described species has been reported from EPR $9^{\circ} \mathrm{N}$, to our knowledge. Because of the reticulate sculpture, we suspect that it is a neomphalid.

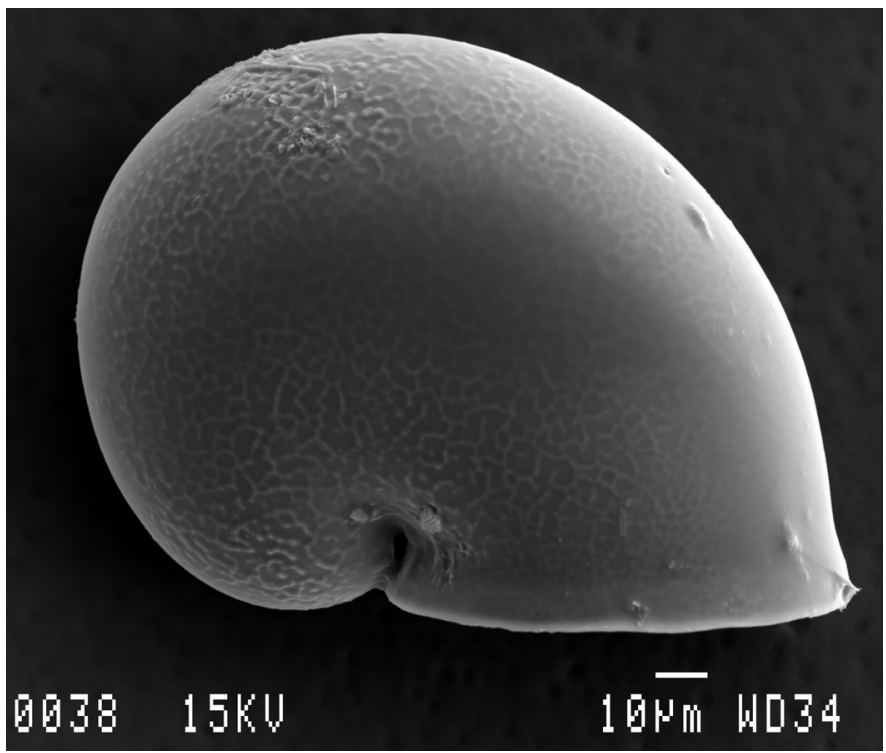

See also Fig. 4A in Mullineaux et al. (1996)

\section{Frequency:}

Pump EPR 1999-2000: Occasional

Pump EPR 2004: Common

Trap EPR 2004-2005: Common

\section{Can be confused with:}
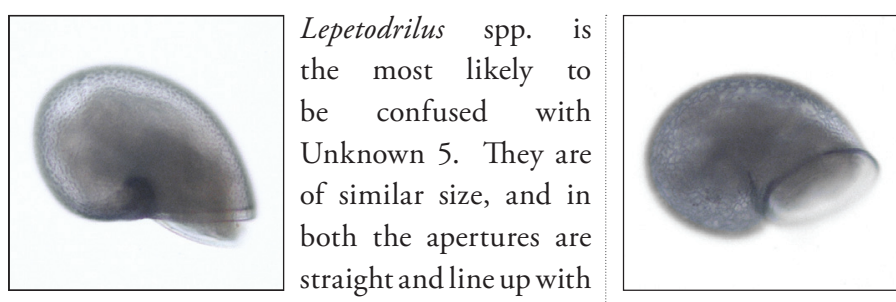

the base of the shell. In

Unknown 5, however, the aperture, when seen from the side, appears to take up about $2 / 3$ of the shell diameter, whereas in Lepetodrilus it is about half. Unknown 5's aperture rim is narrower and it flares out to the sides and at the outer edge. Lepetodrilus has pitted sculpture rather than reticulate, but this is not usually obvious under the light microscope.
Unknown benthic sp. A is about $10 \mu \mathrm{m}$ smaller than Unknown 5, but is similar in appearance and also has reticulate sculpture. It has a slight left-hand twist, which tends to make it roll to expose the aperture. Unknown 5, however, is

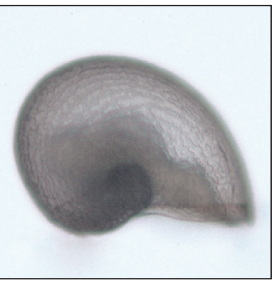
Clypeosectus delectus is similar in size to Unknown 5, but the aperture does not form a straight line with the base, and it has coarse pitted sculpture, rather than reticulate. 


\section{Can be confused with:}

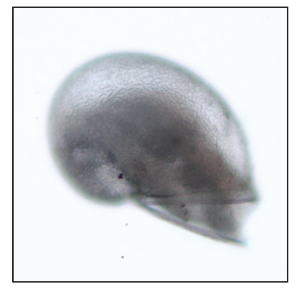

Unknown

Lepetodrilus spp. has

a more streamlined appearance, with the aperture length about half the diameter of the protoconch. Unknown 5 is more rounded and the aperture is closer to $2 / 3$ the protoconch diameter. The aperture rim is narrower in Unknown 5, and it flares out at the anterior edge and at the sides. Unknown 5 has reticulate rather than pitted sculpture, but this may not be apparent under the light microscope.

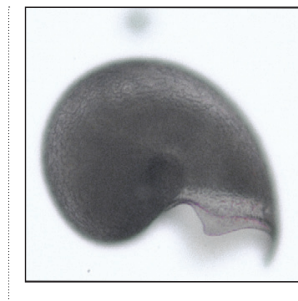

Gorgoleptis emarginatus is approximately the same size as Lepetodrilus spp. Its sculpture is much coarser, and it has points at the outer edge and both sides of the aperture, giving it a scalloped appearance. The aperture does not line up with the base as it does in Lepetodrilus.

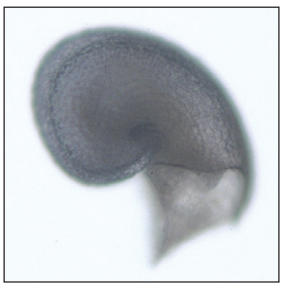

Gorgoleptis sp. 3 is also approximately the same size as Lepetodrilus spp. Its sculpture is much coarser, it has a point at the outer edge of the aperture. The aperture does not line up with the base as it does in Lepetodrilus. 


\section{Lepetodrilus spp. Family Lepetodrilidae.}

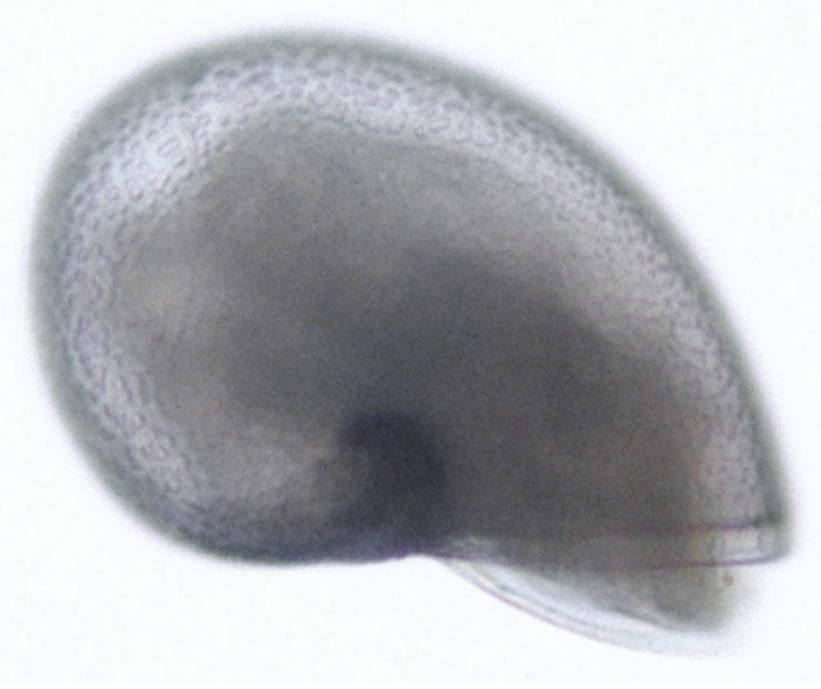

Size: $170-180 \mu \mathrm{m}$

\section{Morphology:}

These are small protoconchs with fine pitted sculpture. In some individuals the pits appear to form lines, but this is not usually evident under the light microscope. The line of the aperture continues straight to the posterior edge of the shell in the apical view. There is a distinct medium-width aperture rim visible under the compound microscope. Five species of Lepetodrilus - L. cristatus, L. elevatus, L. ovalis, L. pustulosus (all described in McLean, 1988) and L. tevnianus McLean 1993, are present at EPR $9^{\circ} \mathrm{N}$. All of these species have protoconchs that are similar in size and shape. Under the light microscope some individuals are nearly transparent (as shown above), while others are more opaque; it is possible that this is a taxonomically useful trait, but the species cannot be distinguished morphologically at this time.

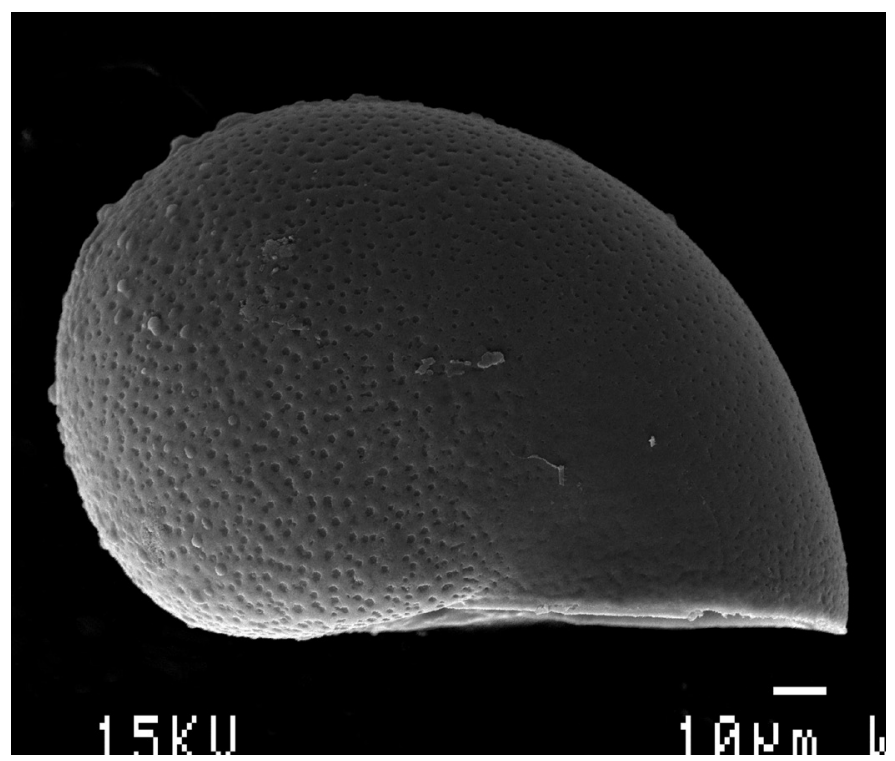

See also Fig. 1 in Mullineaux et al. (1996)

\section{Frequency:}

Pump EPR 1999-2000: Common

Pump EPR 2004: Common

Trap 2004-2005: Common

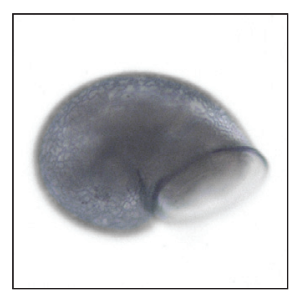

Unknown benthic sp. A is about $10 \mu \mathrm{m}$ smaller than Lepetodrilus spp. and has reticulate rather than pitted sculpture. It tends to roll to expose the aperture when moved with a probe,

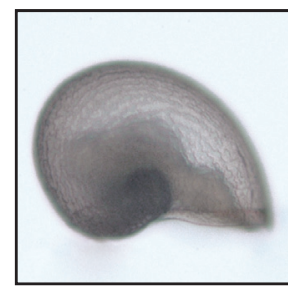

Clypeosectus delectus has coarser sculpture than does Lepetodrilus spp., and its aperture does not line up with the base.

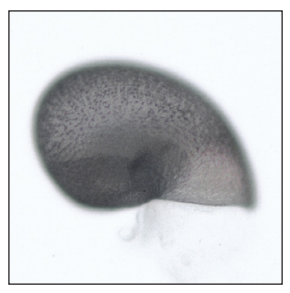

Lepetodrilus-like. There is a group of slightly larger protoconchs $(-190-195 \mu \mathrm{m})$ that closely resembles Lepetodrilus spp. We have termed them Lepetodrilus-like. They have coarser pitted sculpture than Lepetodrilus spp., and the aperture is slightly curved, sometimes appearing to come to a blunt point in the front. They appear to lack an aperture rim. 


\section{Can be confused with:}

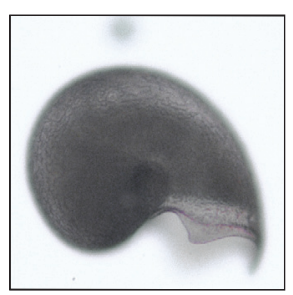

Gorgoleptis emarginatus is approximately the same size as Clypeosectus and has similar sculpture. The chief distinction between the two genera is that Gorgoleptis emarginatuss has a sharp point at the anterior edge and sides of the aperture, giving it a scalloped appearance. If these points have been broken off, the curved remnants of the aperture rim can give a clue to their presence.

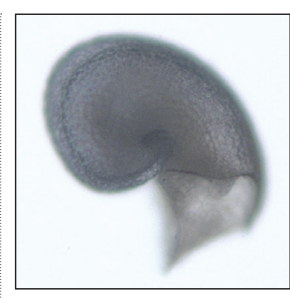

Gorgoleptis sp. 3 is approximately the same size as Clypeosectus and has similar sculpture. Gorgoleptis sp. 3 has a sharp point at the anterior edge of the aperture and apparently lacks an aperture rim.

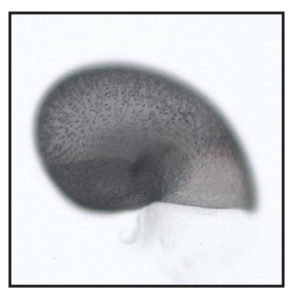

Lepetodrilus-like. These are about $15-20 \mu \mathrm{m}$ larger than Clypeosectus delectus. Their sculpture is somewhat finer and does not show any lineation. Unlike Clypeosectus, their apertures more or less line up with their bases, though the apertures themselves may be slightly curved. They appear to lack an aperture rim. 


\section{GASTROPODA}

\section{Clypeosectus delectus McLean, 1989. Family Lepetodrilidae.}

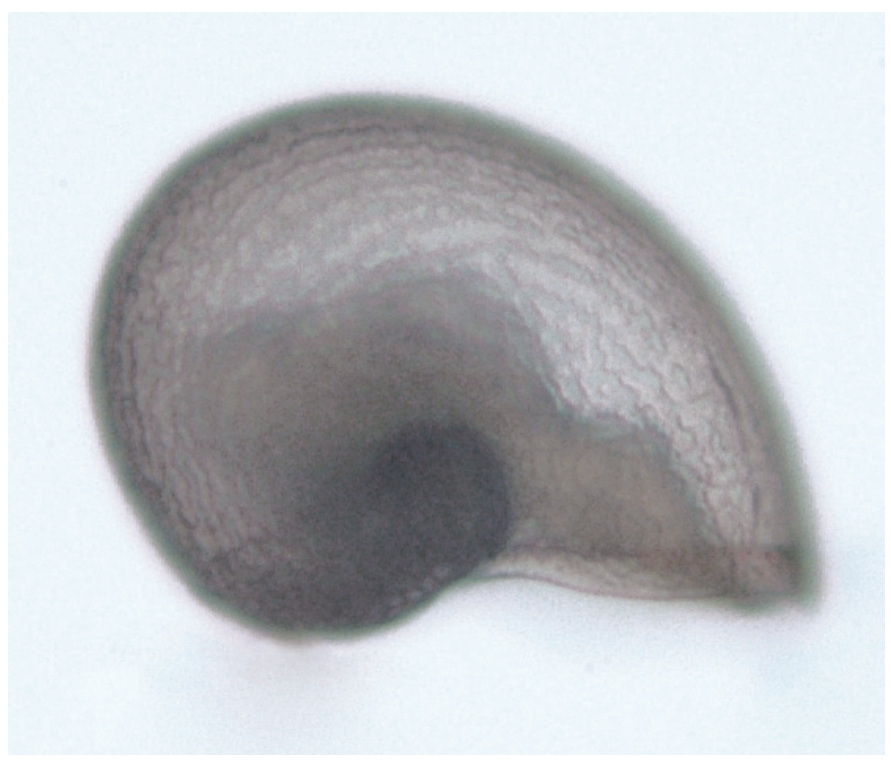

Size: $170-180 \mu \mathrm{m}$

\section{Morphology:}

Small protoconchs with coarse pitted sculpture in closely spaced rows, giving the effect of lineate sculpture. The aperture is slightly wavy, with a distinct medium-width rim visible under the compound microscope.

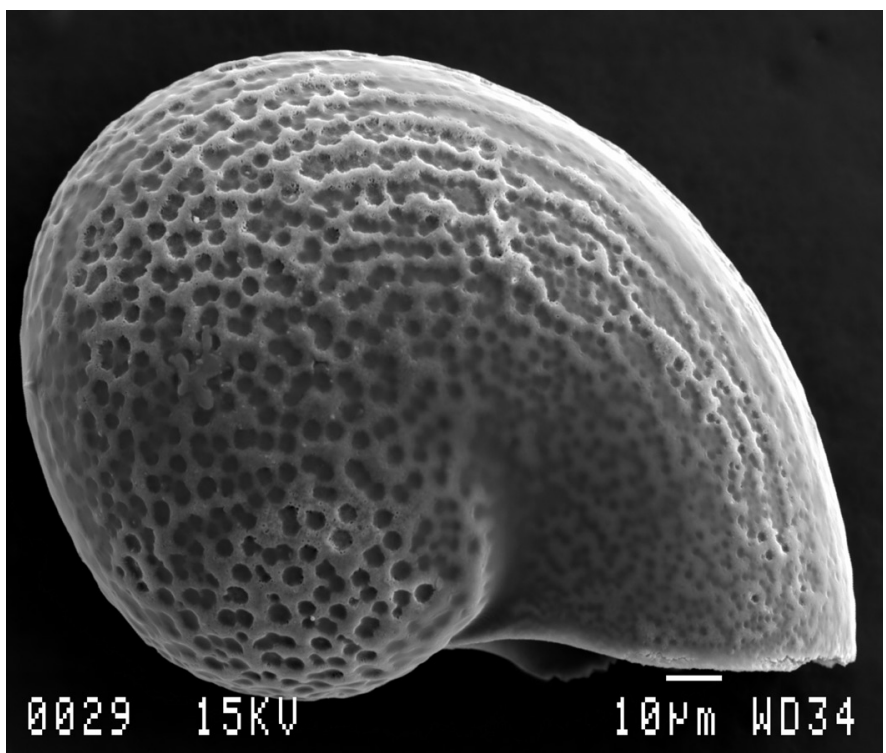

See also Fig. 2 in Mullineaux et al. (1996), Fig. 10 in Turner et al. (1985), and p. 86 in Desbruyères et al. (2006; right photo shows the larva, left shows a juvenile with the protoconch visible)

\section{Frequency:}

Pump EPR 1999-2000: Occasional

Pump EPR 2004: Frequent

Trap EPR 2004-2005: Occasional

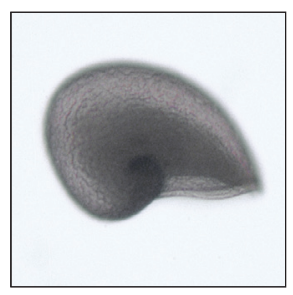

Pointy apex is very
similar to Clypeosectus
delectus. It is possible
that both protoconchs
represent different
forms of the same
species (or possibly
two species in the same genus), but because of consistent differences in their morphology, we have kept them separate for the present. The chief differences between the two groups are that the sculpture of $C$. delectus is coarser, the shape of the shell is more rounded and the aperture rim is wider. The protoconch of $C$. delectus is also slightly larger $(175 \mu \mathrm{m}$ vs. $160 \mu \mathrm{m})$ than pointy apex.

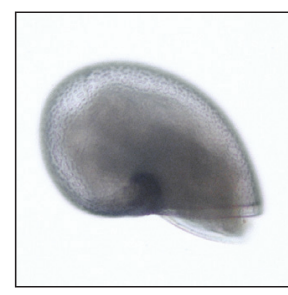

Lepetodrilus spp. is approximately the same size as $C$. delectus. The distinguishing features are that in $C$. delectus the line of the aperture does not line up with the posterior portion of the shell, whereas in Lepetodrilus it forms a nearly straight line. The sculpture in Lepetodrilus is much finer and more widely spaced and usually doesn't show any obvious lineation under the dissecting microscope.

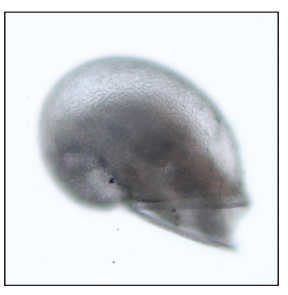

Unknown 5 is about the same size as $C$. delectus, but as for Lepetodrilus, the aperture and the base form a nearly straight line. The narrow aperture rim flares out to the sides and at the outer edge. This species has reticulate, rather than pitted, sculpture. 
GASTROPODA 


\section{Gorgoleptis emarginatus McLean, 1988. Family Lepetodrilidae.}

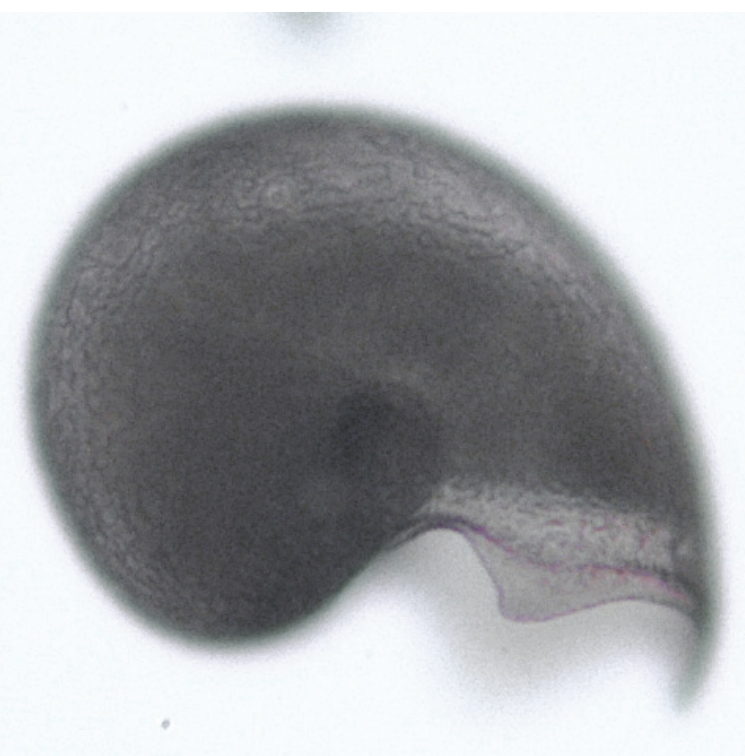

Size: $175-180 \mu \mathrm{m}$

\section{Morphology:}

Gorgoleptis emarginatus is one of three presumed Gorgoleptis morphs we find in plankton samples at EPR $9^{\circ} \mathrm{N}$. It has coarse pitted sculpture in rows that follow the curve of the shell. The most distinctive feature of these protoconchs is the scalloped edges of the aperture, with sharp points at the anterior edge and on either side. There is a narrow aperture rim, tapering toward the posterior edge. The protoconch matches that of Gorgoleptis emarginatus in size and sculpture, but the scallops are not preserved in post-larval specimens, making the identification somewhat tentative.

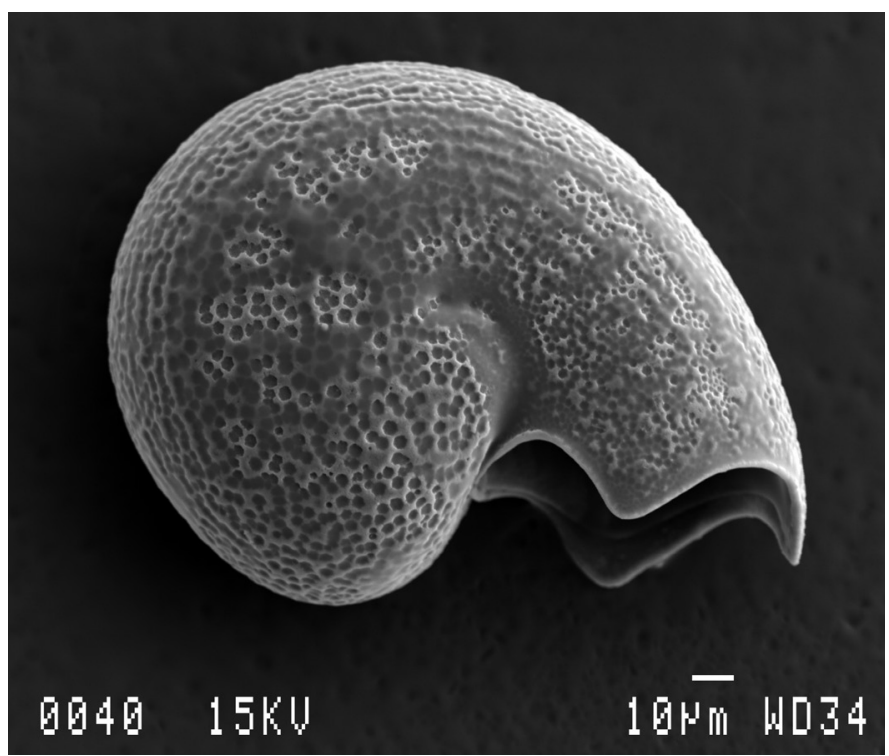

See also Fig. 2 in Mullineaux et al. (1996)

\section{Frequency:}

Pump EPR 1999-2000: Occasional

Pump EPR 2004: Frequent

Trap EPR 2004-2005: Frequent

\section{Can be confused with:}

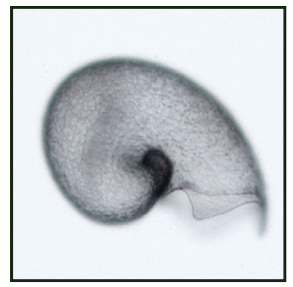

smaller.

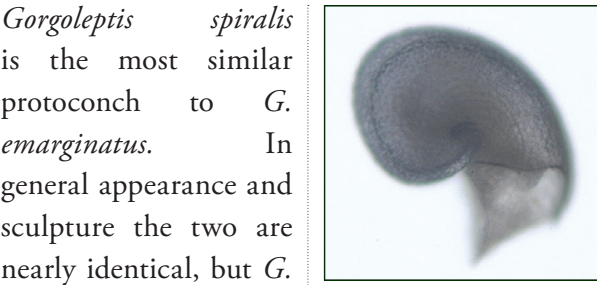

spiralis is about $30 \mu \mathrm{m}$ side points. It is also much less common
Gorgoleptis sp. 3 is approximately the same size as $G$. emarginatus, with similar sculpture. It has a more pronounced point at the outer edge of the aperture and lacks the

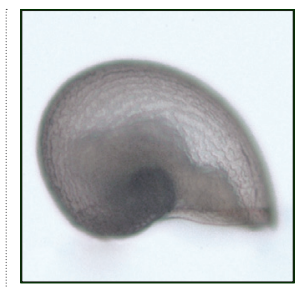

Clypeosectus delectus is similar in size and sculpture to the Gorgoleptis species. The main difference is in the shape of the aperture: all the Gorgoleptis species have at least one sharp point, whereas in Clypeosectus it is nearly straight. 
GASTROPODA 


\section{Gorgoleptis sp. 3 Family Lepetodrilidae.}

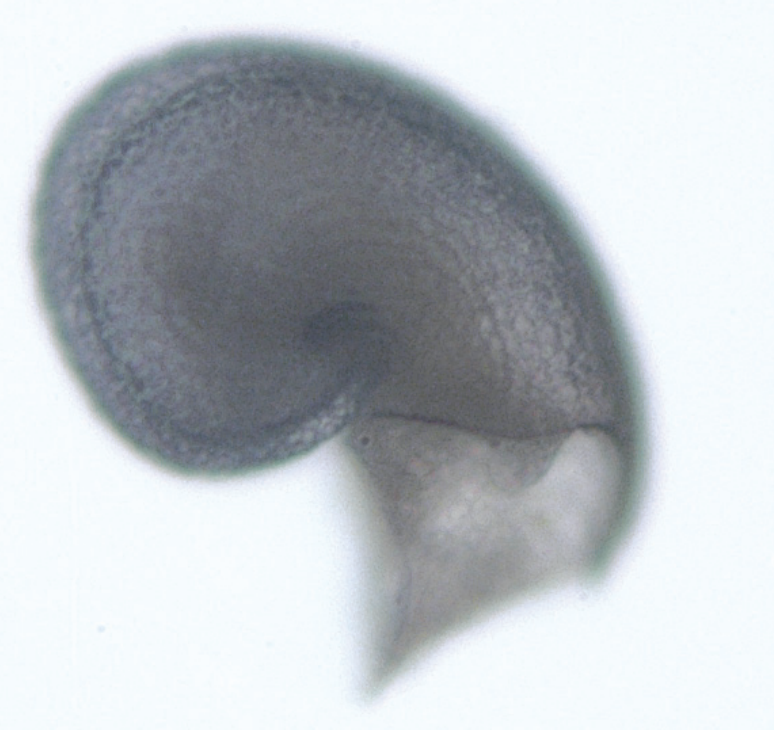

Size: $180-185 \mu \mathrm{m}$

\section{Morphology:}

This protoconch closely resembles the two Gorgoleptis protoconchs in sculpture and is roughly the same size as Gorgoleptis emarginatus. It differs from the others in having only a single sharp point at the anterior edge of the aperture, and the sides are sinuous rather than being scalloped. If it has an aperture rim, it is very narrow.

A third species of Gorgoleptis, Gorgoleptis patulus McLean, 1988, was described from the Galápagos Rift. Its protoconch is unknown, but it could be a possible candidate for this morph. The species has not been reported from EPR $9^{\circ} \mathrm{N}$.

\section{Frequency:}

Pump EPR 1999-2000: Rare

Pump EPR 2004: Rare (1 individual collected off-axis)

Trap EPR 2004-2005: Not collected

\section{Can be confused with:}

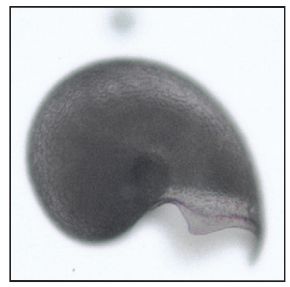

Gorgoleptis emarginatus is nearly the same size as Gorgoleptis sp. 3, being about $5 \mu \mathrm{m}$ smaller. It has points on the sides of the aperture, whereas Gorgoleptis sp. 3's aperture is only slightly wavy. Gorgoleptis emarginatus is much more common.

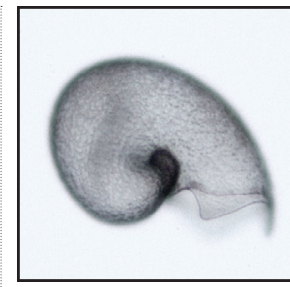

Gorgoleptis spiralis is about $35 \mu \mathrm{m}$ smaller than Gorgoleptis sp. 3 and has side points on the aperture.

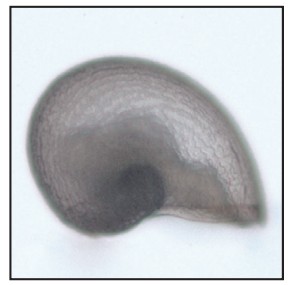

Clypeosectus delectus is similar in size and sculpture to the Gorgoleptis species. The main difference is in the shape of the aperture: Gorgoleptis sp. 3 has a sharp point at the outer edge, whereas in Clypeosectus it is nearly straight. 
GASTROPODA 


\section{Unknown 7. Family Unknown.}

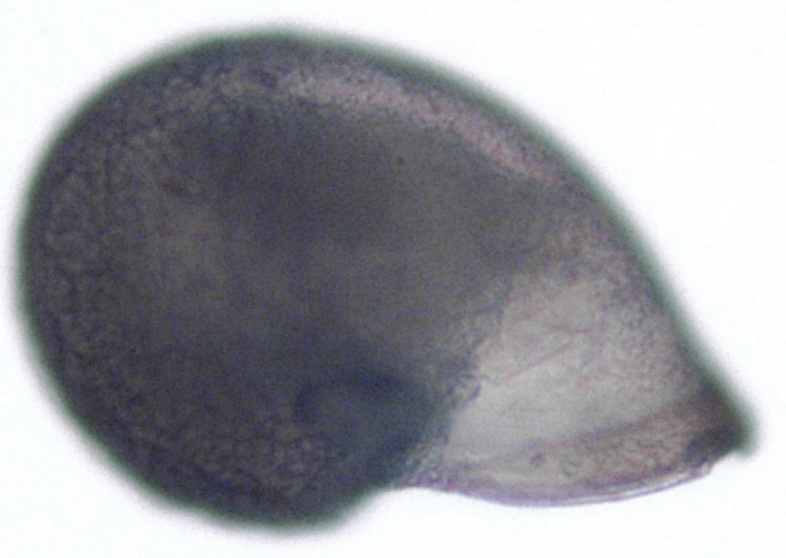

Size: $180-190 \mu \mathrm{m}$

\section{Morphology:}

This is a small protoconch with sculpture consisting of a coarse raised network of reticulate sculpture overlain by five widely spaced lines. These lines are difficult to see with the light microscope, but show up clearly in the SEM. The anterior portion of the shell is smooth. The aperture is slightly sinuous and flared at the anterior edge and it has a medium-width rim, tapering toward the posterior.

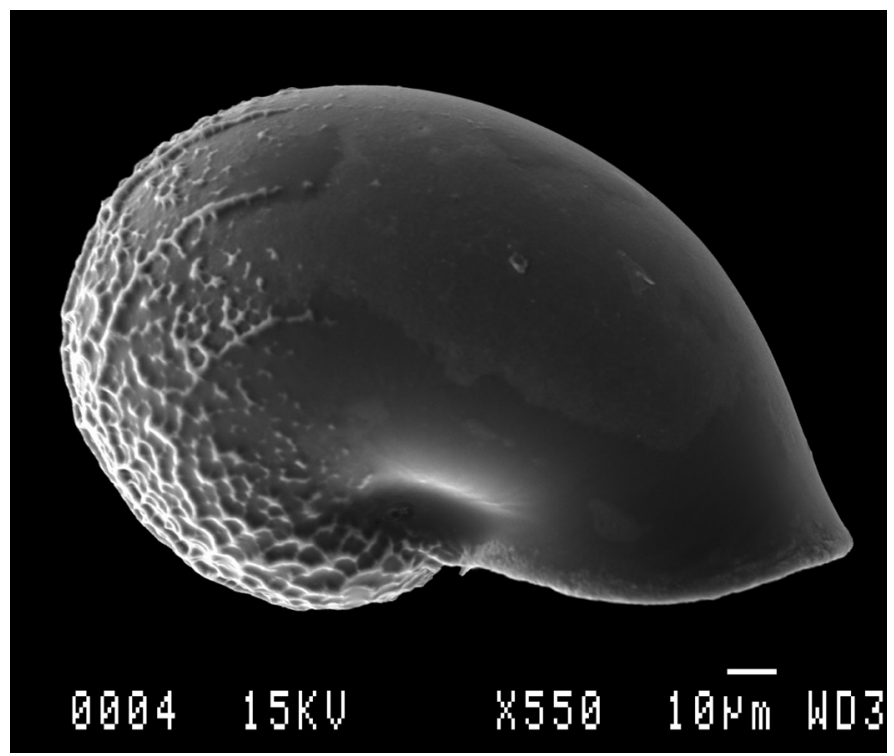

\section{Frequency:}

Pump EPR 1999-2000: Occasional

Pump EPR 2004: Occasional

Trap EPR 2004-2005: Not collected

\section{Can be confused with:}

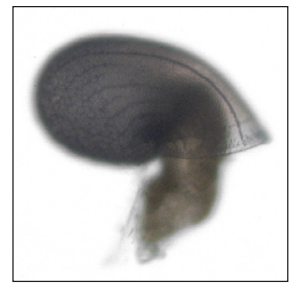

Unknown 7 is most likely to be confused with Unknown 9, which has a similar type of sculpture. Unknown 9 is slightly larger and some of its lineate sculpture extends all the way to the aperture, whereas all five lines in Unknown 7 stop well short of the aperture. Unknown 9 is also shorter in height for its diameter than Unknown 7. The approximate height:diameter figures are 110:190 $\mu \mathrm{m}$ for Unknown 9 and 125:180 $\mu \mathrm{m}$ for Unknown 7.

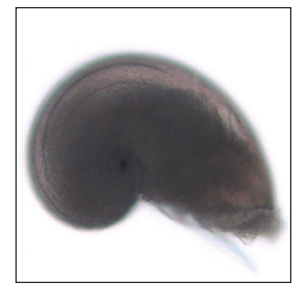

Unknown 7's sculpture and size are similar to that of Unknown 8. Unknown 8 has more closely spaced lines, and it is also greater in height for its diameter than Unknown 7. The approximate height:diameter figures are 135:190 $\mu \mathrm{m}$ for Unknown 8 and 125:180 $\mu \mathrm{m}$ for Unknown 7. 
GASTROPODA 


\section{GASTROPODA}

\section{Lepetodrilus-like protoconchs Family ?Lepetodrilidae.}

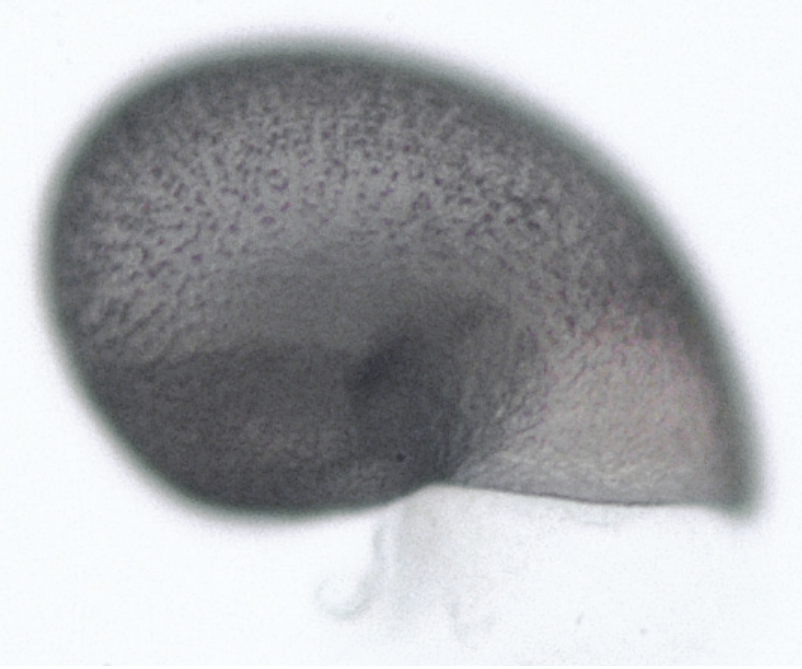

Size: $185-200 \mu \mathrm{m}$

\section{Morphology:}

Lepetodrilus-like protoconchs are quite similar in general appearance to Lepetodrilus spp. They are slightly larger and have coarser pitted sculpture. The aperture is slightly curved and comes to a blunt point at the outer edge. There appears to be no aperture rim.

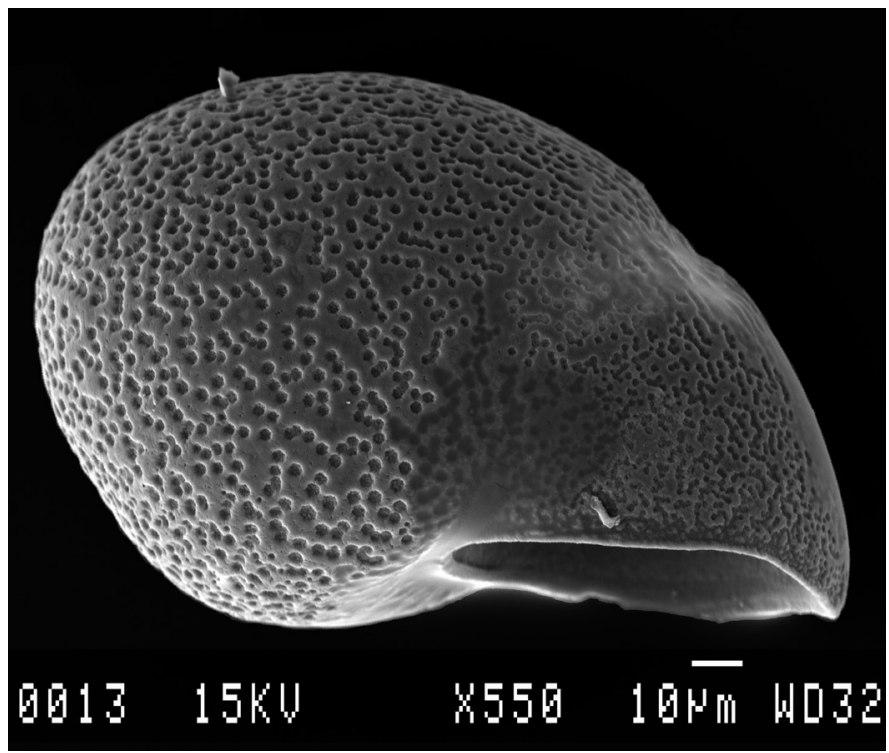

\section{Frequency:}

Pump EPR 1999-2000: Occasional

Pump EPR 2004: Occasional

Trap EPR 2004-2005: Occasional

\section{Can be confused with:}

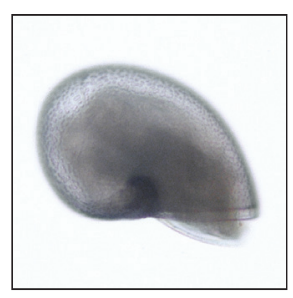

These protoconchs
are most likely to
be confused with
Lepetodrilus spp.
Lepetodrilus spp. are
slightly smaller (170-
$180 \mu \mathrm{m})$ and have a
straight aperture, which straight aperture, which forms a line with the base of the shell. They al
have an aperture rim, which this group lacks.
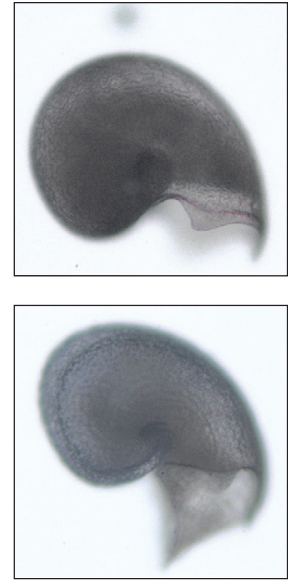

Gorgoleptis emarginatus (upper) and Gorgoleptis sp. 3 (lower). Both species are slightly smaller $\quad(175-185 \mu \mathrm{m})$ and have pitted sculpture, as does this species. The most obvious difference is that both Gorgoleptis have sharp points at the outer edge of the aperture (and $G$. emarginatus has scallops on the sides as well), whereas Lepetodrilus-like protoconchs have only a blunt point on the distal edge.

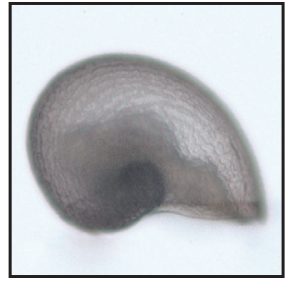

Clypeosectus delectus is smaller $(170-180 \mu \mathrm{m})$ and has an aperture rim. In Clypeosectus and Gorgoleptis, the pitted sculpture often appears to form lines, which has not been seen in the Lepetodrilus-like protoconchs. 
GASTROPODA 


\section{Unknown 8. Family Unknown.}

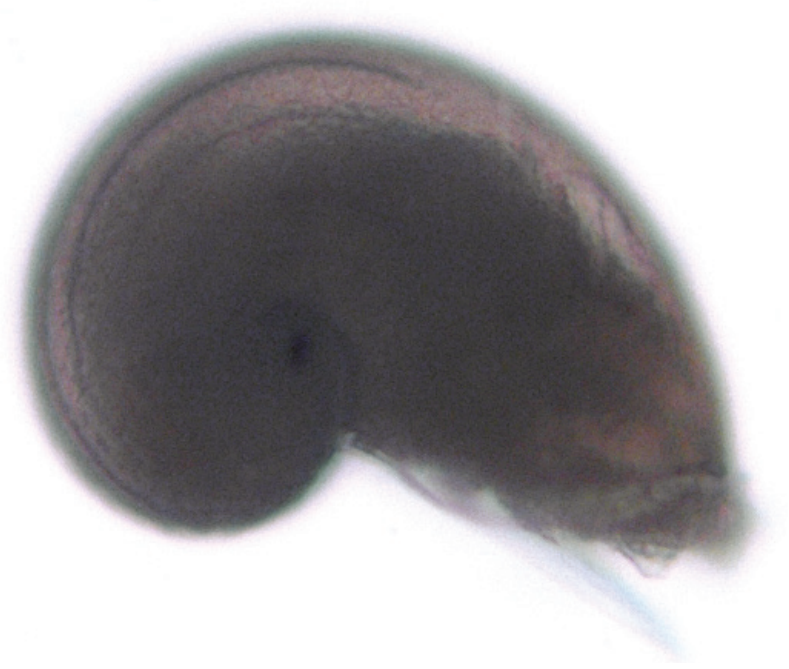

Size: $190-200 \mu \mathrm{m}$

\section{Morphology:}

This is a rather fragile protoconch, generally found with at least the aperture damaged. It is very rounded in appearance, with regularly spaced lines extending about $3 / 4$ of the way to the aperture. There is some hint of sparse reticulate sculpture on the sides and base. The aperture is probably sinuous, and we have seen no evidence of a rim. This protoconch resembles several in the family Skeneidae; for example, see Warén and Bouchet (1993; Fig. 23, A \& C) for images of the protoconchs of Xyloskenea costulifera Marshall, 1988, from deep-sea wood falls and Ventsia tricarinata Warén and Bouchet, 1993, from the Lau Basin.

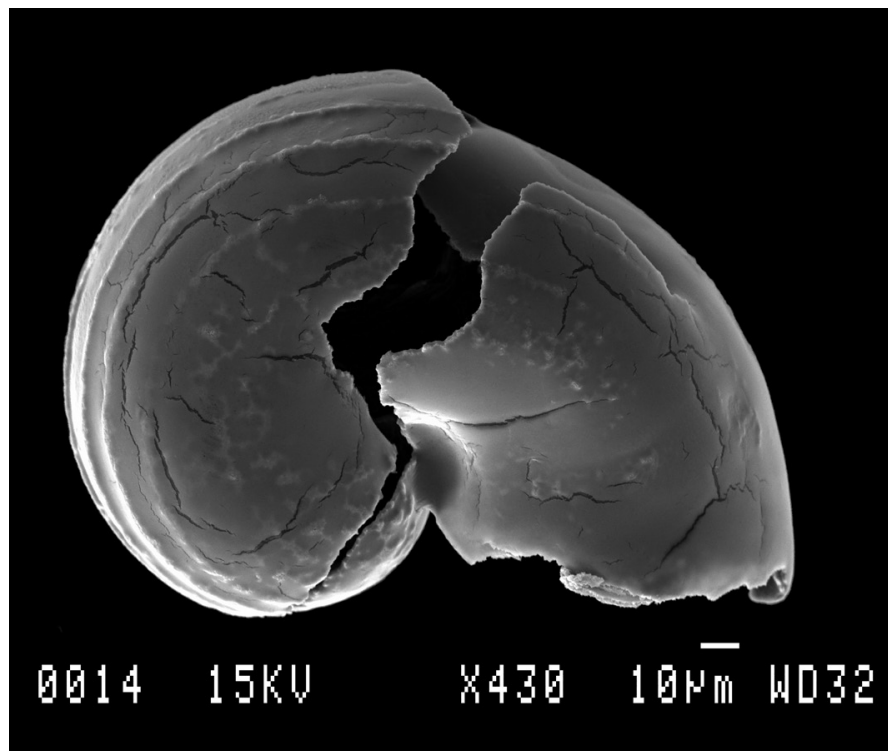

\section{Frequency:}

Pump EPR 1999-2000: Rare

Pump EPR 2004: Rare

Trap EPR 2004-2005: Not collected

\section{Can be confused with:}

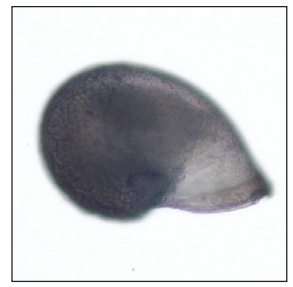

Unknown 8's sculpture and size are similar to that of Unknown 7. Unknown 7 has only five lines that are more widely spaced than those on Unknown 8. It is also shorter in height for its diameter than Unknown 8. The approximate height:diameter figures are $135: 190 \mu \mathrm{m}$ for Unknown 8 and 125:180 $\mu \mathrm{m}$ for Unknown 7. 
GASTROPODA 


\section{GASTROPODA}

\section{Unknown 9. Family Unknown.}
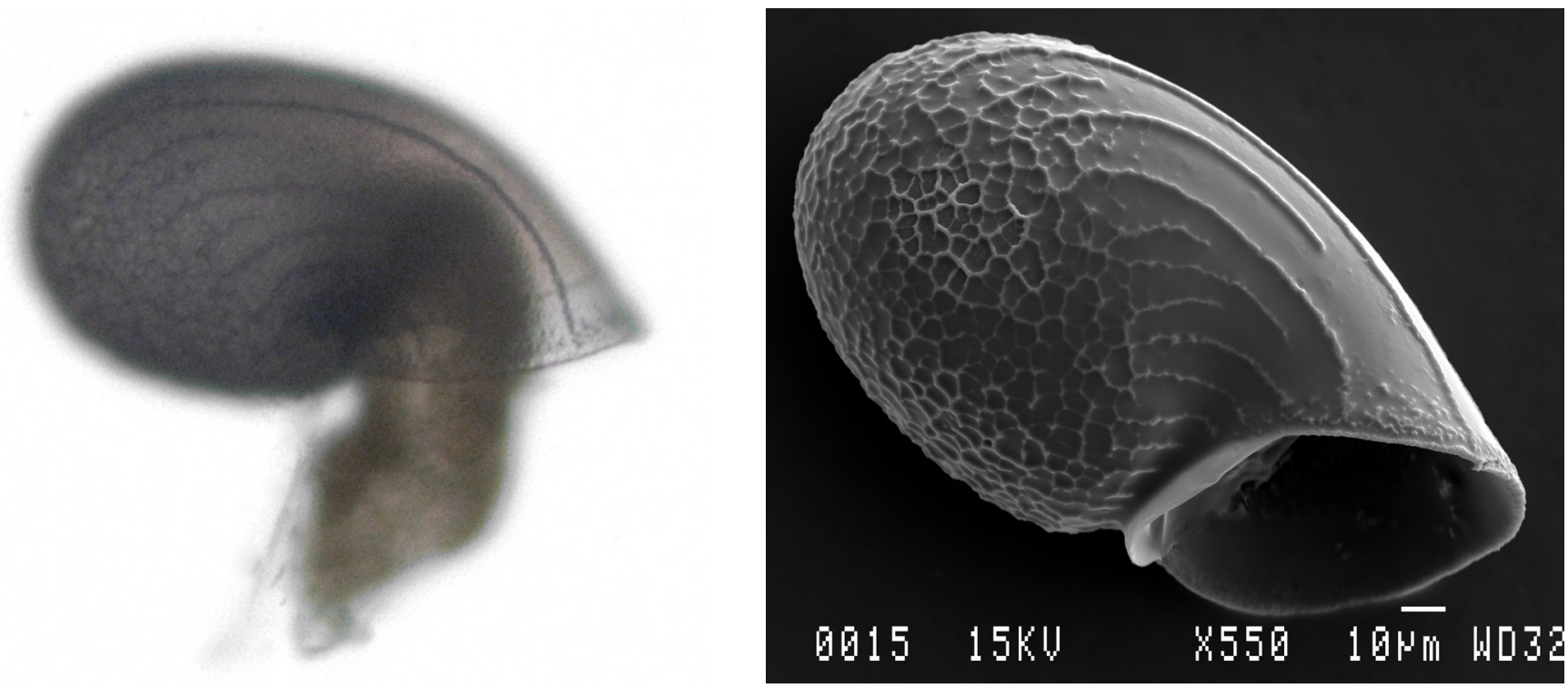

Size: $190-210 \mu \mathrm{m}$

\section{Morphology:}

This protoconch has a short stretch of lineate sculpture at the axis of curvature which then spreads out into an area of interconnected reticulate sculpture that covers the proximal $1 / 3$ of the shell. From this point a few lines extend toward the aperture, most stopping well short of it, but a few reaching all the way. The aperture is roughly circular and is only about $1 / 3$ of the diameter of the shell. There appears to be a narrow aperture rim, surrounded by a wider region of stippling, possibly a continuation of the reticulate sculpture.

\section{Frequency:}

Pump EPR 1999-2000: Not collected on axis Pump EPR 2004: Rare

Trap EPR 2004-2005: Not collected

\section{Can be confused with:}

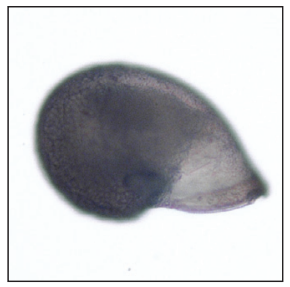

Unknown 9 is most likely to be confused with Unknown 7, which has a similar type of sculpture. Unknown 9 is slightly larger and some of its lineate sculpture extends all the way to the aperture, whereas all five lines in Unknown 7 stop well short of the aperture. Unknown 7 is greater in height for its diameter than Unknown 9. The approximate height:diameter figures are

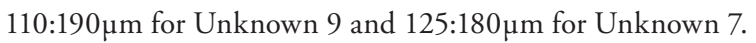


GASTROPODA 


\section{GASTROPODA}

\section{Echinopelta fistulosa McLean, 1989. Family Peltospiridae.}
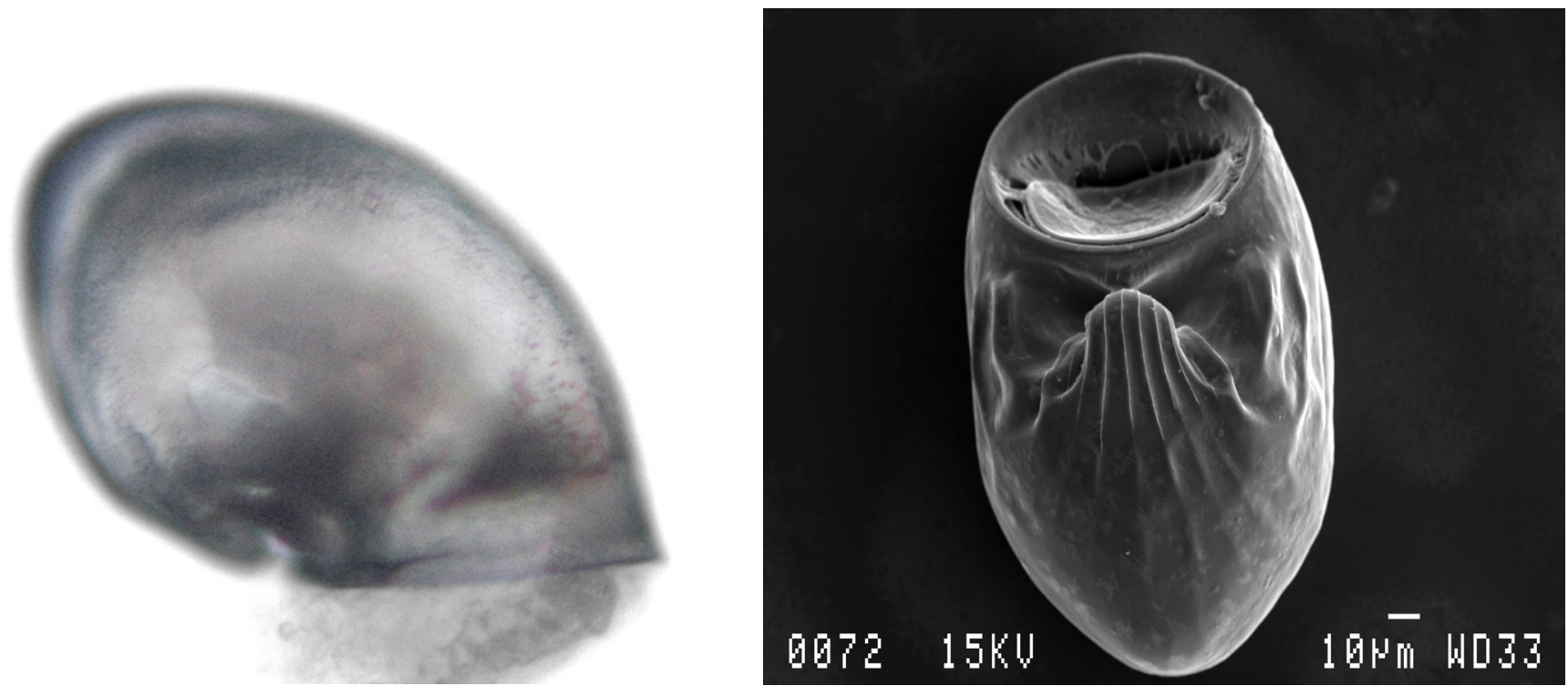

Size: $210-220 \mu \mathrm{m}$

\section{Morphology:}

This group is quite angular in appearance and has the lines beginning on a raised platform at the base of the shell. In this form the lines become indistinct for most of the shell. The aperture is slightly flared and has a narrow rim. We believe this morphotype corresponds to Echinopelta fistulosa, which has the same raised platform on the base (see SEM photo at right of a protoconch broken off a juvenile E. fistulosa).

\section{Frequency:}

Pump EPR 1999-2000: Frequent (but combined with unknown peltospirid $240 \mu \mathrm{m}$ )

Pump EPR 2004: Frequent

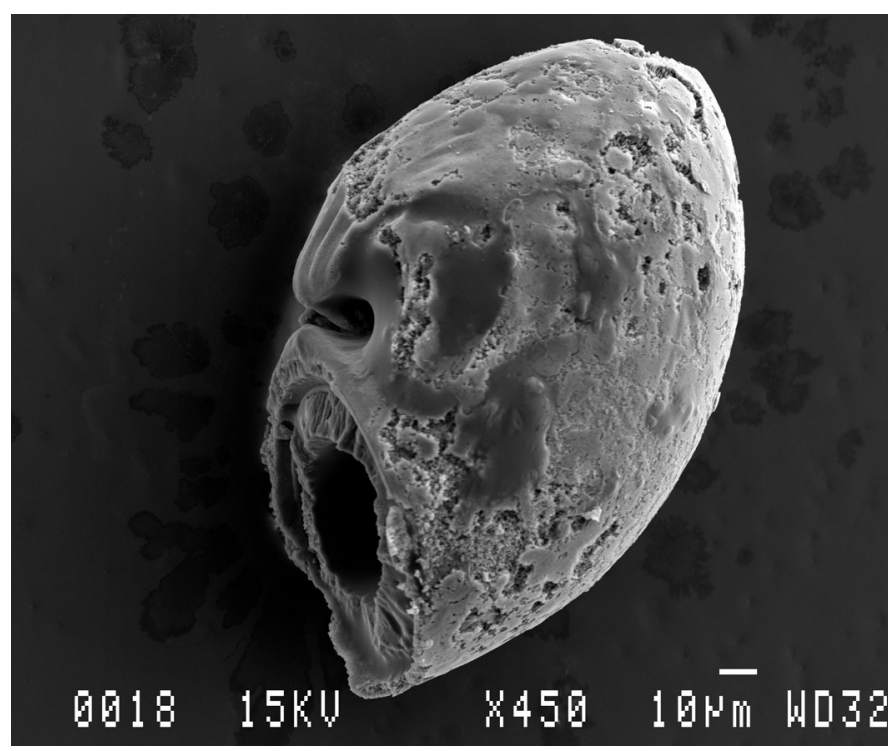

Trap EPR 2004-2005: Occasional

\section{Can be confused with:}

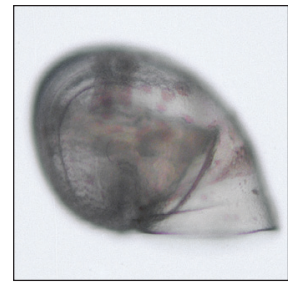

sculpture.
Lirapex granularis is approximately $10 \mu \mathrm{m}$ larger and lacks the raised platform at the base. It also has tubercles at the posterior end in addition to the lineate

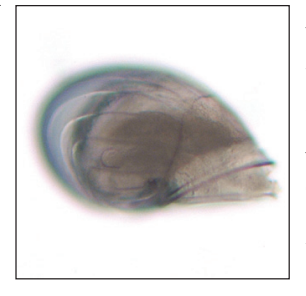

Peltospira sp. is slightly larger and less angular in appearance than Echinopelta. It also does not have the raised platform at the base.

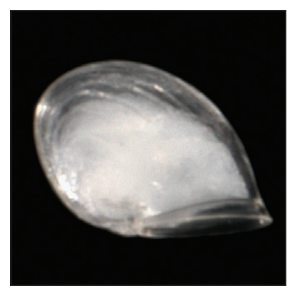

Unknown peltospirid $240 \mu \mathrm{m}$ is similar in outline but is approximately $30 \mu \mathrm{m}$ larger in diameter and does not have the raised platform at the base. 


\section{Can be confused with:}

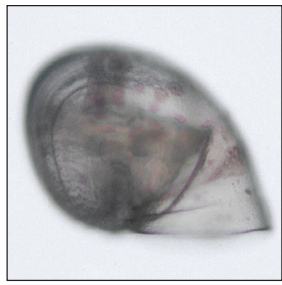

sculpture.
Lirapex granularis is approximately the same size as Peltospira, but is greater in height for its diameter. It also has tubercles at the posterior end in addition to the lineate

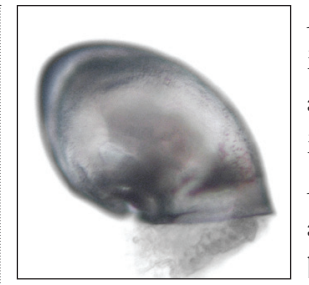

Echinopelta

fistulosa is slightly smaller and more angular in appearance than Peltospira. It also has a raised platform at the base where the lines begin.

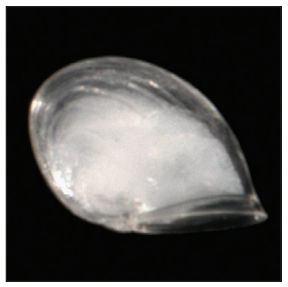

Unknown peltospirid $240 \mu \mathrm{m}$ is greater in height for its diameter, which is approximately $20 \mu \mathrm{m}$ larger than that of Peltospira. 


\section{Peltospira spp. Family Peltospiridae.}

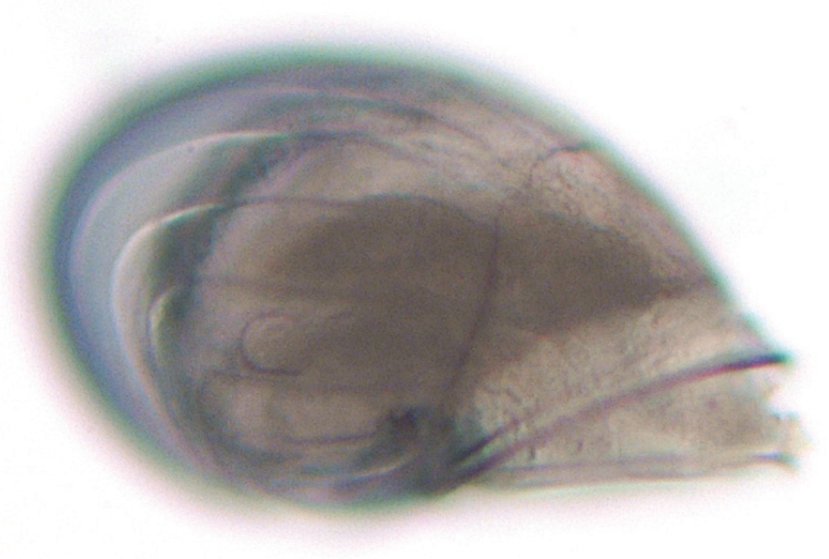

Size: $210-220 \mu \mathrm{m}$

\section{Morphology:}

This protoconch has approximately 16-18 lines, beginning in a $\mathrm{V}$ at the axis of coiling and following the curvature of the shell, stopping abruptly at the same point about $2 / 3$ of the way to the aperture. The aperture is perfectly circular when viewed from the bottom and is surrounded by a narrow rim which flares out to the sides when viewed from the top. It looks more streamlined than most peltospirids, since it is shorter for its diameter and the base is more smoothly rounded. It matches the SEM of Peltospira operculata in Mullineaux et al. (1996) in size and general appearance, but is also very similar to the Nodopelta subnoda protoconch SEM in Desbruyères et al. (2006; p. 117). Molecular work is ongoing and may help to resolve the issue. In the meantime, we have attributed this protoconch to Peltospira, as it is the most common genus at EPR $9^{\circ} \mathrm{N}$. There are at least two species of Peltospira present at EPR $9{ }^{\circ} \mathrm{N}$ : Peltospira delicata McLean, 1989, and Peltospira operculata McLean, 1989. A third species, Peltospira lamellifera Warén \& Bouchet, 1989, has been described from $13^{\circ} \mathrm{N}$ and may also be at $9^{\circ} \mathrm{N}$.

\section{Frequency:}

Pump EPR 1999-2000: Occasional

Pump EPR 2004: Occasional

Trap EPR 2004-2005: Not collected
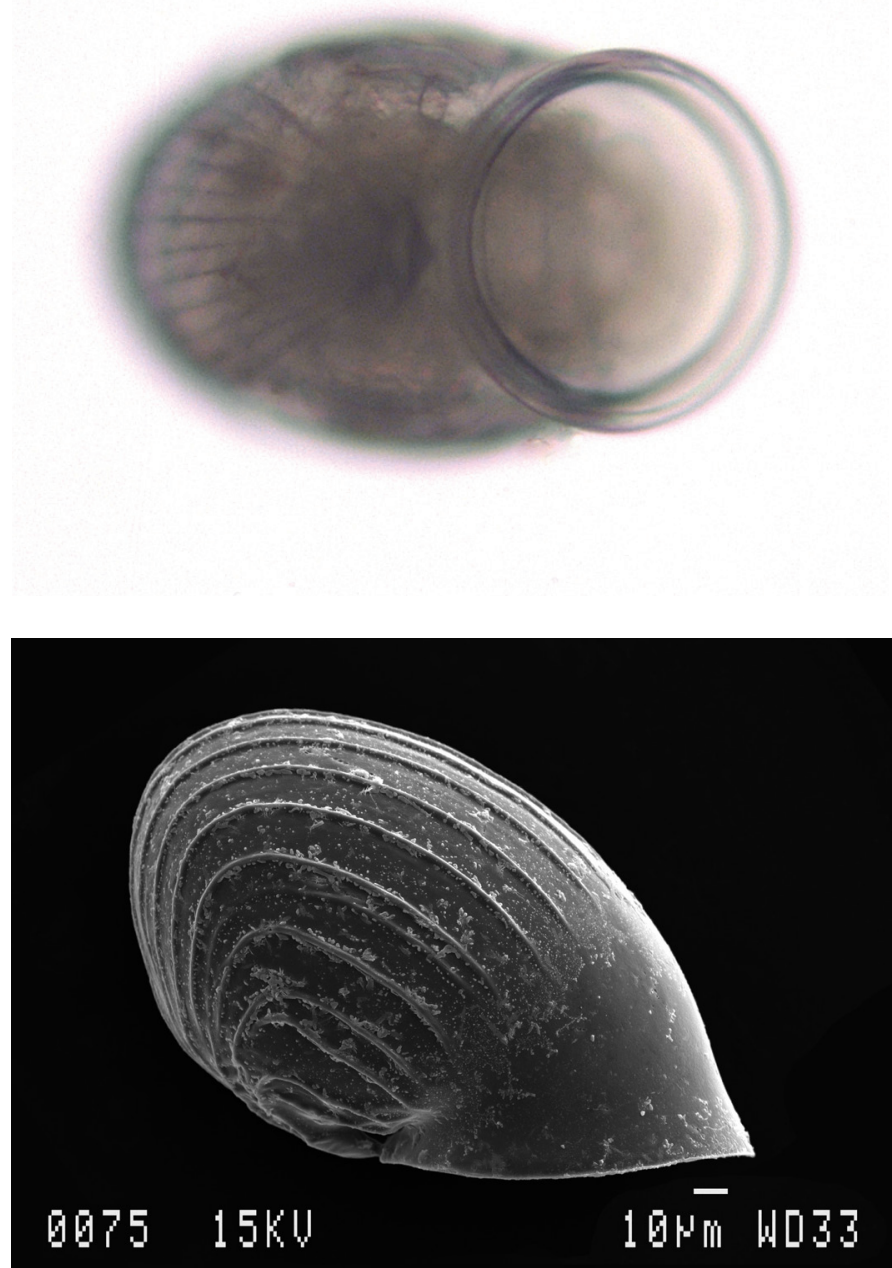

See also Fig. 3 in Mullineaux et al. (1996) 
GASTROPODA 


\section{Lirapex granularis Warén \& Bouchet, 1989. Family Peltospiridae.}

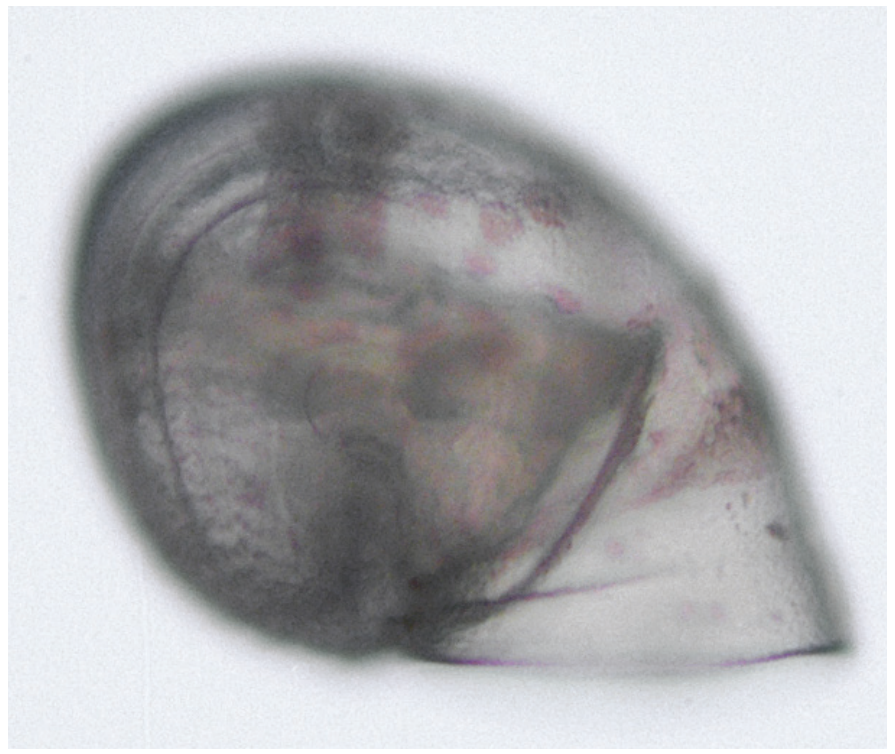

Size: $215-220 \mu \mathrm{m}$

\section{Morphology:}

Lirapex has an unusual type of sculpture consisting of the lineate sculpture typical of peltospirids with numerous tubercles between them, especially near the axis of coiling. Both fade out about halfway to the aperture. When viewed from the bottom under the light microscope, a thick bar running across the shell is visible just posterior to the aperture. The aperture is nearly straight, with a wide rim tapering toward the posterior. The shell is transparent and glassy-looking.

\section{Frequency:}

The species was described from EPR $21^{\circ} \mathrm{N}$ and has been reported from $9^{\circ} \mathrm{N}$, though adults are rarely collected there.

Pump EPR 1999-2000: Occasional

Pump EPR 2004: Occasional

Trap EPR 2004-2005: Occasional
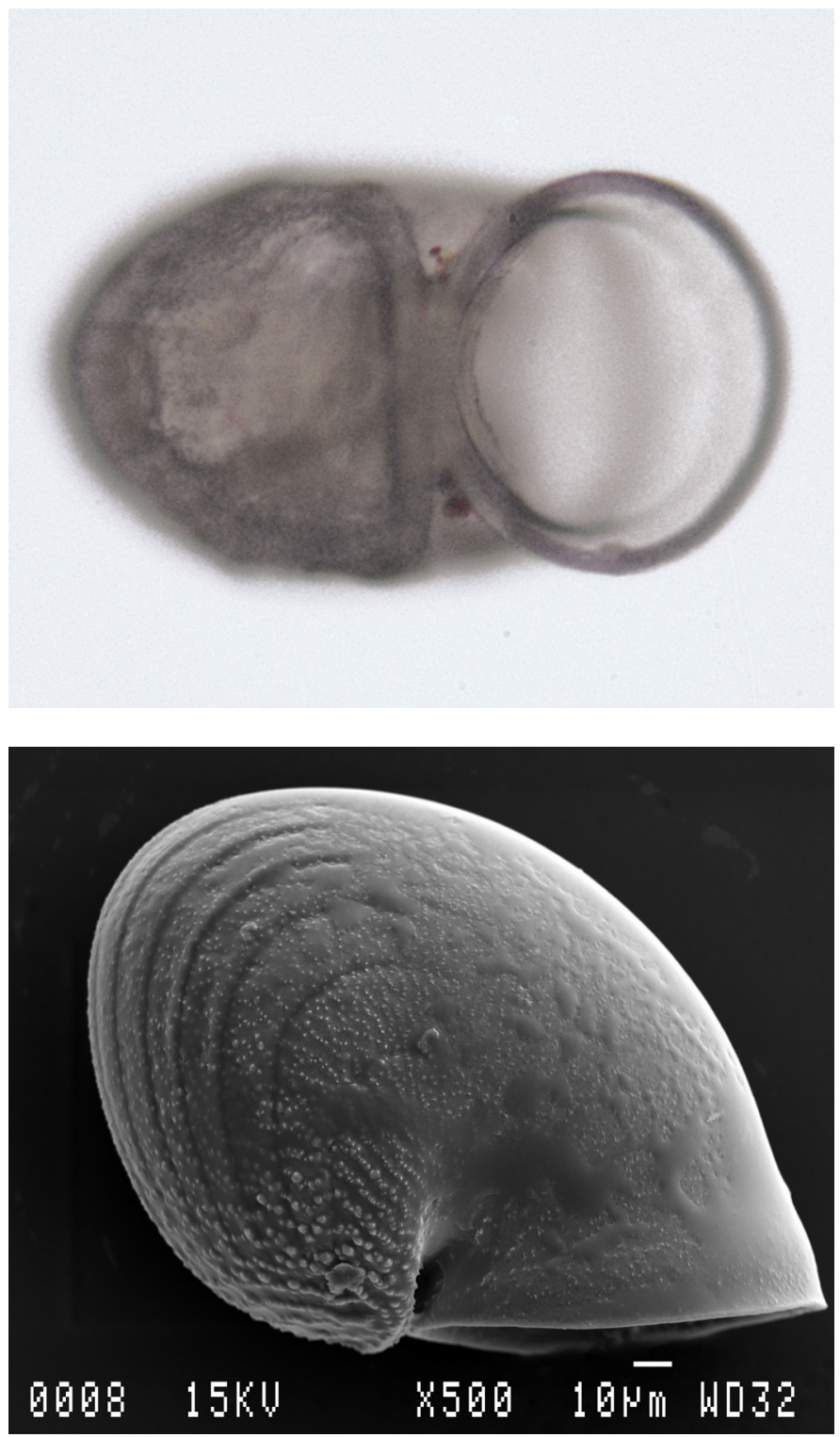

See also Fig. 3 in Mullineaux et al. (1996) and p. 115 in Desbruyères et al. (2006)

\section{Can be confused with:}

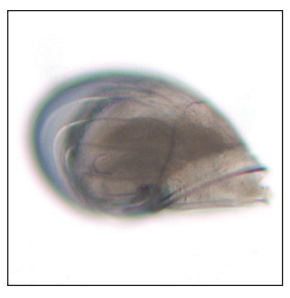

Peltospira spp. is similar in size to Lirapex. However, Peltospira is more streamlined in appearance and doesn't have tubercles or the bar posterior to the aperture.

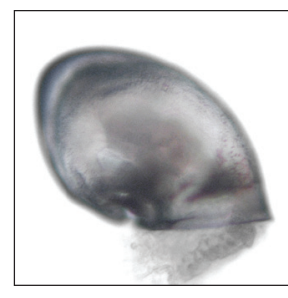

Echinopelta fistulosa is similar in size to Lirapex; however, it is about $10 \mu \mathrm{m}$ smaller, more angular in appearance, has a raised platform at the base and no tubercles.

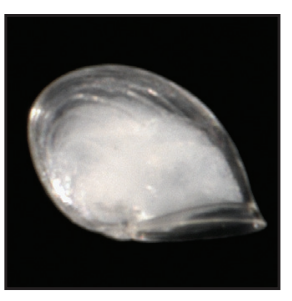

Unknown peltospirid $240 \mu \mathrm{m} \quad$ closely resembles Lirapex in general morphology, but does not have tubercles and is slightly larger. 


\section{Can be confused with:}

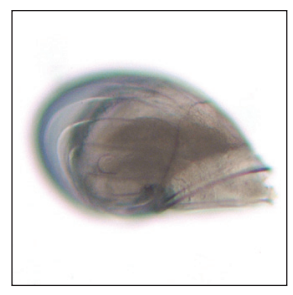

Peltospira spp. is about $20 \mu \mathrm{m}$ smaller than Unknown peltospirid $240 \mu \mathrm{m}$ and is more streamlined in general appearance, being less in height for its diameter.

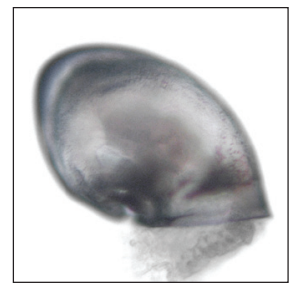

Echinopelta fistulosa is about $30 \mu \mathrm{m}$ smaller and is more angular in appearance. It also has a raised platform at the base where the lines begin. 


\section{Unknown peltospirid $240 \mu \mathrm{m}$ Family ?Peltospiridae.}

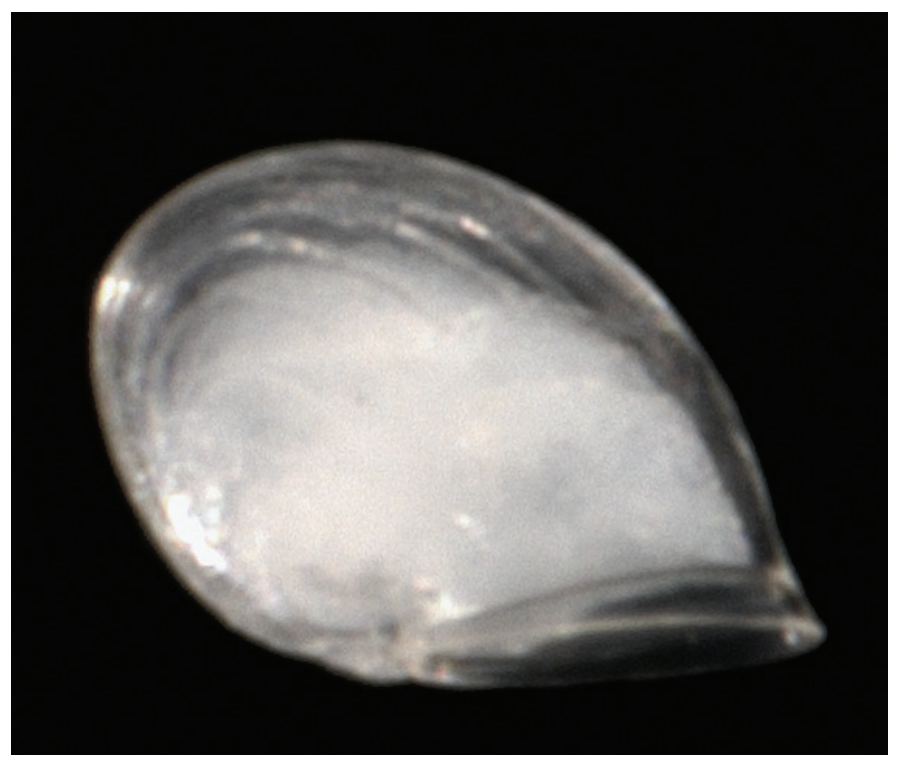

Size: $230-240 \mu \mathrm{m}$

\section{Morphology:}

This is another possibly heterogeneous group of protoconchs. They are slightly larger than the "Peltospira" group and are taller for their diameter, although not as angular as Echinopelta fistulosa. The sculpture begins at the axis of curvature and continues about $2 / 3$ of the way to the aperture, which is slightly flared. From below it closely resembles Peltospira sp., though it is slightly wider for its diameter. The aperture rim is similar in width to Lirapex granularis, wider than in the other peltospirid forms. It may be that the ratio of the diameter to the height will be useful in distinguishing the forms.

\section{Frequency:}

Pump EPR 1999-2000: Frequent (but combined with $210 \mu \mathrm{m}$ size class)

Pump EPR 2004: Frequent

Trap EPR 2004-2005: Occasional

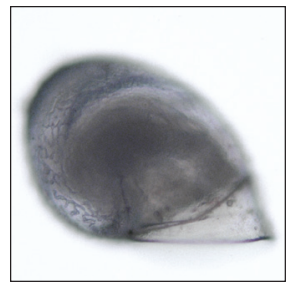

Unknown neomphalid $W$ is quite similar in general appearance and size. The easiest way to distinguish the two is to look at the sculpture - Unknown neomphalid W has reticulate sculpture instead of lineate.

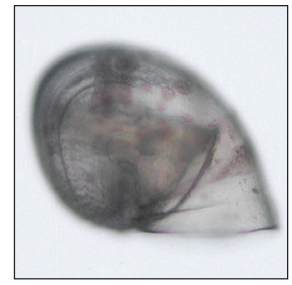

Lirapex granularis is about $20 \mu \mathrm{m}$ smaller than Unknown peltospirid $240 \mu \mathrm{m}$ and has tubercles at the base as well as lineate sculpture. 
GASTROPODA 


\section{GASTROPODA}

\section{Unknown neomphalid B Family ?Neomphalidae.}

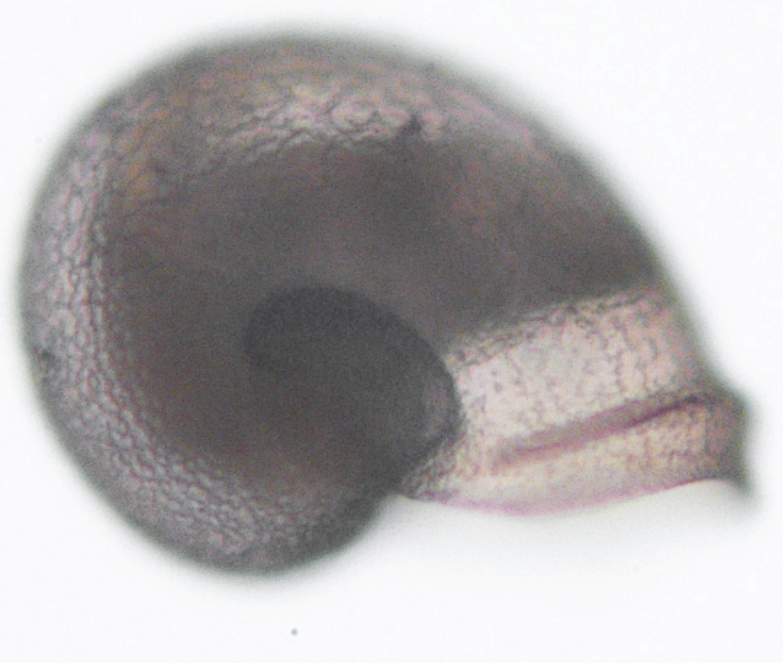

Size: $230-240 \mu \mathrm{m}$

\section{Morphology:}

These protoconchs are moderately large and very distinctive. They have reticulate sculpture over the entire shell, more or less disorganized at the base, but becoming regularly spaced lines toward the aperture. The aperture is slightly sinuous and has a distinct ridge above it. We have not been able to match them with a known vent species, but have tentatively assigned them to Neomphalidae because of their reticulate sculpture and similarity to other neomphalids.

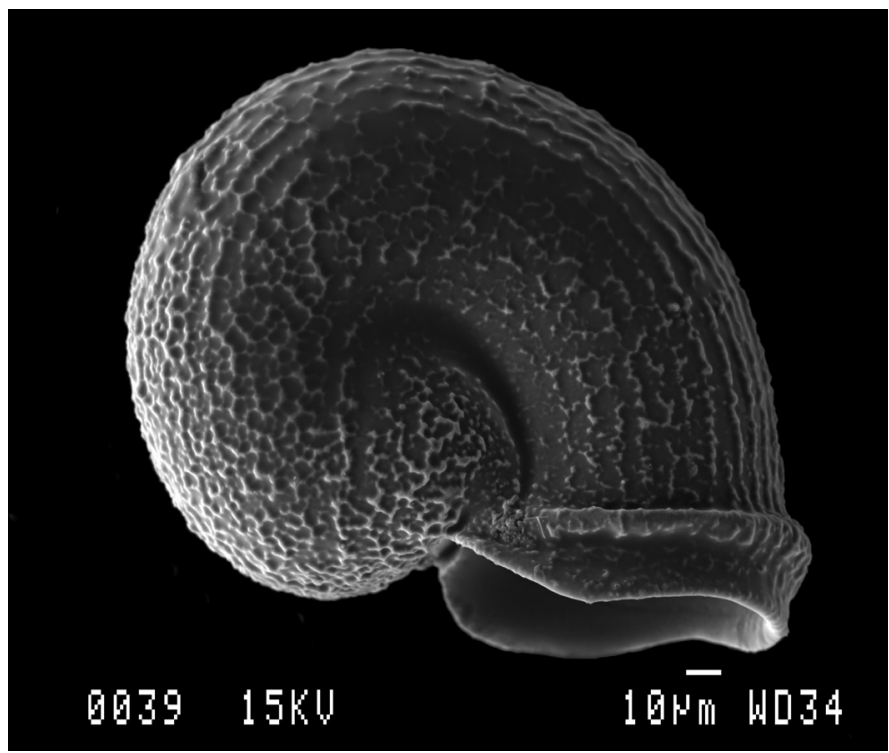

\section{Frequency:}

Pump EPR 1999-2000: Rare

Pump EPR 2004: Not collected

Trap EPR 2004-2005: Occasional

\section{Can be confused with:}

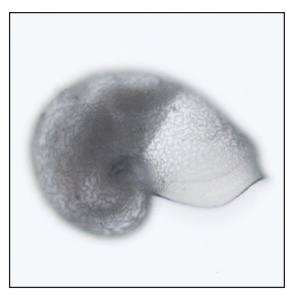

This group is most likely to be confused with one of the Melanodrymia species which they superficially resemble in morphology and size. Melanodrymia aurantiaca has finer reticulate sculpture with no lineation and a more gradual bump above the aperture, rather than a raised ridge.

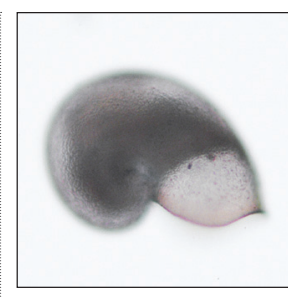

Melanodrymia galeronae also has finer and more irregular reticulate sculpture and no lineation. It lacks either a ridge or a bump above the aperture, which is more sinuous than that of Unknown neomphalid B.

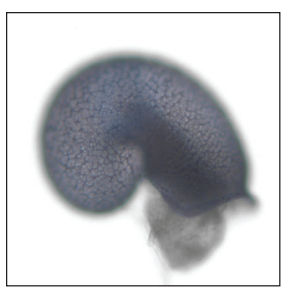

Unknown neomphalid $290 \mu \mathrm{m}$ is about $50 \mu \mathrm{m}$ larger and lacks the ridge above the aperture. Its sculpture is similar near the base, but does not form regular lines distally. 
GASTROPODA 


\section{GASTROPODA}

\section{Cyathermia naticoides Warén \& Bouchet, 1989. Family Neomphalidae.}
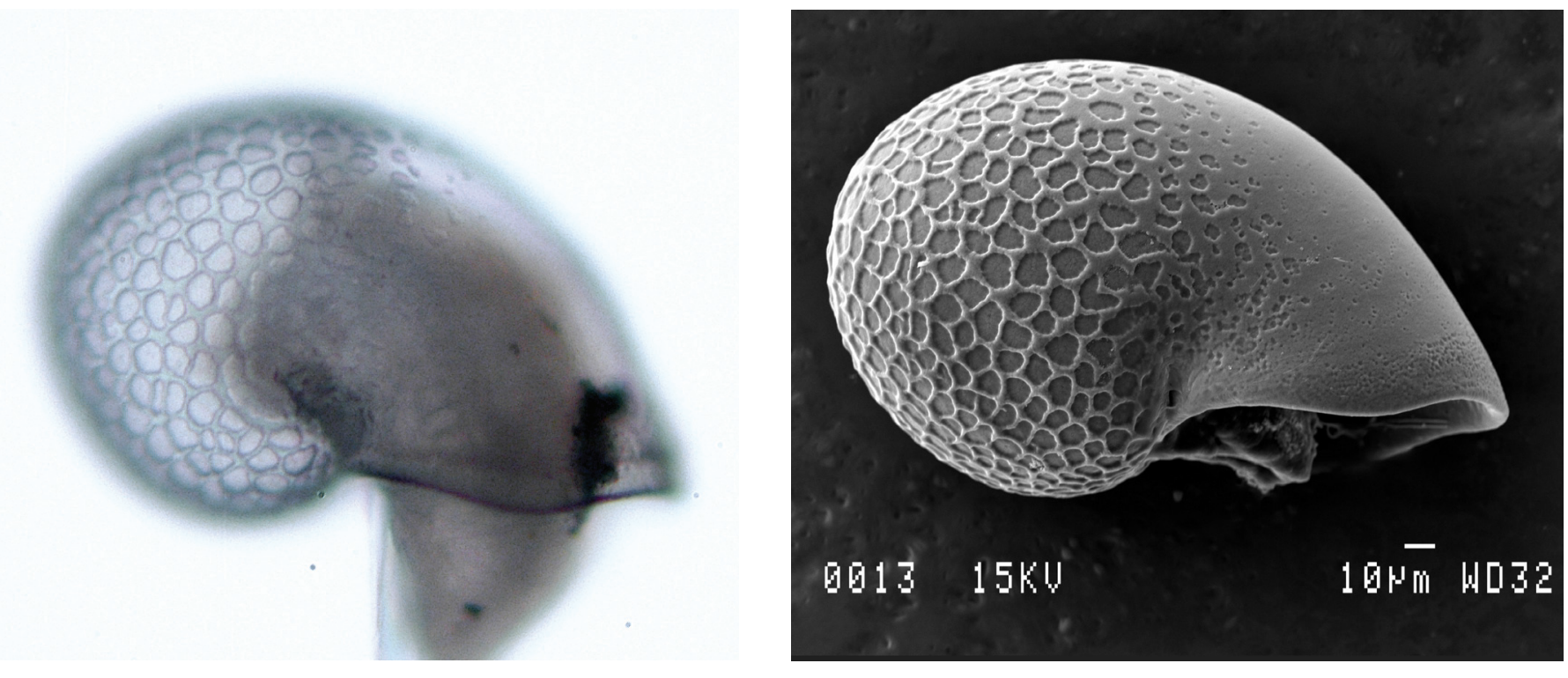

Size: $230-240 \mu \mathrm{m}$

\section{Morphology:}

Cyathermia naticoides has a moderately large protoconch. The posterior is covered by coarse reticulate sculpture which gives the appearance of bubbles under the light microscope. The anterior portion is smooth. The aperture is slightly sinuous and

\section{Frequency:}

Pump EPR 1999-2000: Common

Pump EPR 2004: Common

Trap EPR 2004-2005: Common

\section{Can be confused with:}

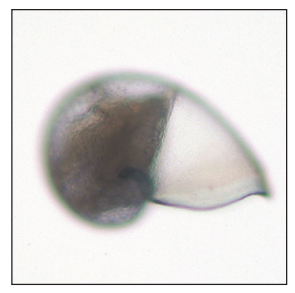

The protoconchs can be easily confused with those of Neomphalus fretterae, although the adults look quite different. The chief differences between the two are that Neomphalus has finer reticulate sculpture and the outer edge flares out at the aperture. The aperture rim is wider in Neomphalus than in Cyathermia, tapering toward the posterior edge. 
GASTROPODA 


\section{Neomphalus fretterae McLean, 1981. Family Neomphalidae.}

Size: $240-250 \mu \mathrm{m}$

\section{Morphology:}

Neomphalus fretterae has a moderately large protoconch with reticulate sculpture over the proximal half of the shell. The distal half is smooth, with the outer edge flaring out above the aperture. The aperture is sinuous and there is a wide rim, tapering toward the inner edge, which is visible under the light microscope.

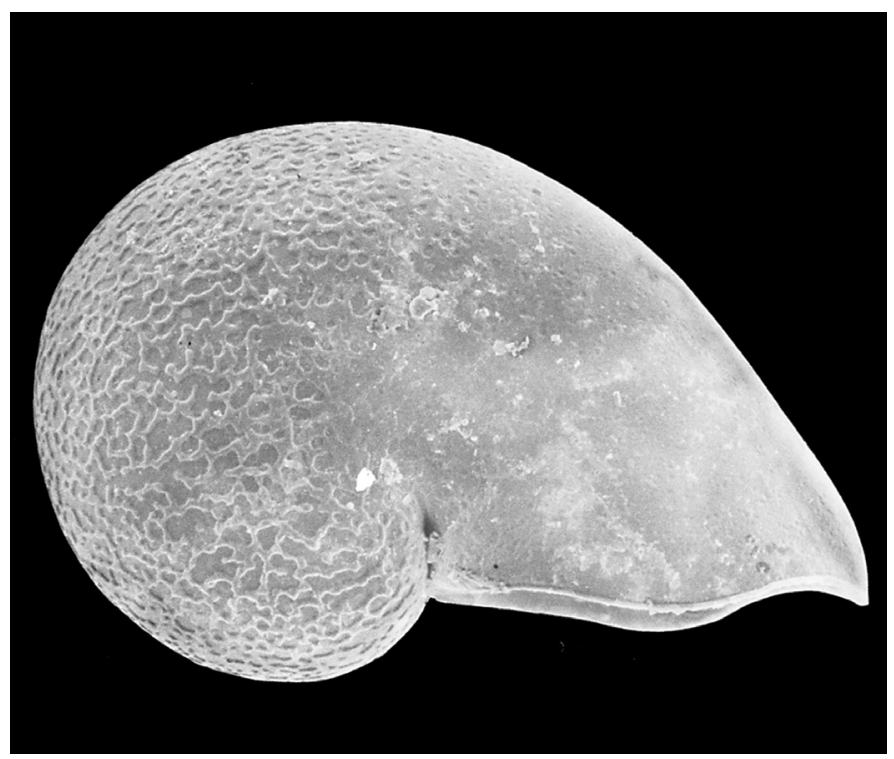

The SEM above is Fig. 2D in Mullineaux et al. (1996), with kind permission of Springer Science and Business Media.

\section{Frequency:}

Pump EPR 1999-2000: Frequent

Pump EPR 2004: Frequent

Trap EPR 2004-2005: Frequent

\section{Can be confused with:}

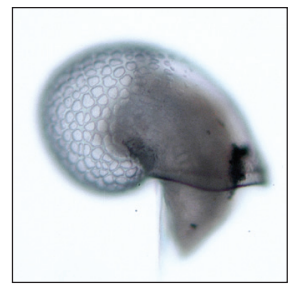

The species that Neomphalus fretterae is most likely to be confused with is Cyathermia naticoides, as both are the same size and very similar in appearance. The main differences are that Neomphalus fretterae has finer reticulate sculpture, a flare at the outer edge of the aperture and the aperture rim is about twice as wide. 


\section{Can be confused with:}

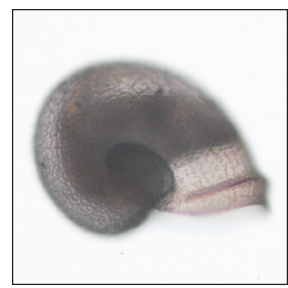

Unknown neomphalid sp. B. This protoconch is very similar in size and general appearance. However, it has a thin ridge that parallels the aperture, forming a distinct rim. The aperture is straighter in this species and the sculpture is stronger and more regular, forming distinct rows at the anterior end of the shell.

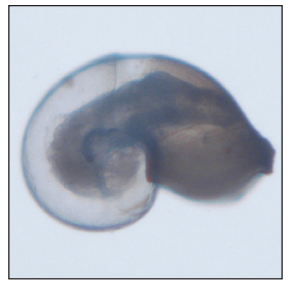

Bathymargarites symplector. This protoconch is similar in general appearance, but is much larger $(-350 \mu \mathrm{m})$ and lacks the overall reticulate sculpture. 


\section{GASTROPODA}

\section{Melanodrymia ?galeronae Warén \& Bouchet, 2001. Family Neomphalidae.}

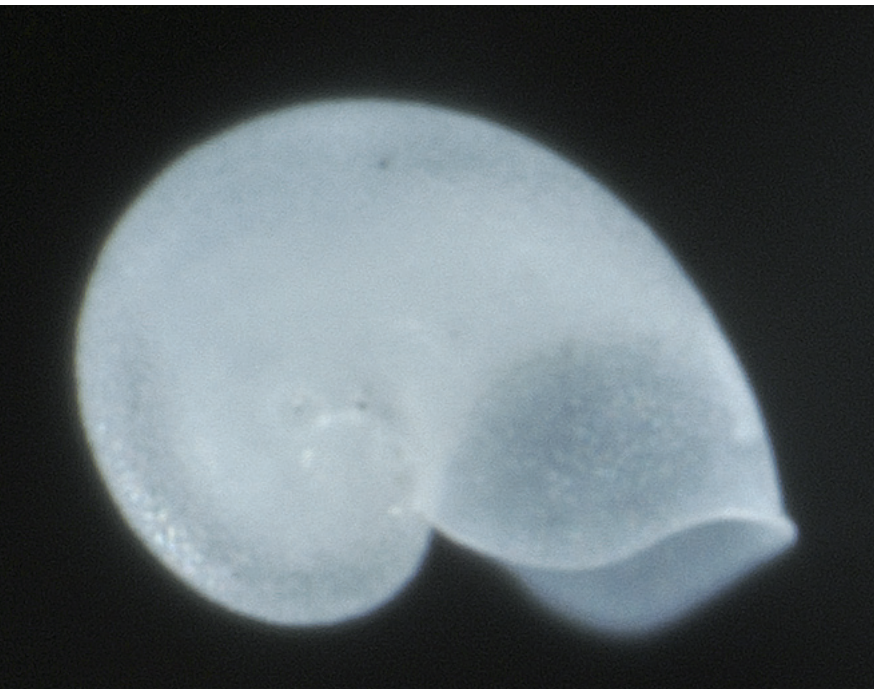

Size: $240-250 \mu \mathrm{m}$

\section{Morphology:}

This is a moderately large protoconch with overall fine reticulate sculpture. The anterior edge flares at the aperture, which is strongly sinuous.

\section{Frequency:}

Pump EPR 1999-2000: Rare

Pump EPR 2004: Not collected

Trap EPR 2004-2005: Rare

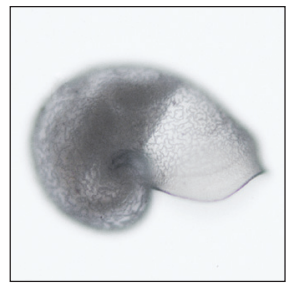

Melanodrymia ?galeronae is most likely to be confused with its congener, Melanodrymia aurantiaca. The protoconchs are very similar in size and general appearance. However, the sculpture is finer on $M$. ?galeronae, the aperture is less strongly sinuous and it lacks the distinct bump above the aperture.

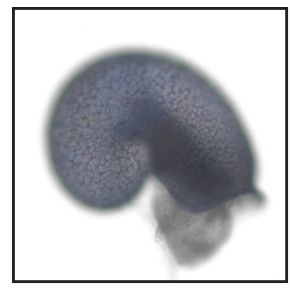

Unknown neomphalid $290 \mu \mathrm{m}$. This protoconch is very similar in general appearance and sculpture and may well be an undescribed Melanodrymia species. It is, however, larger $(290 \mu$ against $250 \mu \mathrm{m})$ and the aperture is more deeply sinuous, as well as flaring out more at the outer edge. 
GASTROPODA 


\section{Neolepetopsis spp. Four species (McLean, 1990). Family Neolepetopsidae.}

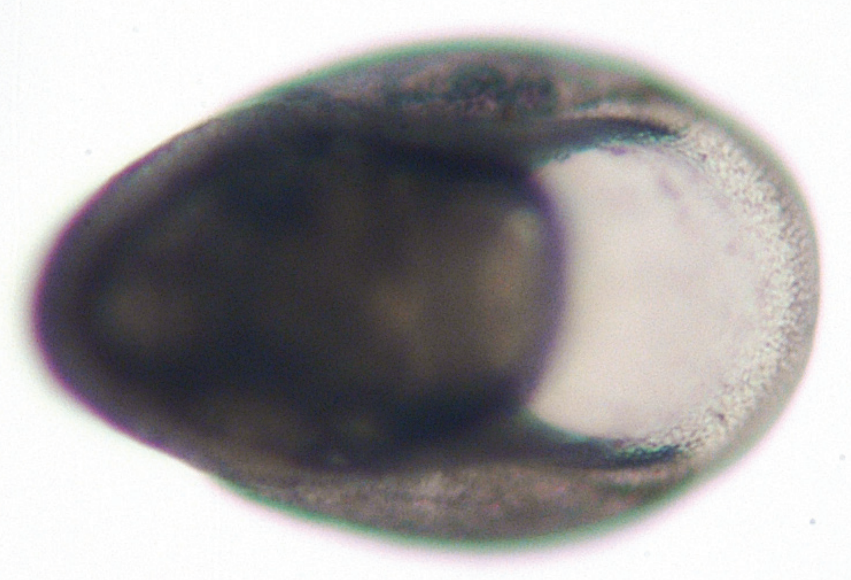

Size: $240-260 \mu \mathrm{m}$

\section{Morphology:}

This protoconch is moderately large and has fine pitted sculpture over the entire surface, giving it a grainy appearance under the light microscope. It is flattened, so it will generally be found lying with the aperture down, and there are deep indentations at the sides of the aperture. From above, the outline of the shell is oval (photo above, left), but when viewed from the side the back of the shell comes to a blunt point, as if it had been compressed from the sides. The morphology and size match $N$. densata, the only species for which the protoconch is known and it is the most likely candidate based on adult habitat (it is found at $13^{\circ} \mathrm{N}$ and the other species are from $21^{\circ} \mathrm{N}$ or Gorda Ridge), but we cannot eliminate the other possibilities.

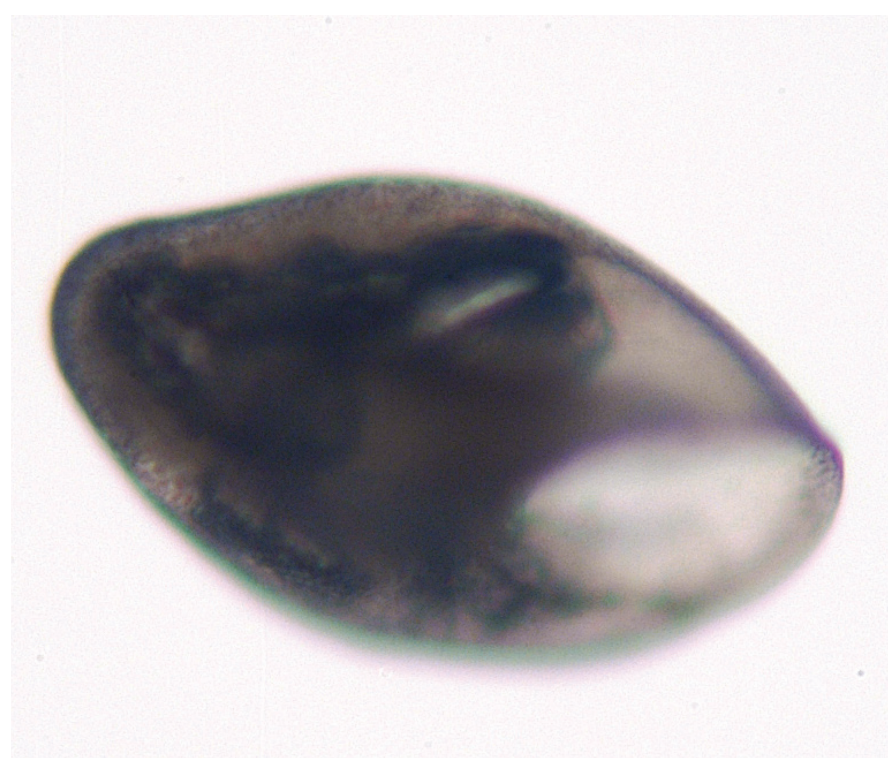

See also SEM in Warén \& Bouchet, 2001, p. 144 (Fig. 15a-c).

\section{Frequency:}

Pump EPR 1999-2000: Not collected

Pump EPR 2004: Not collected

Trap EPR 2004-2005: Rare

\section{Can be confused with:}

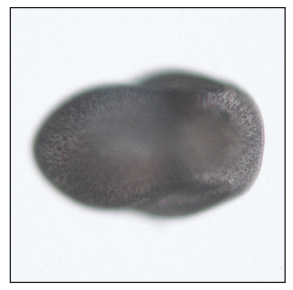

The only other protoconch this is likely to be confused with is Eulepetopsis vitrea, in the same family. Their sizes and general appearance are similar and they both have the deep indentations at the sides of the aperture. However, viewed from above, the base of Neolepetopsis is oval, while that of Eulepetopsis is indented where the aperture meets the base. In the apical view, the posterior portion of Eulepetopsis is smoothly rounded, but Neolepetopsis comes to a point, as mentioned above. 
GASTROPODA 


\section{Pachydermia laevis Warén \& Bouchet, 1989. Family Neomphalidae.}

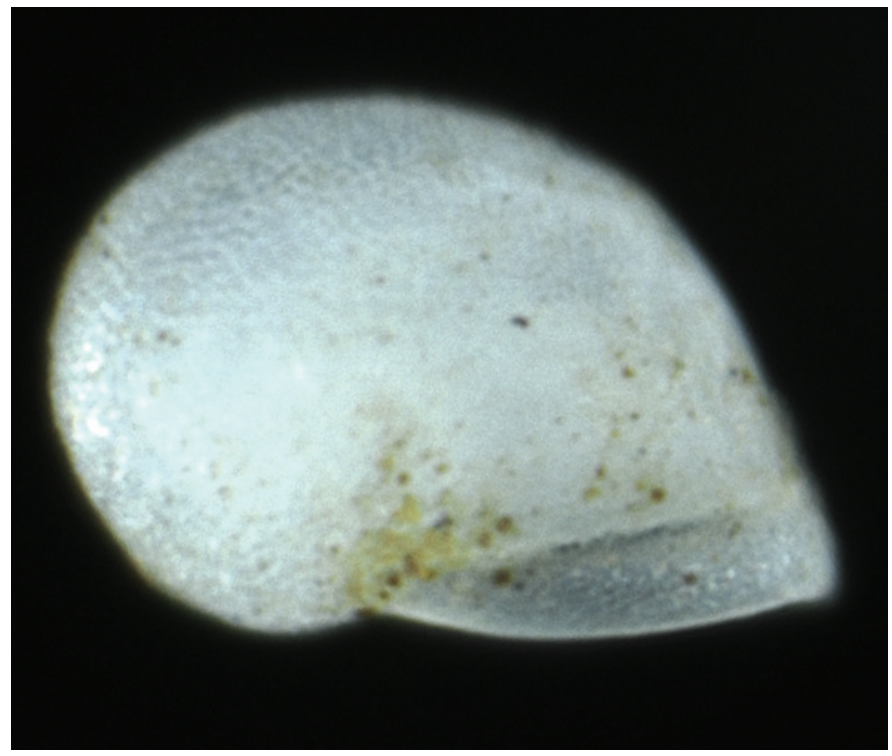

Size: $245-250 \mu \mathrm{m}$

\section{Morphology:}

Pachydermia laevis has a moderately large protoconch with regular overall interconnected reticulate sculpture, strongly marked in the proximal region and becoming finer and less distinct toward the aperture. The aperture is slightly curved with a thickened broad rim that tapers slightly toward the inner edge.

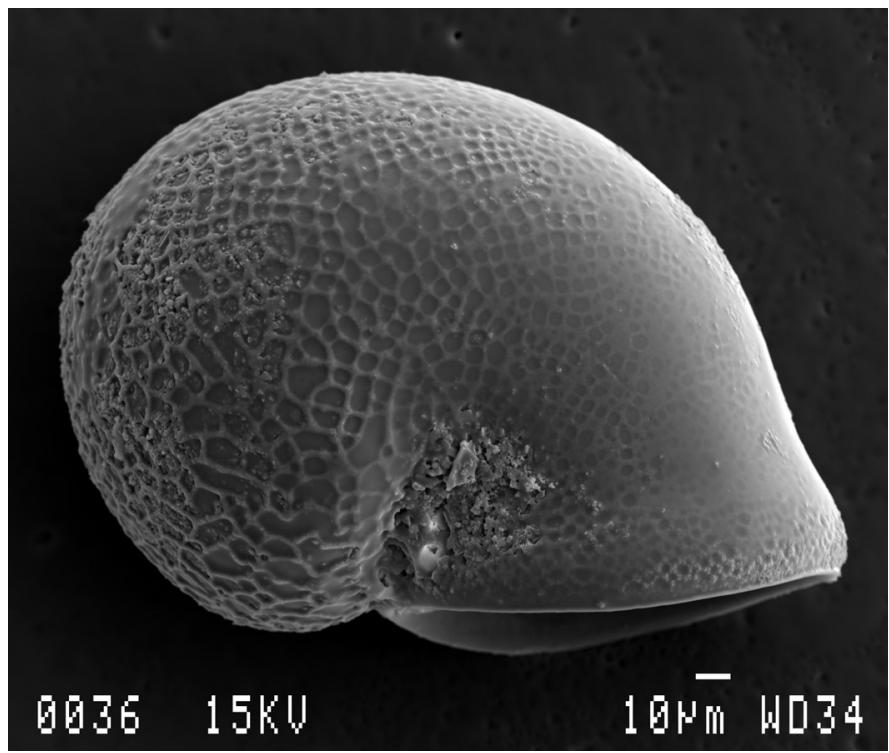

\section{Frequency:}

Pump EPR 1999-2000: Frequent

Pump EPR 2004: Frequent

Trap EPR 2004-2005: Occasional

\section{Can be confused with:}

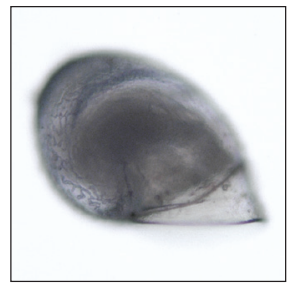

Pachydermia laevis is most likely to be confused with Unknown neomphalid W, as they are approximately the same size and both have reticulate sculpture. However, Unknown neomphalid W lacks the thickened aperture rim and its sculpture is coarser and less regular and is limited to the proximal half of the shell. 
GASTROPODA 


\section{Eulepetopsis vitrea McLean, 1990. Family Neolepetopsidae.}
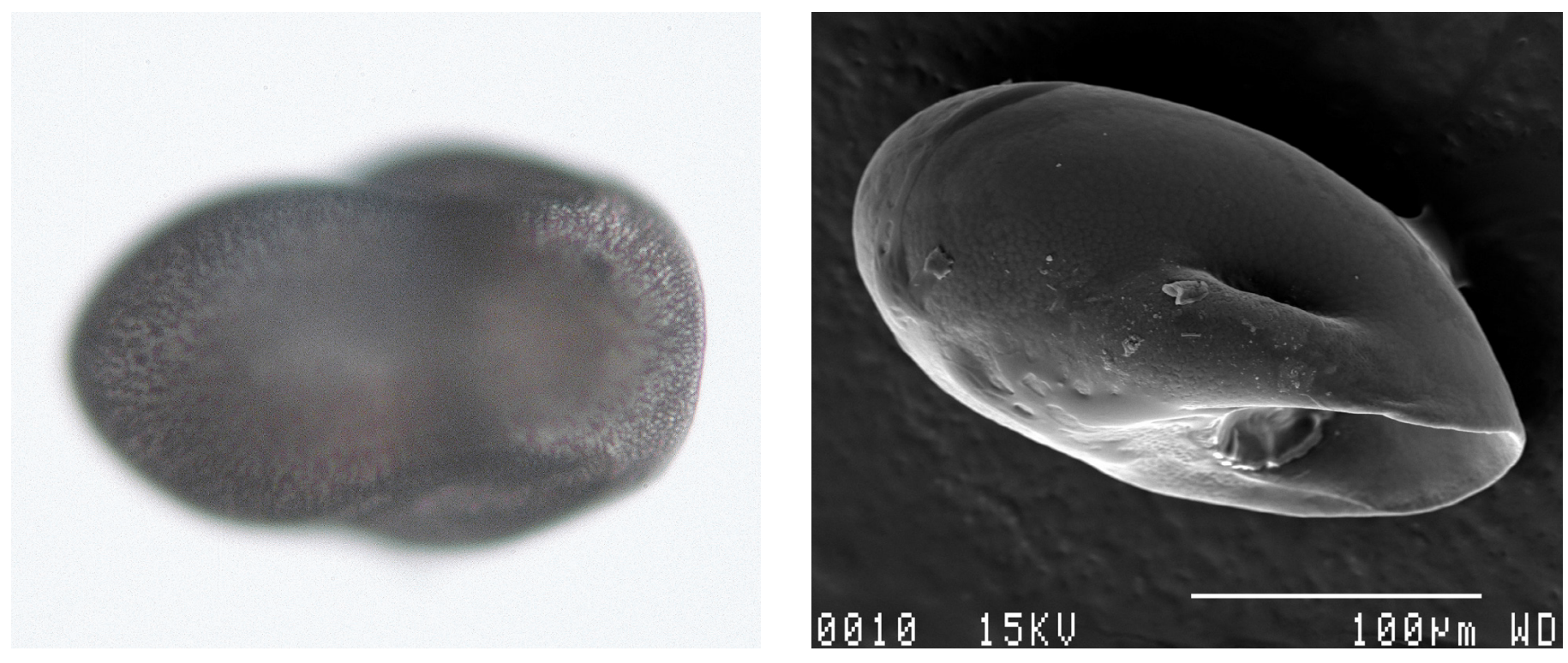

Size: $245-250 \mu \mathrm{m}$

\section{Morphology:}

This is a moderately large protoconch, with shallow, coarse pitted sculpture over the entire shell, giving it a grainy appearance under the light microscope. The shell is dorsoventrally flattened, so it is usually found either with the aperture facing down or lying at an angle with the aperture visible. The posterior portion of the aperture flares out from the body, forming a deep indentation on both sides. The posterior of the shell is smoothly rounded.

\section{Frequency:}

Pump EPR 1999-2000: Frequent

Pump EPR 2004: Frequent

Trap EPR 2004-2005: Occasional

\section{Can be confused with:}

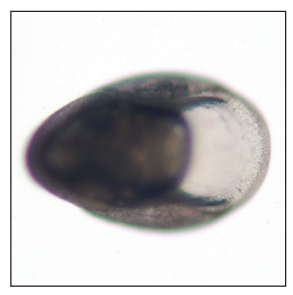

The only protoconch that is likely to be confused with Eulepetopsis vitrea in our samples is another genus in the same family, Neolepetopsis sp. Both protoconchs are about the same size and similar in appearance. However, the posterior edge of Neolepetopsis is slightly flattened laterally, giving it a more pointed look. This is best seen when

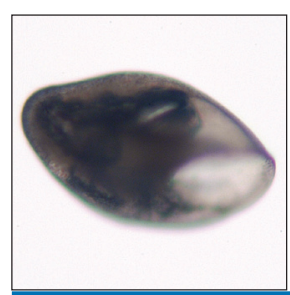
viewed from the side. Viewed from above, the Neolepetopsis protoconch is oval, whereas that of Eulepetopsis is indented behind the aperture. 
GASTROPODA 


\section{GASTROPODA}

\section{Unknown neomphalid W Family Neomphalidae.}

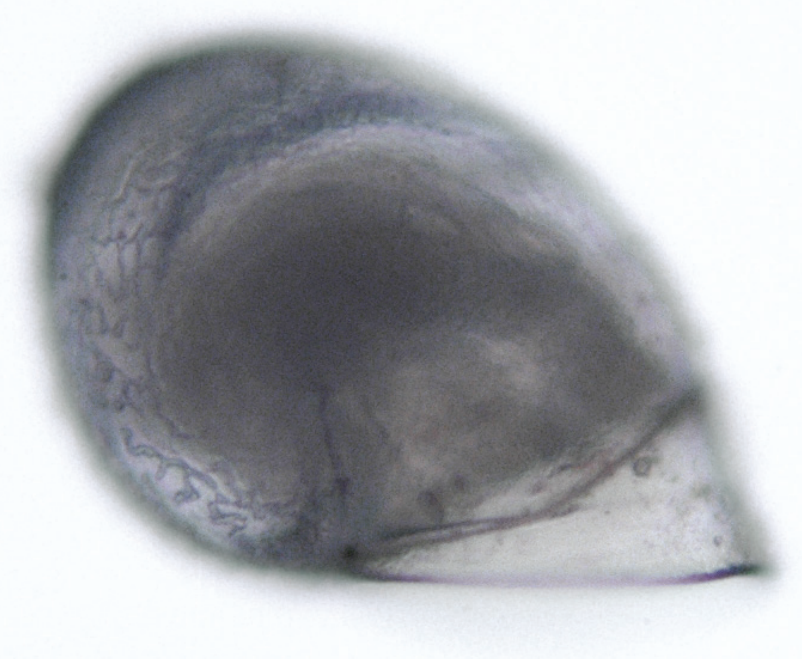

Size: $250-260 \mu \mathrm{m}$

\section{Morphology:}

This is a moderately large protoconch with coarse reticulate sculpture over the proximal half of the shell. Under the dissecting microscope the sculpture sometimes appears lineate and the general outline of the shell is typical of peltospirids, but the reticulate sculpture is easily visible under the compound microscope. The aperture is straight and there is a wide rim, tapering toward the posterior edge of the aperture, visible under the light microscope. Warén \& Bouchet, 1989, described a species with a very similar protoconch as Depressigyra planispira (later amended to Planorbidella planispira), but since later specimens of this species appear to have a different protoconch (A. Warén, pers. comm.), we have kept our original designation.

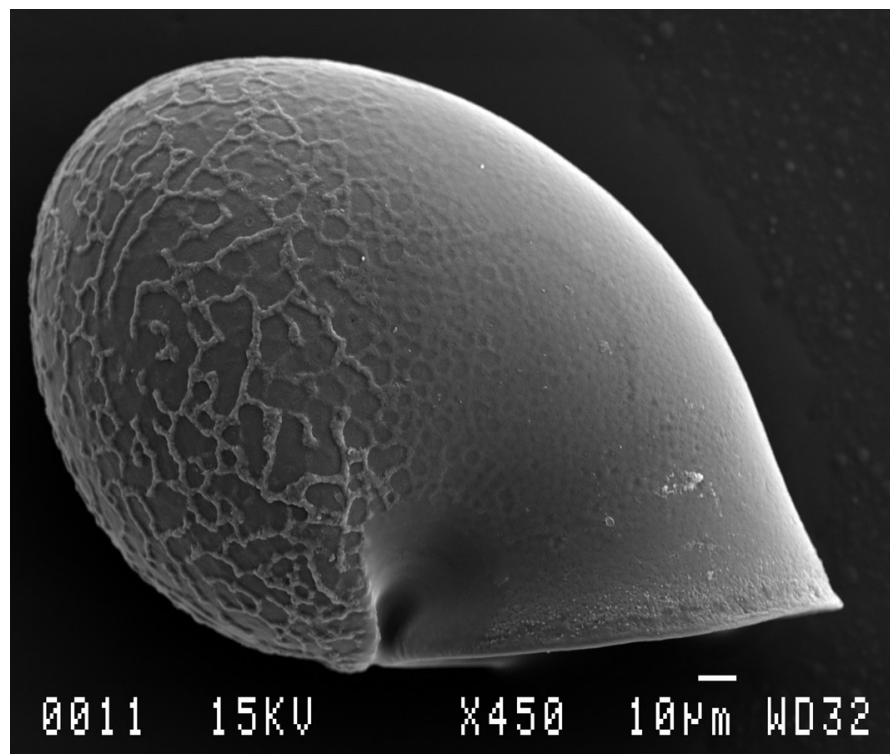

\section{Frequency:}

Pump EPR 1999-2000: Frequent

Pump EPR 2004: Frequent

Trap EPR 2004-2005: Occasional

\section{Can be confused with:}

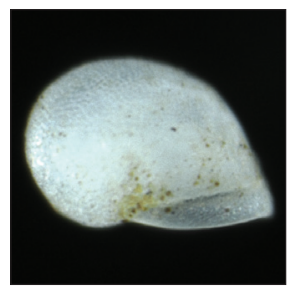

Pachydermia laevis. Unknown neomphalid W lacks the thickened aperture rim and its sculpture is coarser, less regular and limited to the proximal portion of the shell.

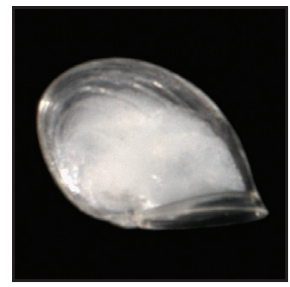

Unknown peltospirid $240 \mu \mathrm{m}$ is similar in size and shape, but has lineate sculpture, instead of reticulate. This may not be obvious viewed from the side, but when viewed from the top, the edges of the lines can be seen if lineate sculpture is present. 


\section{Can be confused with:}

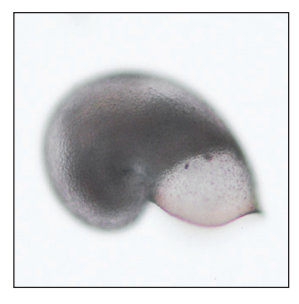

Melanodrymia aurantiaca is most likely to be confused with its congener, Melanodrymia ?galeronae. The protoconchs are very similar in size and general appearance. However, the sculpture is finer on $M$. ?galeronae, the aperture is less deeply sinuous and it lacks the distinct bump above the aperture, instead having a gentle curve which ends in a flare at the aperture.

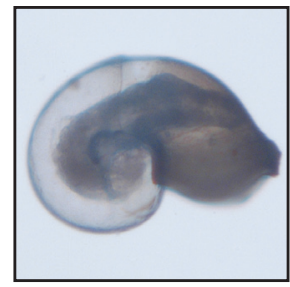

Bathymargarites symplector. This protoconch is similar in general appearance, but is much larger $(-350 \mu \mathrm{m})$ and lacks the overall reticulate sculpture. 


\section{GASTROPODA}

\section{Melanodrymia aurantiaca Hickman, 1984. Family Neomphalidae.}
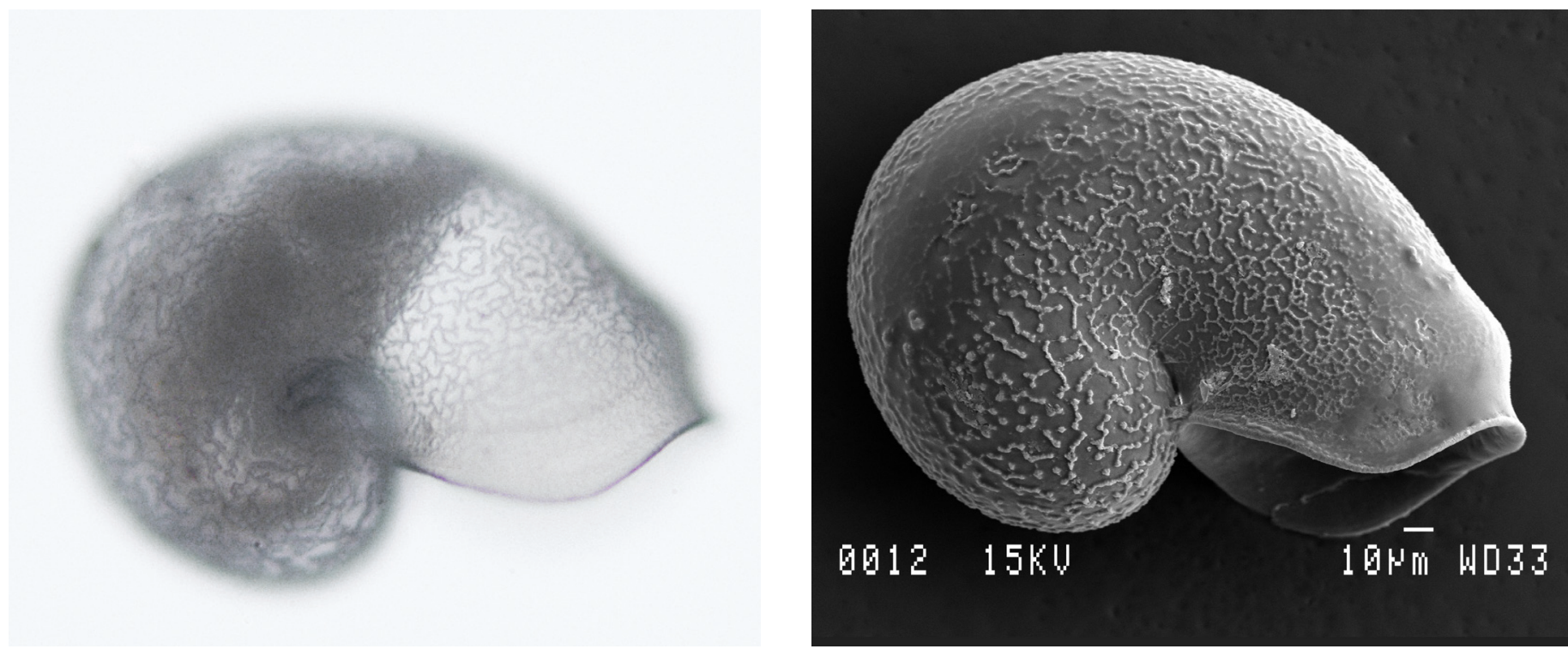

Size: $250-260 \mu \mathrm{m}$

\section{Morphology:}

Melanodrymia aurantiaca has a moderately large protoconch entirely covered with irregular reticulate sculpture, giving it a grainy appearance when viewed under a light microscope. The aperture is deeply sinuous and there is a broad ridge or bump at the anterior edge of the shell above the aperture.

\section{Frequency:}

Pump EPR 1999-2000: Frequent

Pump EPR 2004: Frequent

Trap EPR 2004-2005: Occasional

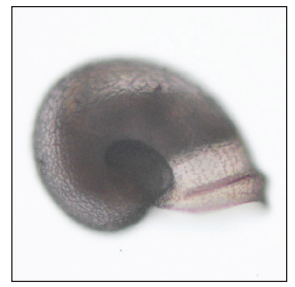

Unknown neomphalid sp. B. This protoconch is very similar in size and general appearance. However, instead of having a thick bump at the anterior edge, it has a narrow ridge that parallels the aperture, forming a distinct rim. The aperture is much straighter in this species and the sculpture is stronger and more regular, forming distinct rows at the anterior end of the

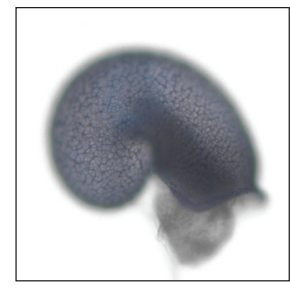

Unknown neomphalid $290 \mu \mathrm{m}$. This protoconch is very similar in general appearance and sculpture and may well be an undescribed Melanodrymia species. It is, however, larger $(290 \mu \mathrm{m}$ against $260 \mu \mathrm{m})$ and the aperture is more deeply sinuous, as well as flaring out at the outer edge.

shell. 


\section{Can be confused with:}

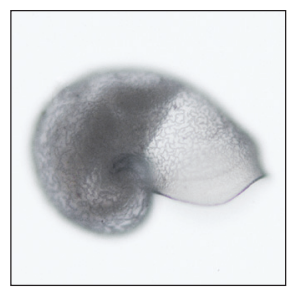

Melanodrymia aurantiaca is about $30 \mu \mathrm{m}$ smaller, with finer sculpture. Its aperture is more smoothly curved.

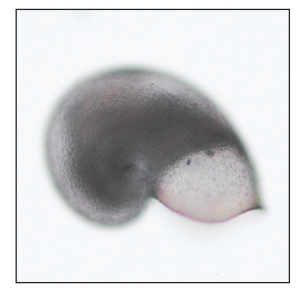

Melanodrymia ?galeronae is about $40 \mu \mathrm{m}$ smaller, also with finer sculpture and a more smoothly curved aperture. 


\section{GASTROPODA}

\section{Unknown ?neomphalid $290 \mu \mathrm{m}$ Family ?Neomphalidae.}
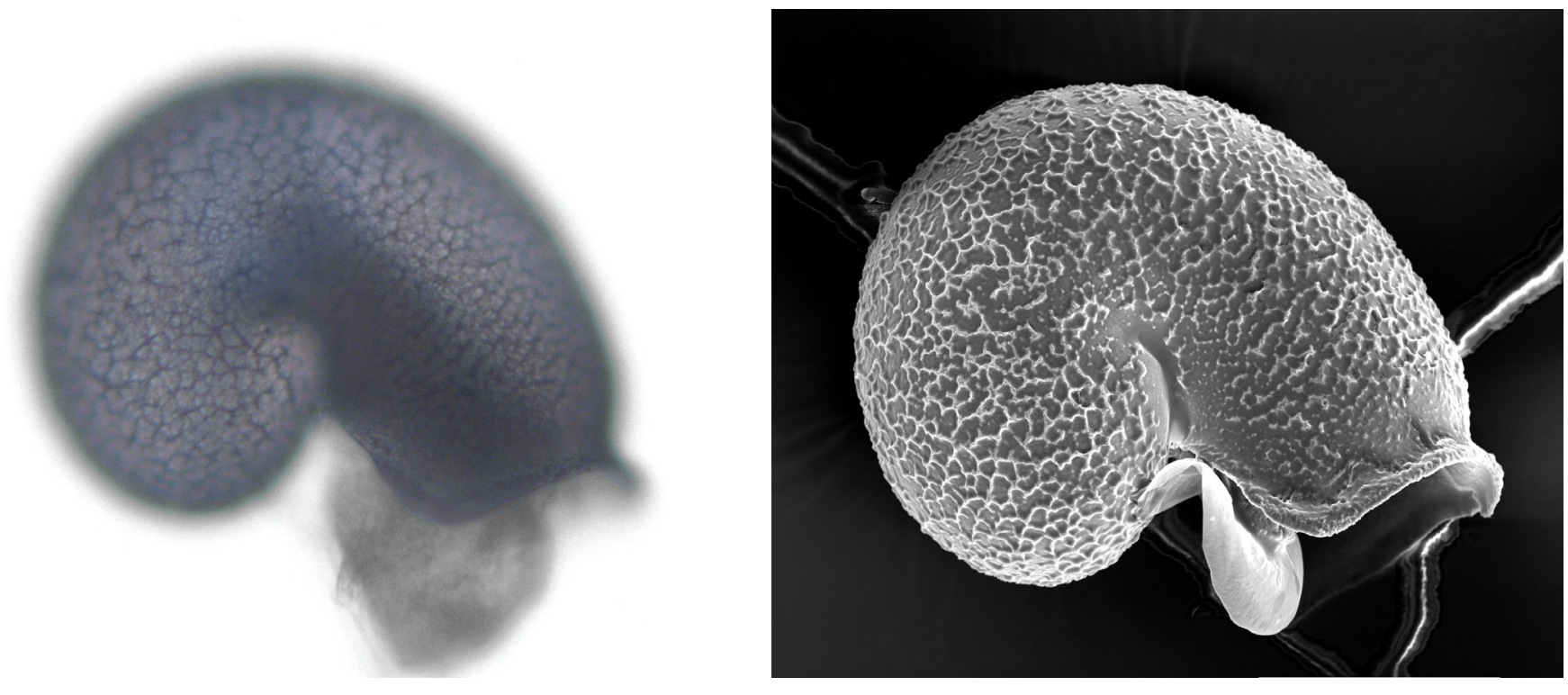

Size: $280-290 \mu \mathrm{m}$

\section{Morphology:}

This is a large protoconch with reticulate sculpture over the entire shell. The outer edge of the aperture flares out and the sides are deeply sinuous, coming to blunt points. The outline of the shell is smoothly rounded and there is no apparent aperture rim. It resembles Melanodrymia spp. in general appearance and sculpture and may well be an undescribed species in that genus.

\section{Frequency:}

Pump EPR 1999-2000: Not collected

Pump EPR 2004: Rare

Trap EPR 2004-2005: Rare

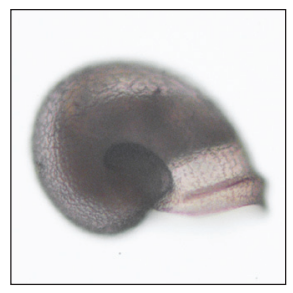

Unknown neomphalid B is about $50 \mu \mathrm{m}$ smaller. Its sculpture forms regular lines distally and it has a distinct ridge parallelling the aperture.

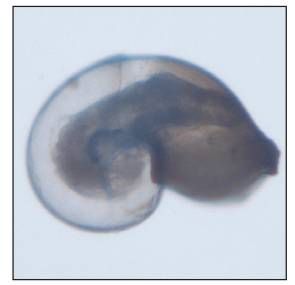

Bathymargarites symplector is $30-50 \mu \mathrm{m}$ larger. Its shell is nearly smooth, with only a few faint axial striations on distal half of shell. 
GASTROPODA 


\section{Rhynchopelta concentrica McLean, 1989. Family Peltospiridae.}
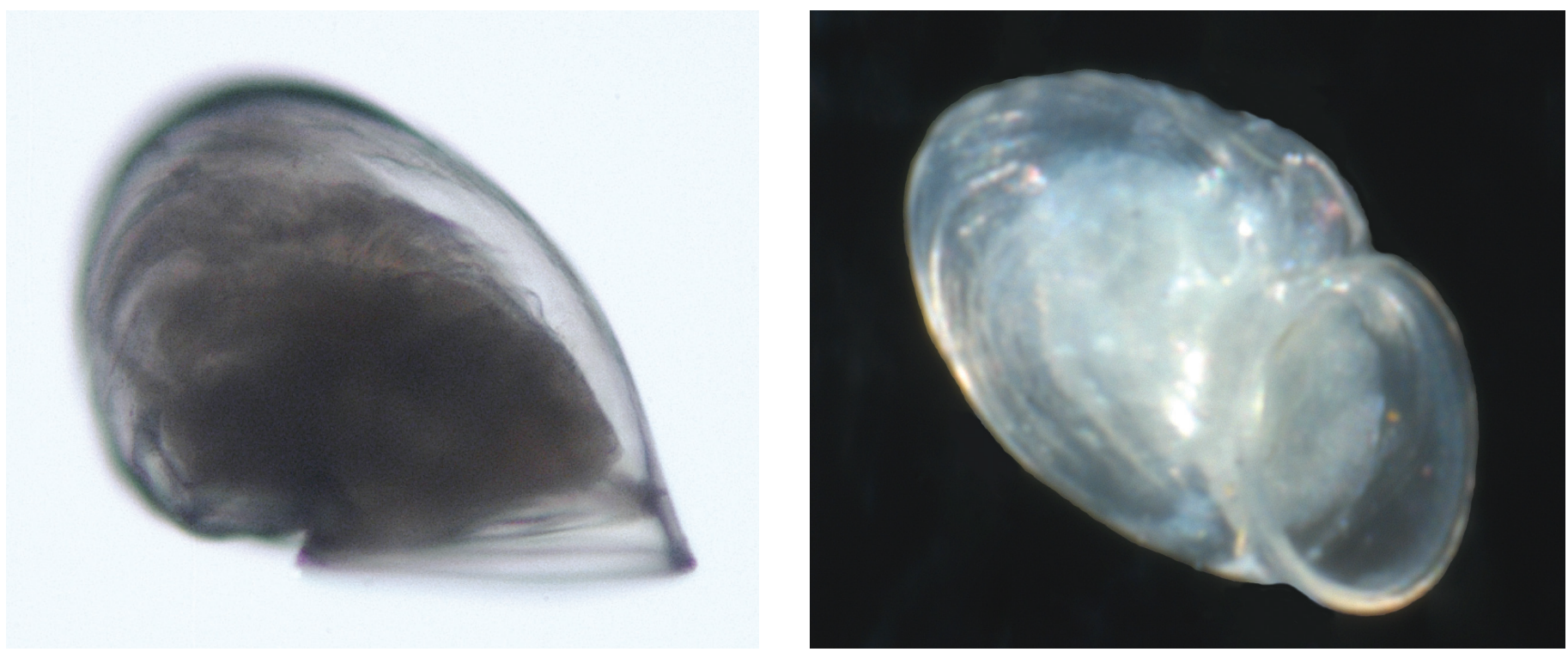

Size: $280-290 \mu \mathrm{m}$

\section{Morphology:}

This is one of the few easily identified peltospirids. It is a large protoconch with strong lineation extending about $2 / 3$ of the way to the aperture. Like most peltospirids, the aperture is straight viewed from the side and flares out to the sides when viewed from from the top. There is also an abrupt ridge on either side of the base near the axis of coiling. The shell is transparent and robust; they are seldom found damaged.

\section{Frequency:}

Pump EPR 1999-2000: Frequent

Pump EPR 2004: Frequent

Trap EPR 2004-2005: Frequent

\section{Can be confused with:}

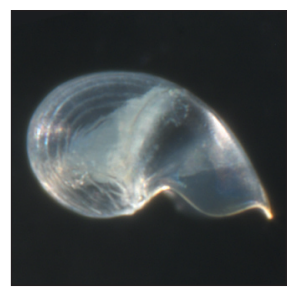

Rhynchopelta is unlikely to be confused with any other protoconch. The only other peltospirid protoconch close to it in size, Ctenopelta porifera (pictured at left), is quite different morphologically. 
GASTROPODA 


\section{Ctenopelta porifera Warén \& Bouchet, 1993. Family Peltospiridae.}

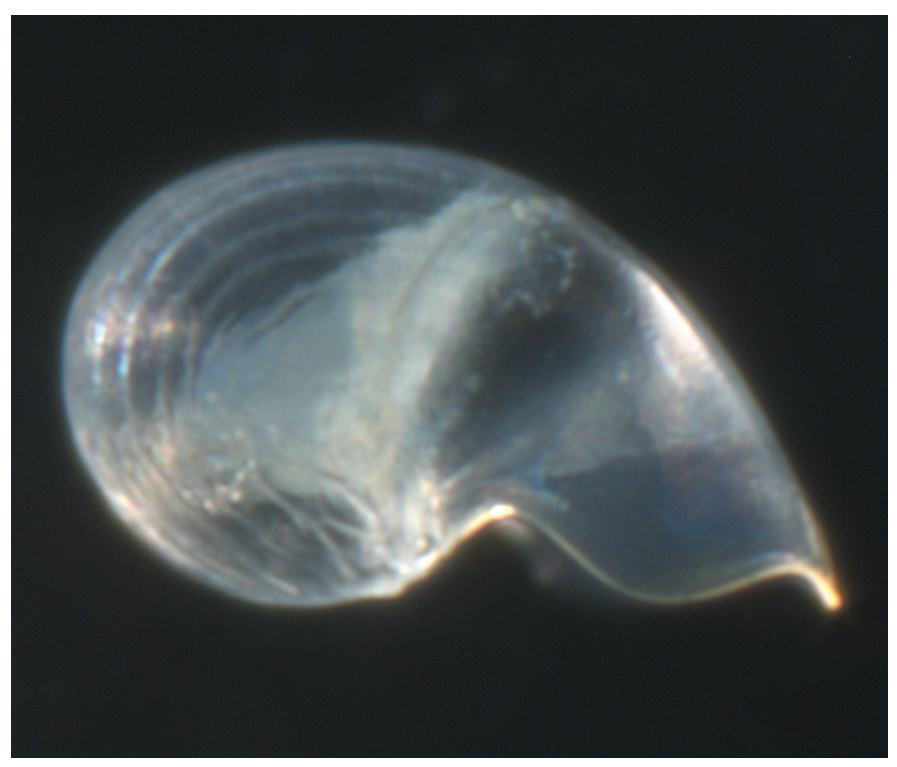

Size: $290-310 \mu \mathrm{m}$

\section{Morphology:}

This is the largest peltospirid protoconch we have found at EPR. Lineate sculpture, narrowly spaced, covers the posterior half of the protoconch. The anterior portion is smooth. The aperture is deeply sinuous and not circular when viewed from beneath, unlike all other peltospirids we have found.

\section{Frequency:}

Pump EPR 1999-2000: Not collected

Pump EPR 2004: Rare

Trap EPR 2004-2005: Rare

\section{Can be confused with:}

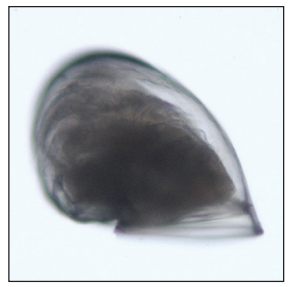

Because of its size and distinctive sculpture and morphology, this species is unlikely to be confused with any other protoconch. Rhynchopelta concentrica (pictured at left) is nearly as large, but is quite different in appearance. 
GASTROPODA 


\section{GASTROPODA}

\section{Bathymargarites symplector Warén \& Bouchet, 1989.}

\section{Family Trochidae.}

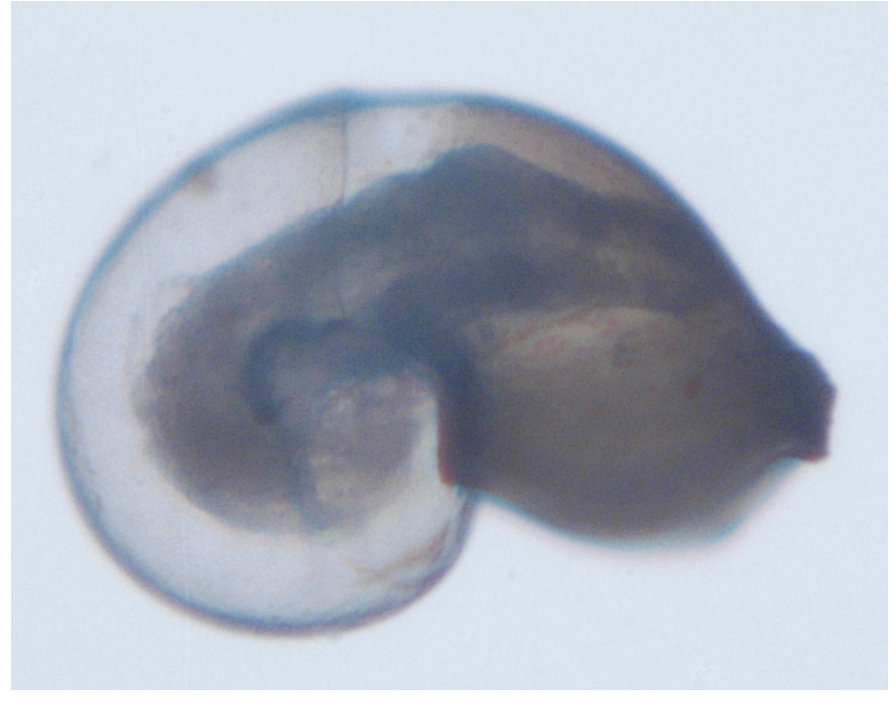

Size: $320-350 \mu \mathrm{m}$

\section{Morphology:}

The shell consists of two parts, a proximal smooth portion approximately $200 \mu \mathrm{m}$ in diameter and a distal portion with axial striations. The aperture is curved, flares out at the anterior edge and is asymmetrical, extending farther out on the apical side than on the basal side.

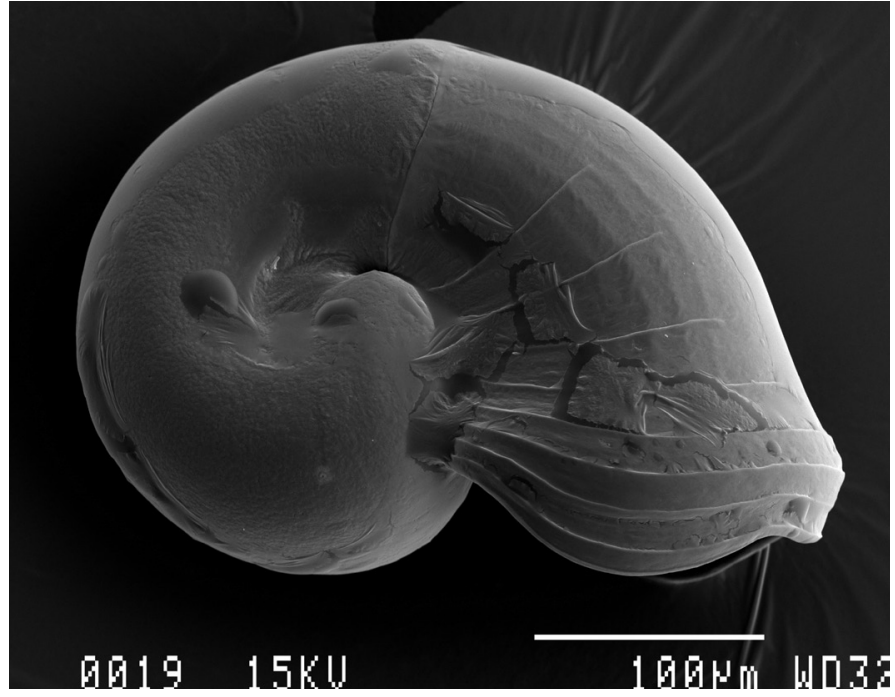

See also Warén \& Bouchet, 1989, Figure 10, for SEM photos of larval and juvenile shells.

\section{Frequency:}

Pump EPR 1999-2000: Rare

Pump EPR 2004: Rare

Trap EPR 2004-2005: Frequent

\section{Can be confused with:}

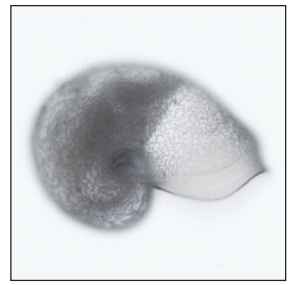

Bathymargarites' larval shell is unique among the species at $9^{\circ} \mathrm{N}$ and is therefore not likely to be confused with any other species. It has a superficial similarity to Melanodrymia aurantiaca, shown at left, but the latter is much smaller $(-260 \mu \mathrm{m})$ and has reticulate sculpture over the entire shell. 
GASTROPODA 


\section{Laeviphitus sp. Family Elachisinidae.}

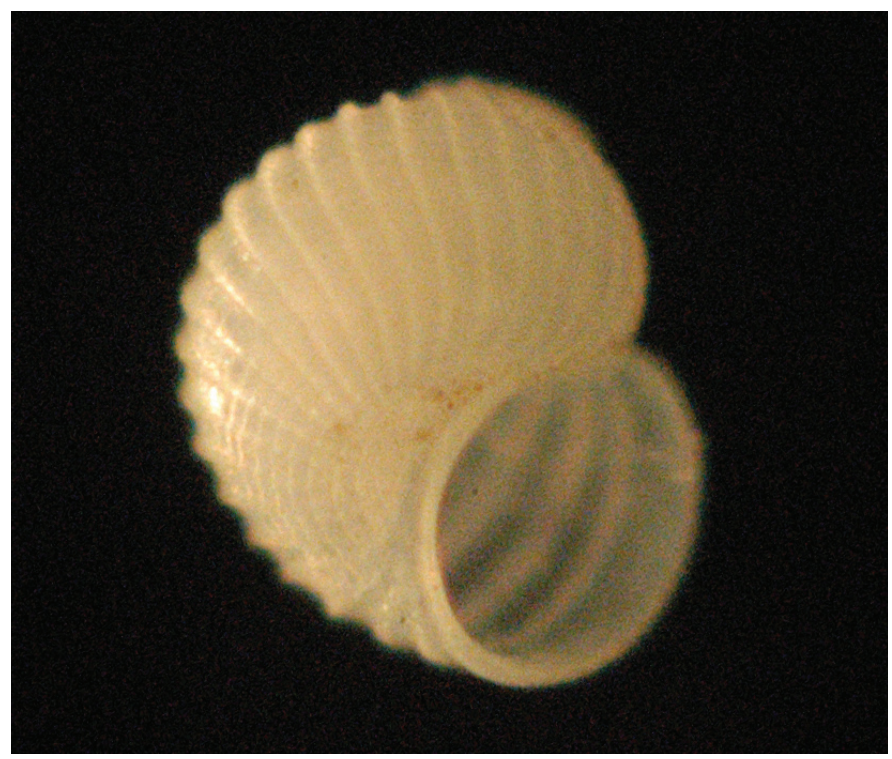

Size: $360-400 \mu \mathrm{m}$

\section{Morphology:}

Laeviphitus has a large coiled protoconch. It is presumably planktotrophic, with an unornamented protoconch I and protoconch II with fine spiral ridges and strong axial ribs to form a distinctive crosshatched pattern. The species is unknown, as no adults in this genus have been collected on the EPR, though members of the genus have been collected at vent and seep sites elsewhere.

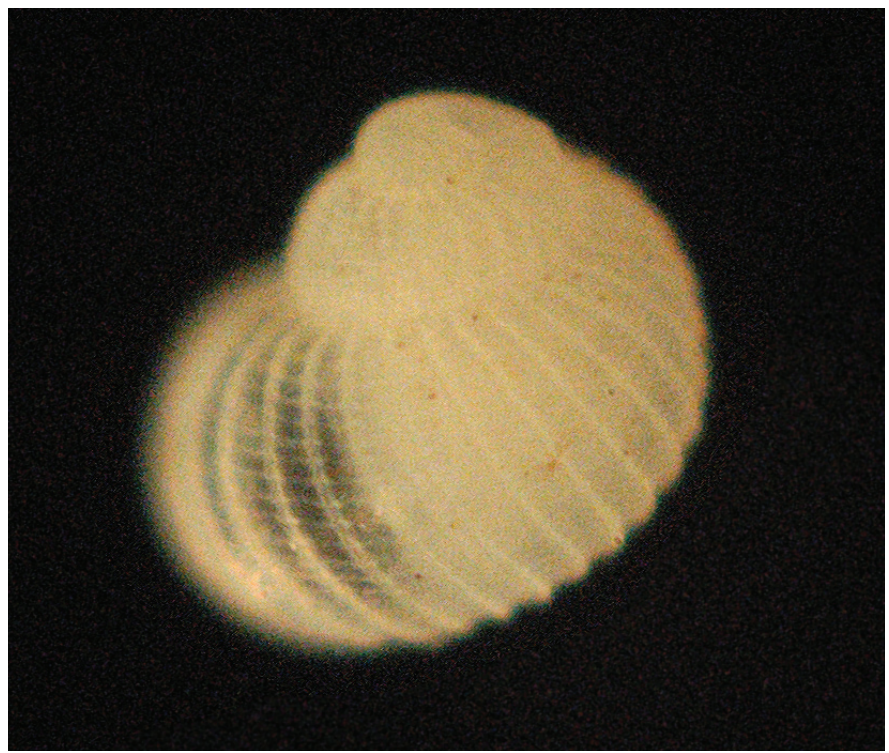

See also Mullineaux et al. (1996), Figure 5e\&f, for SEM photos

\section{Frequency:}

Pump EPR 1999-2000: Frequent

Pump EPR 2004: Common

Trap EPR 2004-2005: Common

\section{Can be confused with:}

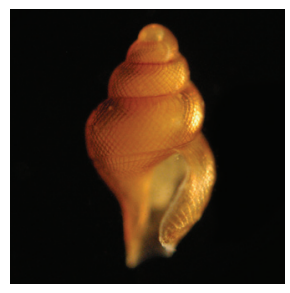

There are few coiled larvae in the plankton at $9^{\circ} \mathrm{N}$ and it is unlikely that this species would be confused with any other. Phymorhynchus protoconchs are also large and coiled, but have a taller spire and an ornamented protoconch I. The patterning on protoconch II in Phymorhynchus is diamond-shaped. 
GASTROPODA 
Phymorhynchus sp.

(presumably Phymorhynchus major Warén \& Bouchet, 2001). Family Conidae.

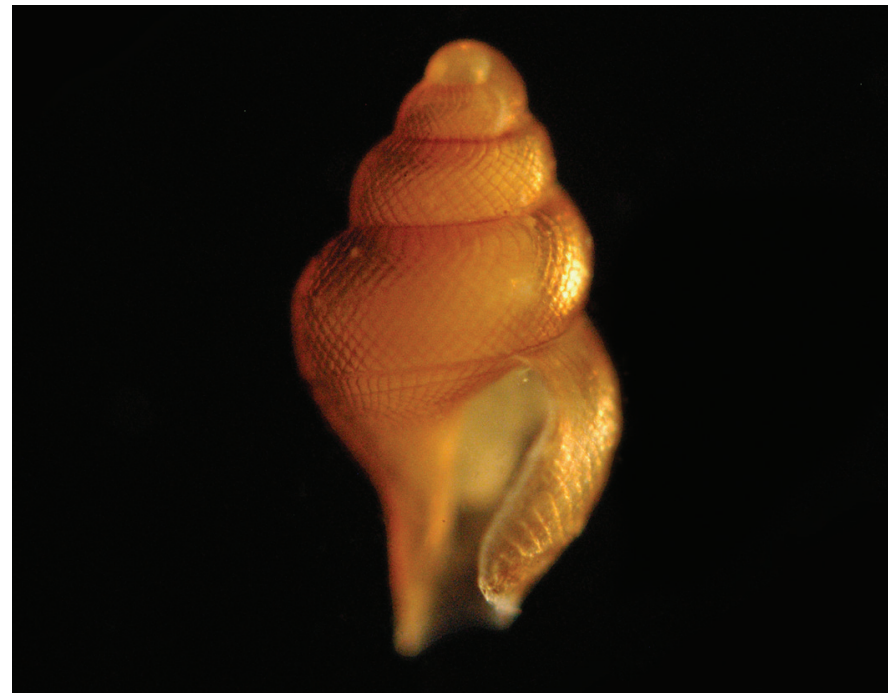

Size: $>1 \mathrm{~mm}$ (late-stage, left photo), $240 \mu \mathrm{m}$ (PI only, right photo)

\section{Morphology:}

This is a large coiled larva with planktotrophic development. The sculpture of PI appears to consist of parallel spiral lines under the light microscope, although there are short axial bars on each line visible at high magnification (above, right). PII has regularly spaced diagonal axial ribs that cross to form a diamond-shaped pattern. Most late stage individuals appear golden brown, as shown above left.

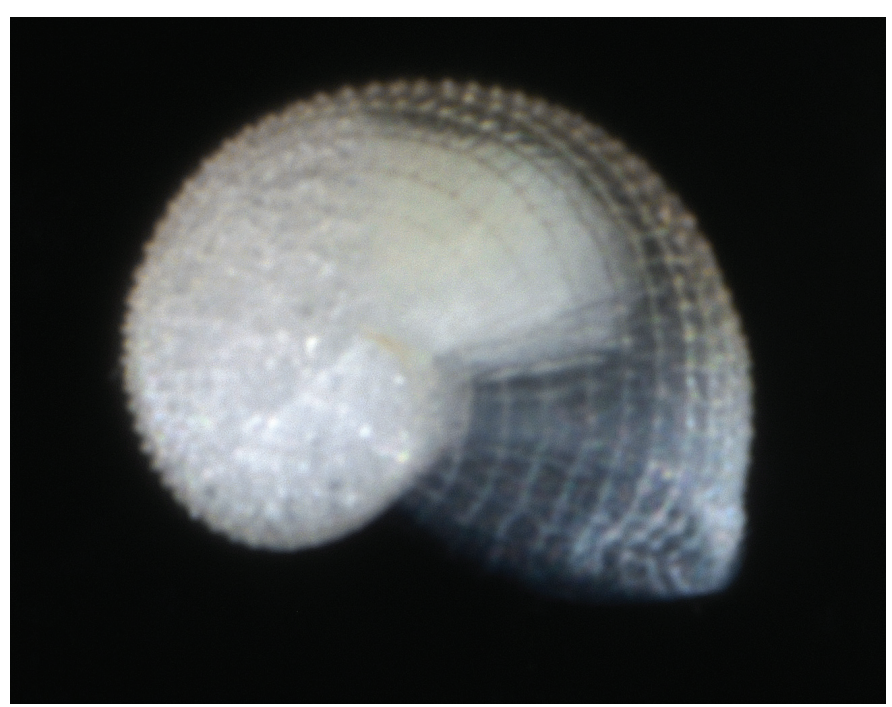

See Gustafson and Lutz (1994) for SEM of larva collected from an egg capsule at the Galápagos Rift and Lutz et al. (1986), Fig 1C,D for SEM's of larval shell on juvenile

\section{Frequency:}

Pump EPR 1999-2000: Not collected on axis

Pump EPR 2004: Not collected

Trap EPR 2004-2005: Not collected

\section{Can be confused with:}

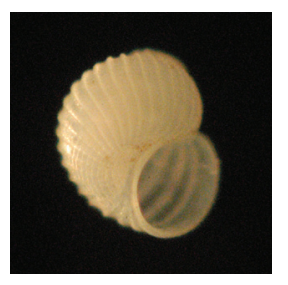

smaller $(400 \mu \mathrm{m})$.
The larva of Phymorhynchus major is unlikely to be confused with any other species, as there are so few coiled larvae at $9^{\circ} \mathrm{N}$ and its sculpture is so distinctive. Laeviphitus also shows cross-hatched sculpture on PII, but in that case the lines form rectangles rather than diamonds and the spire is much flatter. It is also generally white and much 


\section{Bathymodiolus thermophilus Kenk \& Wilson, 1985.}

Family Mytilidae.

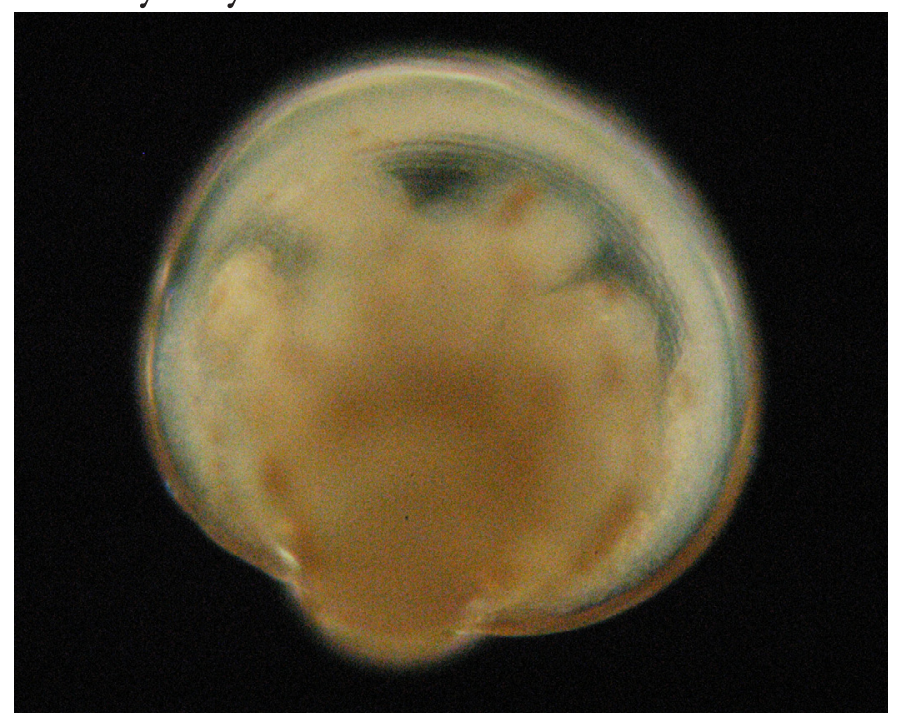

Size: $400-450 \mu \mathrm{m}$

\section{Morphology:}

Bathymodiolus thermophilus have planktotrophic larvae. We find them in our plankton samples when they are close to settling. It is possible that we do not collect them as trochophores or D-stage larvae because they may be too small to be caught on our $63 \mu \mathrm{m}$ sieves. Near to settlement they are brownish in color.

\section{Frequency:}

Pump EPR 1999-2000: Occasional Pump EPR 2004: Rare

Trap EPR 2004-2005: Not collected

\section{Can be confused with:}

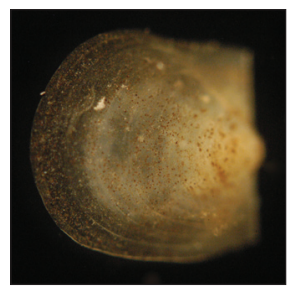

Bathymodiolus thermophilus is similar in color to juvenile Bathypecten, but is much smaller $(<450$ $\mu \mathrm{m}$ vs. $>1 \mathrm{~mm}$ ) and not scallop-shaped. 


\section{Bathypecten vulcani Schein-Fatton, 1985. Family Pectinidae.}
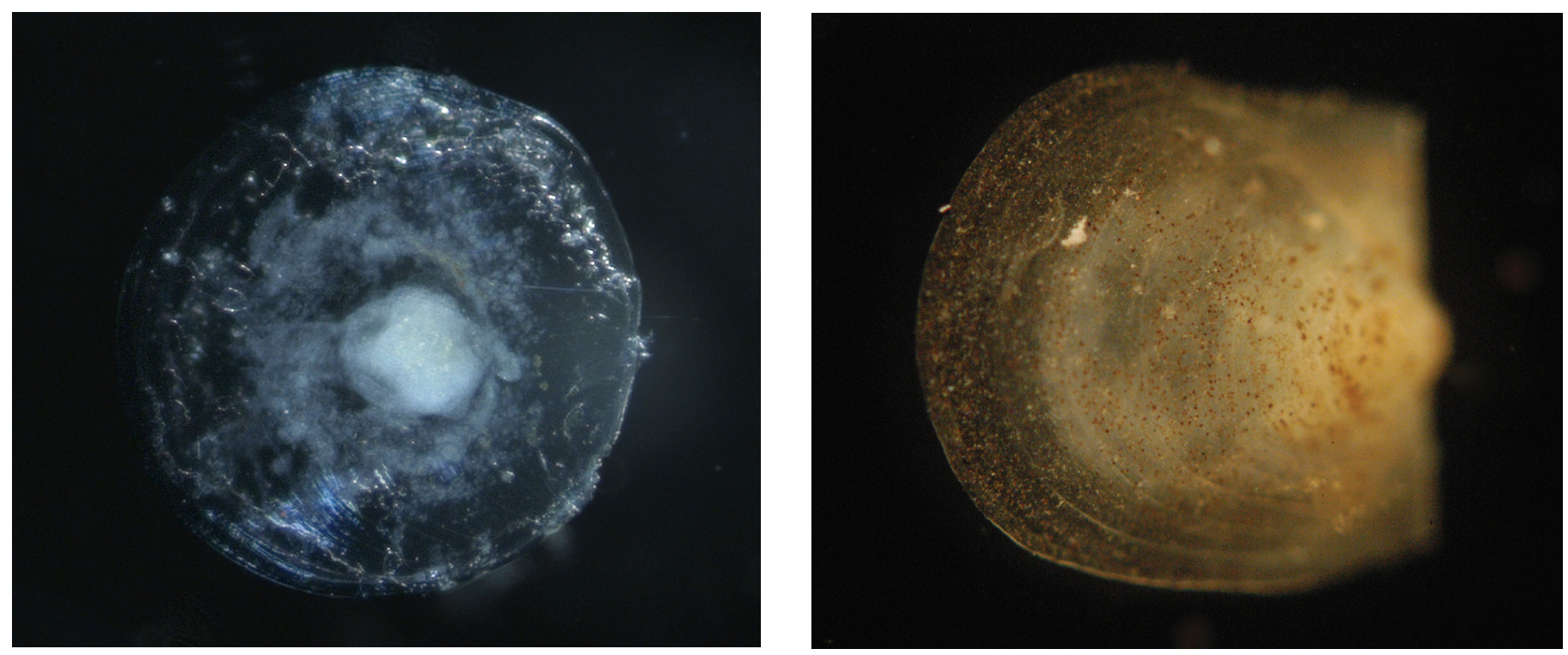

Size: $840 \mu \mathrm{m}$ (larva, above left), >1mm (juvenile)

\section{Morphology:}

\section{Frequency:}

Shell thin, fragile, transparent to translucent. Most of the individuals we collect are larger than $2 \mathrm{~mm}$ and possess the typical scallop morphology of the specimen on the right. These would presumably be swimming juveniles rather than larvae. Pump EPR 1999-2000: Not collected Pump EPR 2004: Not collected Trap EPR 2004-2005: Not collected

\section{Can be confused with:}

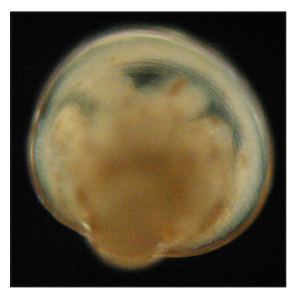

Bathymodiolus thermophilus is similar in color to juvenile Bathypecten, but is much smaller $(<450$ $\mu \mathrm{m}$ vs $>1 \mathrm{~mm}$ ) and not scallop-shaped. 
POLYCHAETA 


\section{Amphisamytha galapagensis Zottoli, 1983. Family Ampharetidae.}
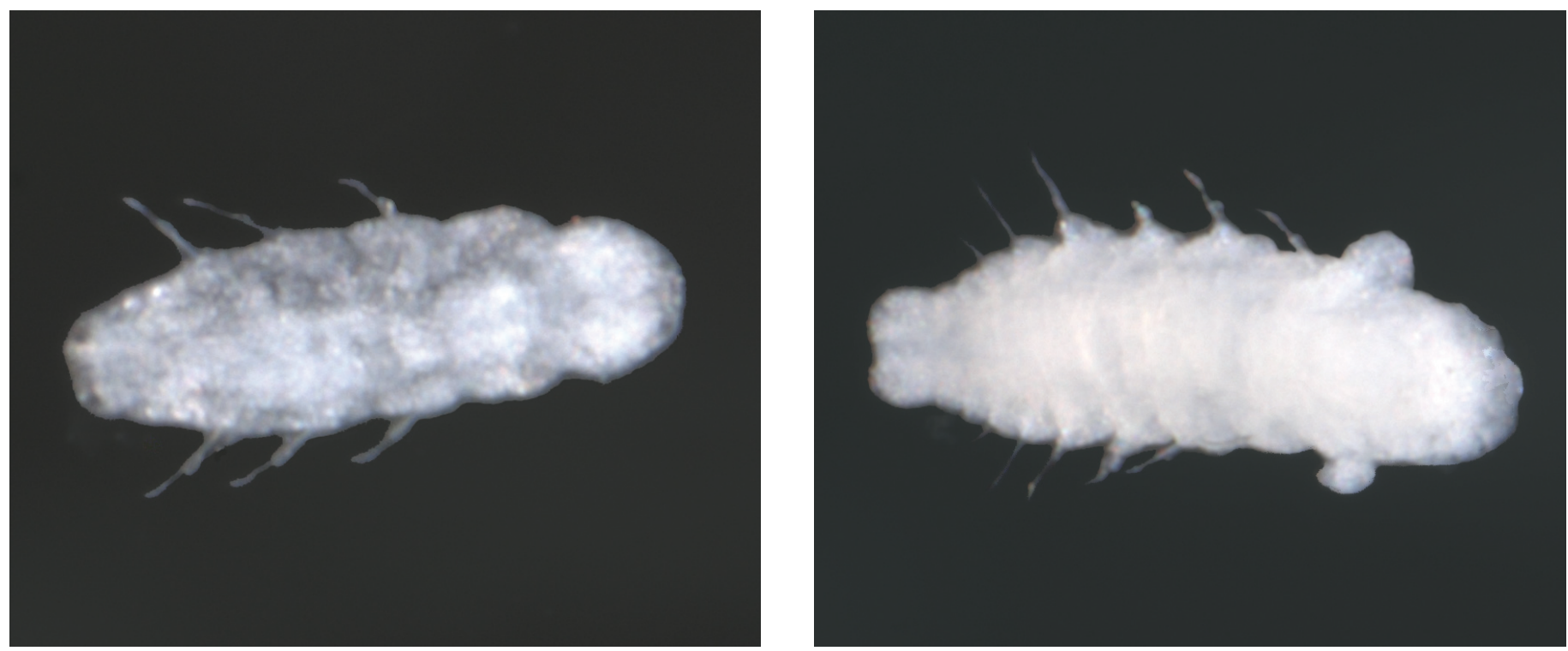

Size: $280-500 \mu \mathrm{m}$

\section{Morphology:}

Smallest individuals (3-4 chaetigers) have neither appendages nor distinctive morphology, as shown above left. At around $400 \mu \mathrm{m}$ and 5-6 chaetigers they develop a pair of smooth gills behind the prostomium (shown above in right photo); the adults will ultimately have four pairs, but the remaining three pairs appear much later in development. Since the smallest larvae are so featureless, it is possible that there may be more than one species represented.

\section{Frequency:}

Pump EPR 1999-2000: Not distinguished from other polychaete larvae

Pump EPR 2004: Not collected

\section{Can be confused with:}

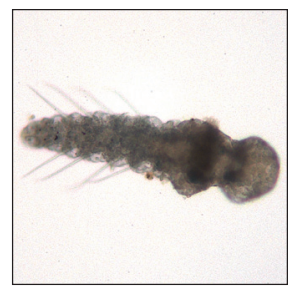

The smallest Amphisamytha larvae fall in the size range of the nectochaetes. Nectochaete larvae have a ciliary band circling the body near the anterior end (at right in photo) and are generally thinner for their length than Amphisamytha.

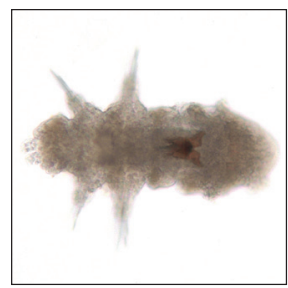

Ophryotrocha larvae are similar in size and general outline to Amphisamytha, but have a prominent jaw apparatus visible through the body wall. Their parapodia are also more prominent than those of Amphisamytha. 
POLYCHAETA 


\section{Archinome rosacea Blake, 1985. Family Archinomidae.}

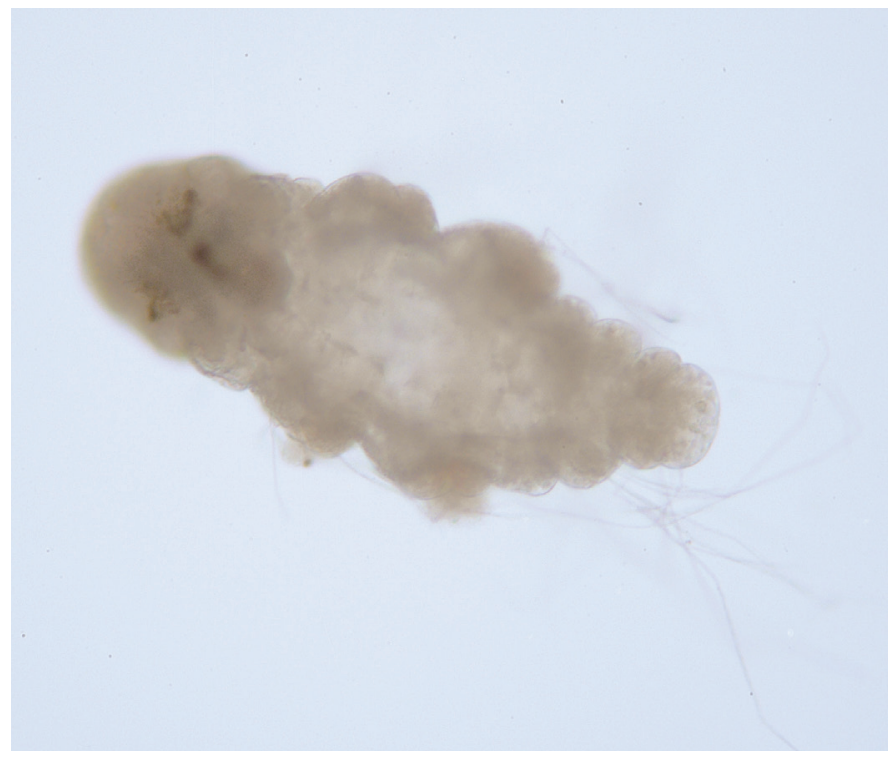

Size: $310-490 \mu \mathrm{m}$

\section{Morphology:}

These larvae are very distinctive and unlikely to be confused with anything else. They are thick-bodied, tapering slightly toward the ends. Their chaetae are long, delicate and flexible and they often become tangled with debris or other animals in the sample. There are usually three pigmented areas visible on the head, as shown above at left.

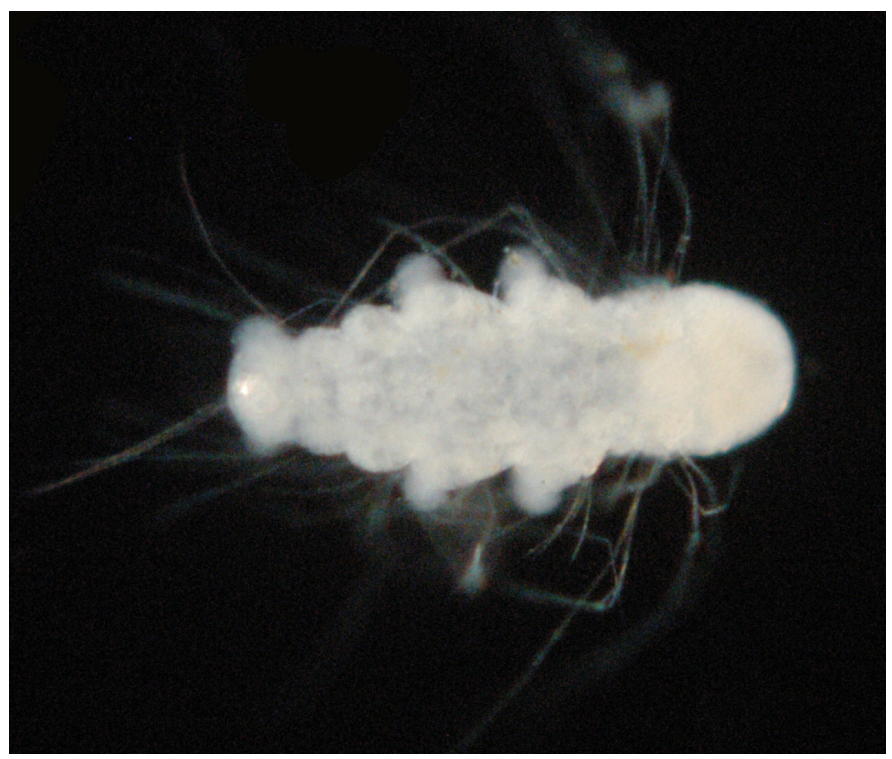

Frequency:

Pump EPR 1999-2000: Occasional

Pump EPR 2004: Frequent

\section{Can be confused with:}

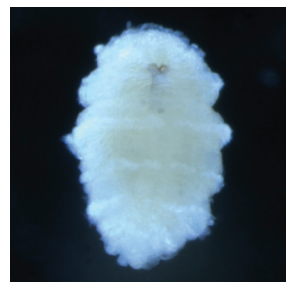

Unknown polychaete B is similar in size and general outline; however, it lacks the long delicate chaetae of Archinome. In larger specimens a distinct jaw apparatus is visible through the body wall. 
POLYCHAETA 


\section{"Chaetosphaerids" Unknown families.}

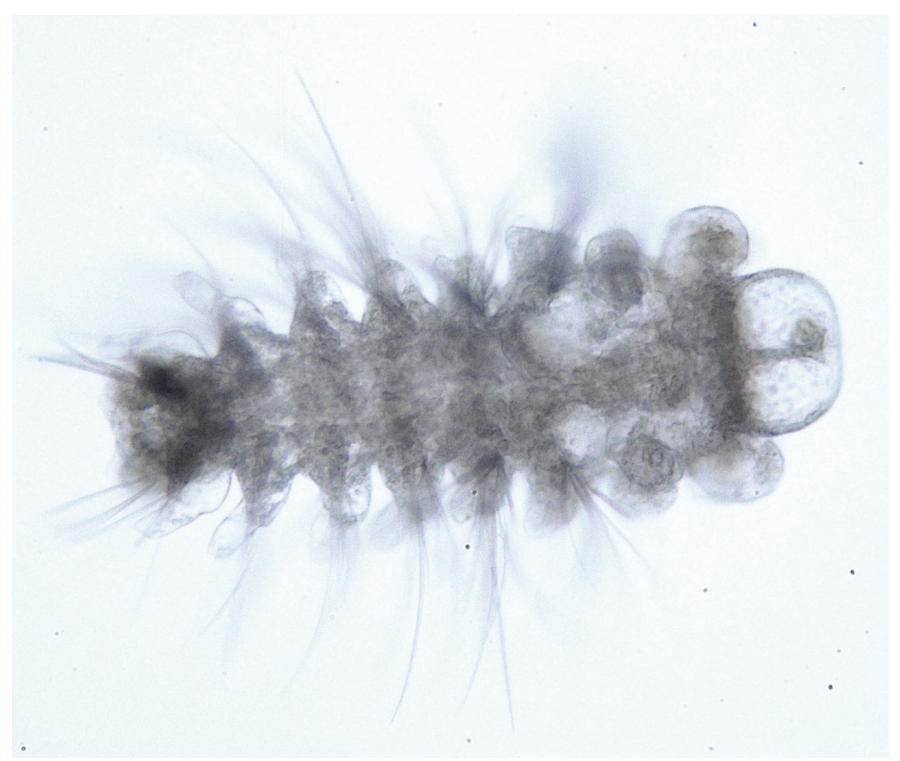

Size: Regular type: $280-400 \mu \mathrm{m}$,

Spiny type: $200-320 \mu \mathrm{m}$

\section{Morphology:}

We have been referring to these larvae as "chaetosphaerids" because many of them bear a superficial resemblance to some spionid larvae. However, we do not believe that they are necessarily spionids, nor that they are a homogeneous group. These larvae are common enough that it seems likely that they are vent species. Nonetheless, we have not been able to match them up with any known species, as they do not resemble the young juveniles of any polychaete we have seen. Attempts to resolve the identification using molecular methods are ongoing.

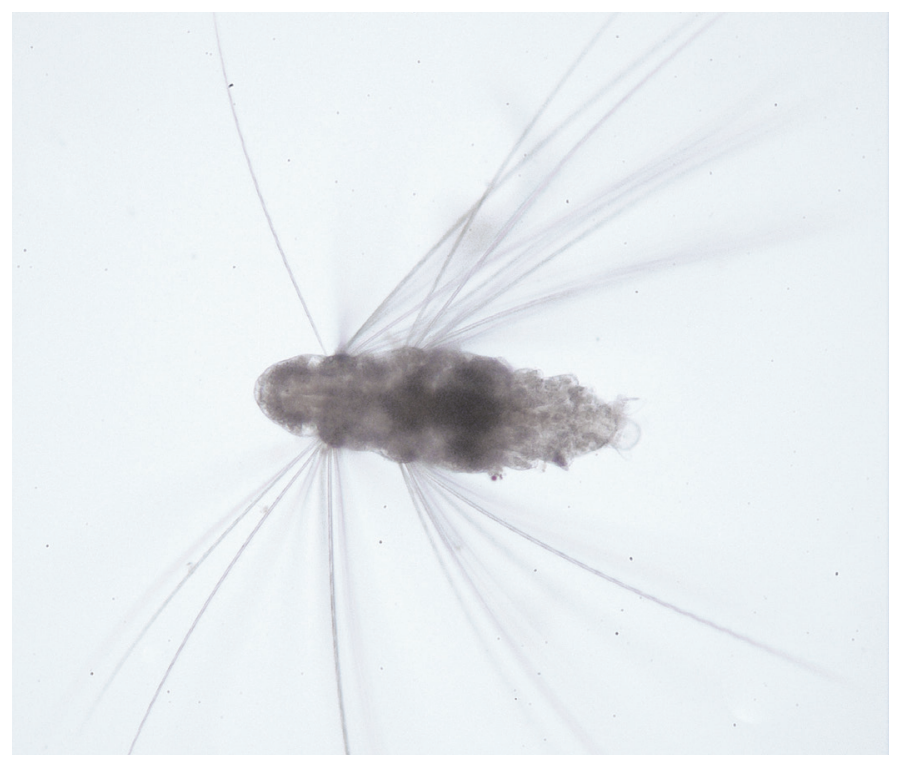

\section{Frequency:}

Pump EPR 1999-2000: Occasional

Pump EPR 2004: Common 
POLYCHAETA 


\section{Glycera sp. Family Glyceridae.}

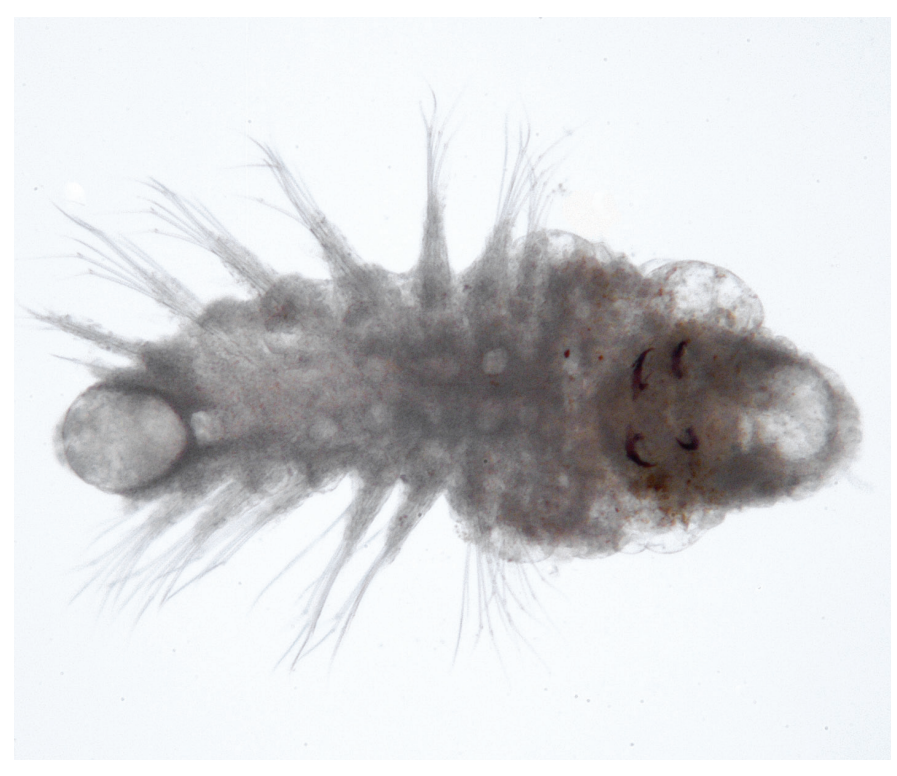

Size: $-600-700 \mu \mathrm{m}$, depending on number of chaetigers

\section{Morphology:}

These larvae have long parapodia, usually angled toward the posterior of the body. The head is blunt and conical, with a dark pigmented collar around it, and there are four small antennae which form a cross at the tip of the prostomium, though these are not always visible. Small jaws can usually be seen through the body wall. We have found glycerid polychaetes (Glycera sp.) on settlement blocks around the periphery of the $9^{\circ} \mathrm{N}$ vents. These larvae may be that species or possibly another non-vent species.

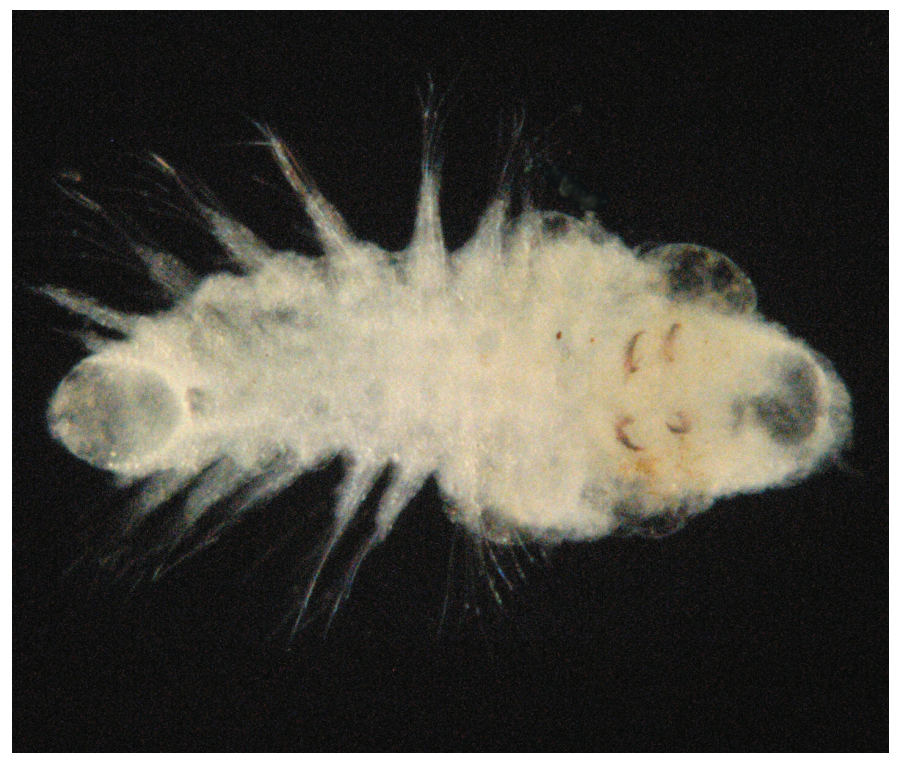

\section{Frequency:}

Pump EPR 1999-2000: Not collected on axis Pump EPR 2004: Frequent

\section{Can be confused with:}

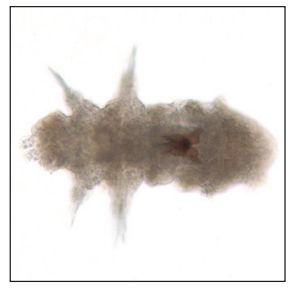

Glycera sp. is most likely to be confused with Ophryotrocha sp., since both species have visible jaws. However, the shape of the jaws is quite different and we generally find Ophryotrocha as 2-3 chaetiger larvae $(-280-350 \mu \mathrm{m})$, while Glycera is usually much larger ( $-7-9$ chaetigers, $-600-700 \mu \mathrm{m})$ 
POLYCHAETA 


\section{Nectochaetes Unknown families.}

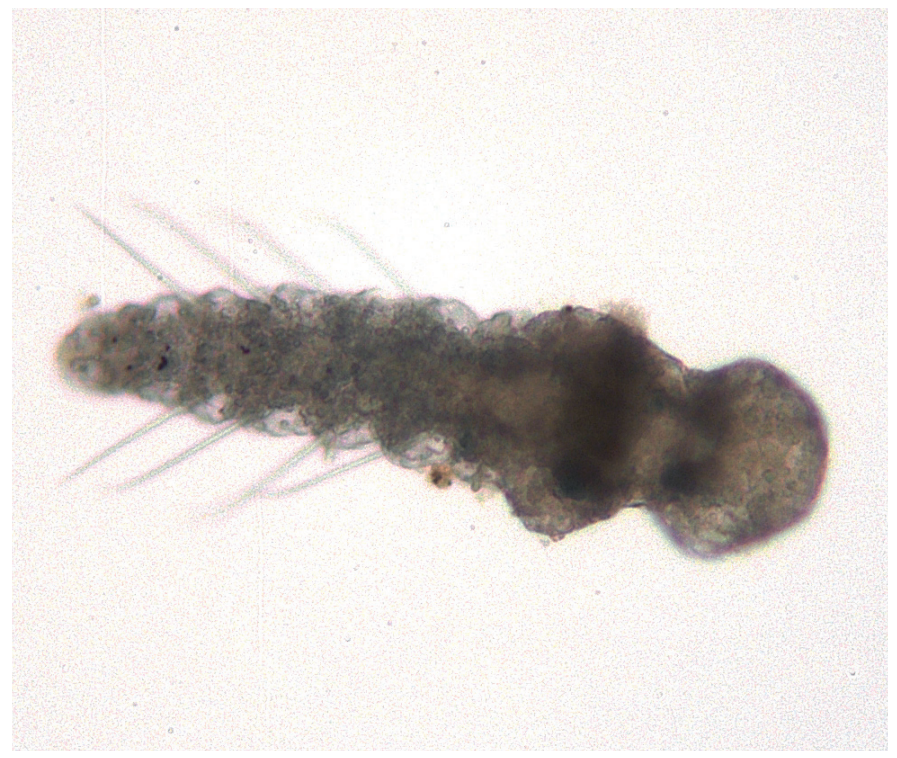

Size: $170-380 \mu \mathrm{m}$

\section{Morphology:}

Nectochaetes of several varieties are often present in our plankton samples. They have a blunt, bulbous prostomium with a ciliary collar surrounding the body. They are relatively thin for their length and their chaetae, usually at least as long as the body is wide, are angled toward the posterior. Preliminary molecular analyses indicate that more than one family is represented in this group.

\section{Frequency:}

Pump EPR 1999-2000: Occasional Pump EPR 2004: Common

\section{Can be confused with:}

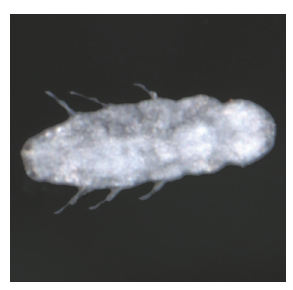

The smallest Amphisamytha larvae fall in the size range of the nectochaetes and have a similar number of chaetigers. Nectochaete larvae have a ciliary band behind the head and are generally thinner for their length than Amphisamytha. 
POLYCHAETA 


\section{Nereis sp., possibly Nereis sandersi Blake 1985. Family Nereididae.}

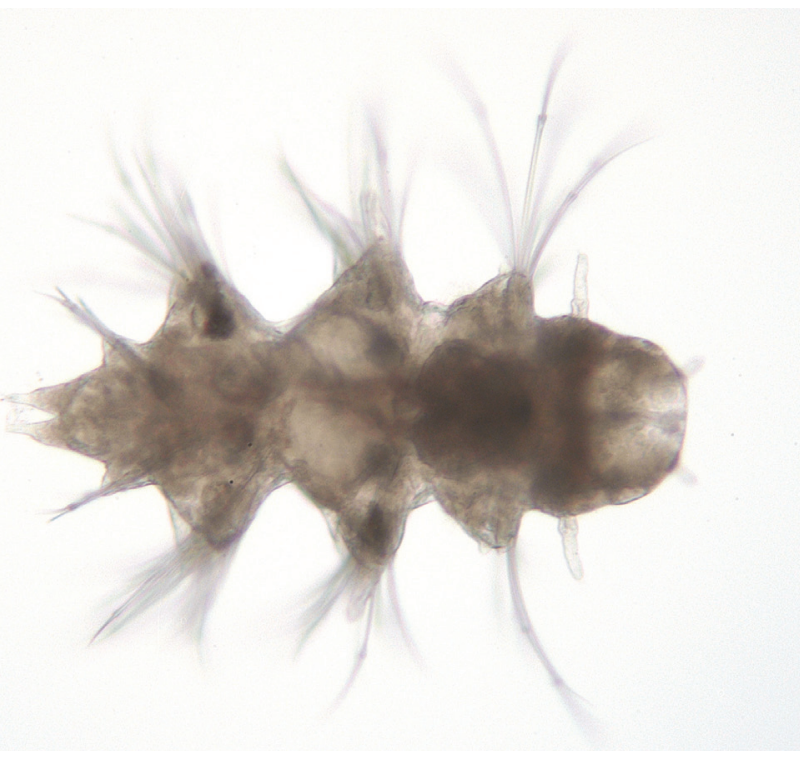

Size: $-300-450 \mu \mathrm{m}$, depending on number of chaetigers

\section{Morphology:}

Nereidid larvae are usually found at the $3-4$ chaetiger stage in our samples. They have visible antennae and tentacular cirri projecting from the sides of the head, as well as a pair of anal cirri. The parapodia are well-developed and there are usually dark or reddish spots visible at the bases of two adjacent pairs, as shown above. This is presumably Nereis sandersi Blake, the only nereidid at $9^{\circ} \mathrm{N}$.

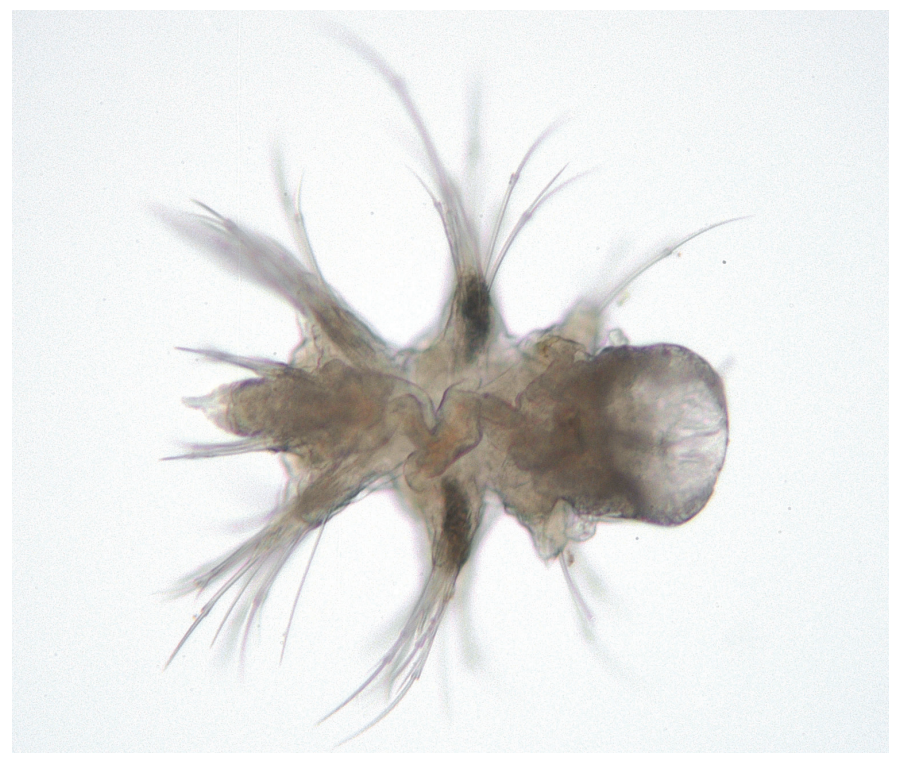

\section{Frequency:}

Pump EPR 1999-2000: Occasional

Pump EPR 2004: Frequent

\section{Can be confused with:}

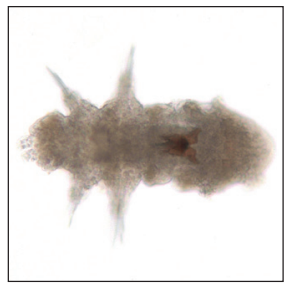

These larvae are most likely to be confused with Ophryotrocha sp., which is superficially similar, but lacks the tentacular cirri and the dark spots on the parapodia. Nereis has larger parapodia with longer chaetae, but lacks the obvious jaw apparatus that Ophryotrocha has. 


\section{Can be confused with:}

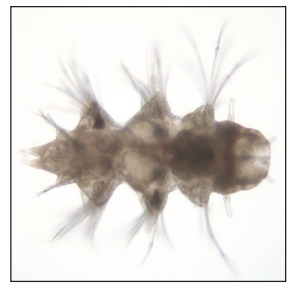

This group is most likely to be confused with Nereis sp. It can be quickly distinguished by its easily visible jaws and by the fact that Nereis larvae have four dark or reddish dots at the base of two adjacent pairs of parapodia. Nereis also has obvious antennae and tentacular cirri projecting from the sides of the head and is generally somewhat larger $(300-450 \mu \mathrm{m}$; individual at left is $400 \mu \mathrm{m}$ ).

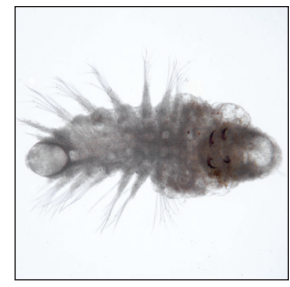

It is possible that Ophryotrocha might be mistaken for a small Glycera sp., as both species have visible jaws. However, the shape of the jaws is quite different and Glycera has four antennae in the form of a cross at the tip of its prostomium. We generally find Glycera sp. when it is much larger - $600-700 \mu \mathrm{m}$ - and with more chaetigers. 


\section{Ophryotrocha sp., possibly Ophryotrocha akessoni Blake, 1985.}

\section{Family Dorvilleidae.}

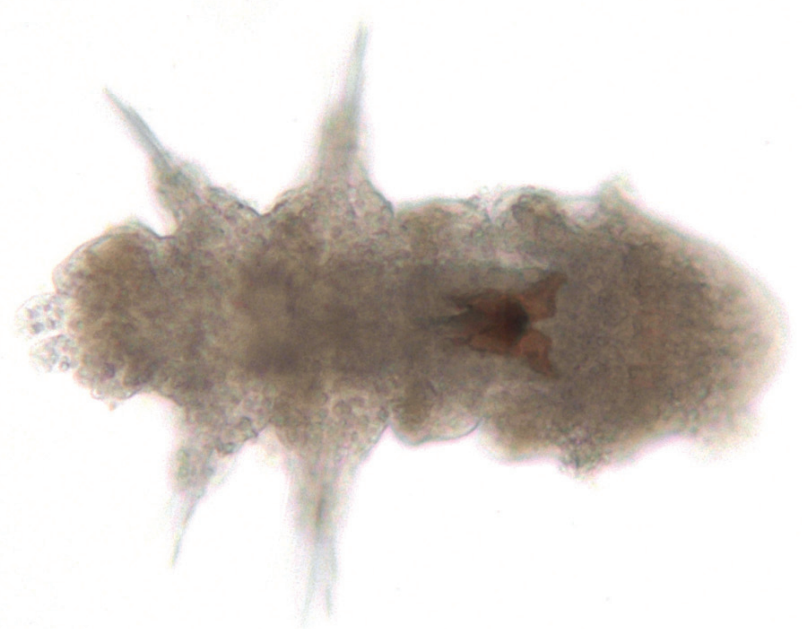

Size: $280 \mu \mathrm{m}$ at 2 chaetigers

\section{Morphology:}

We have attributed these larvae to Ophryotrocha, based on their general appearance, especially the jaw apparatus, which can be seen clearly through the body wall. They have prominent parapodia that stick out to the sides and two anal cirri are usually visible at the posterior end. The adults possess two antennae toward the front of the prostomium and two lateral palps anterior to the jaws; these are sometimes visible in the larvae, but often are indistinct.

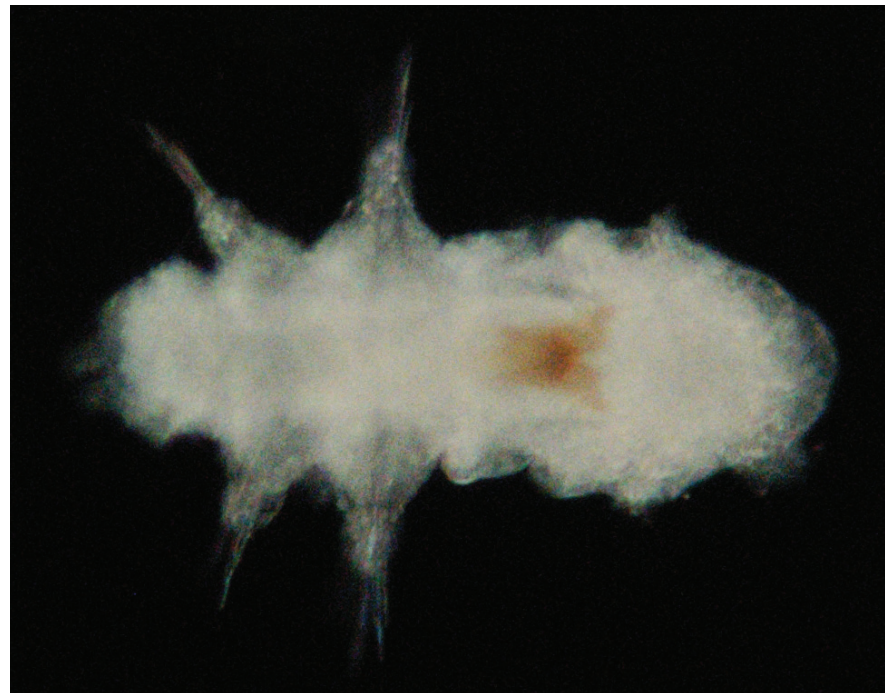

\section{Frequency:}

Pump EPR 1999-2000: Not distinguished from other polychaete larvae

Pump EPR 2004: Common

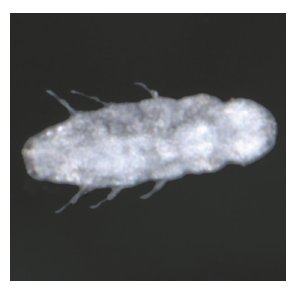

Amphisamytha larvae are approximately the same size as Ophryotrocha, but lack jaws and obvious parapodia.

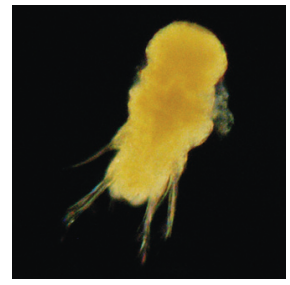

Unknown polychaete $A$ is similar in general outline to Ophryotrocha, but is smaller (this individual is $200 \mu \mathrm{m}$ ), yellower in color and lacks the jaw apparatus. In this group, the chaetae are angled toward the posterior rather than sticking out to the sides. 
POLYCHAETA 


\section{Polynoids Family Polynoidae.}

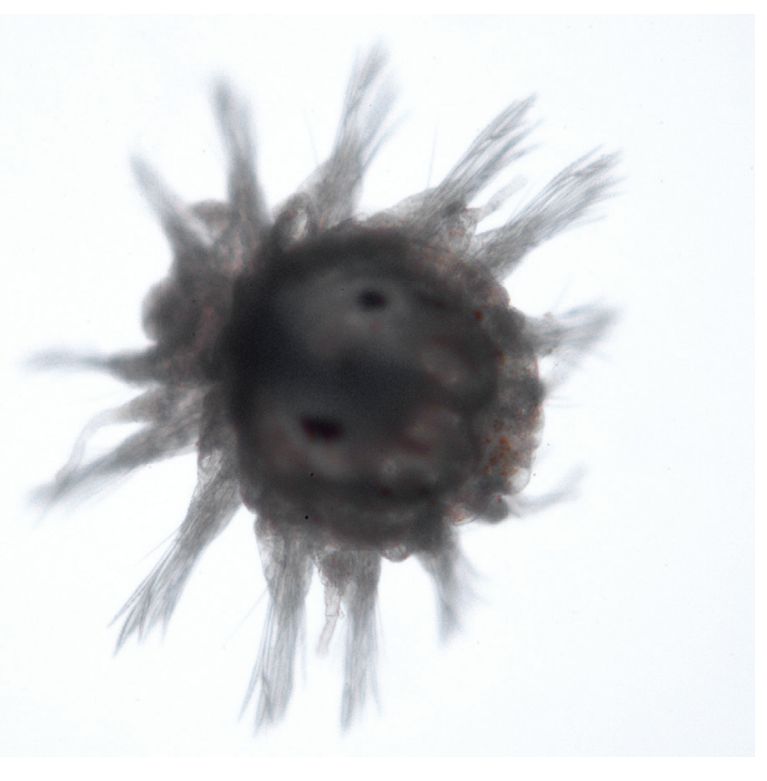

Size: $190 \mu \mathrm{m}$ (left) to $>1 \mathrm{~mm}$

\section{Morphology:}

There are many species of polynoids at the $9^{\circ} \mathrm{N}$ vents and we have not attempted to assign any of the forms we find in the plankton samples to species. Most of the morphotypes we collect are actually juveniles; it is not uncommon for polynoids to metamorphose in the plankton and live there for extended periods before settlement (Young et al., 2001, p.211). They are characterized by having long parapodia and chaetae and large blunt heads with various appendages. They may retain their scales, but these are easily lost.

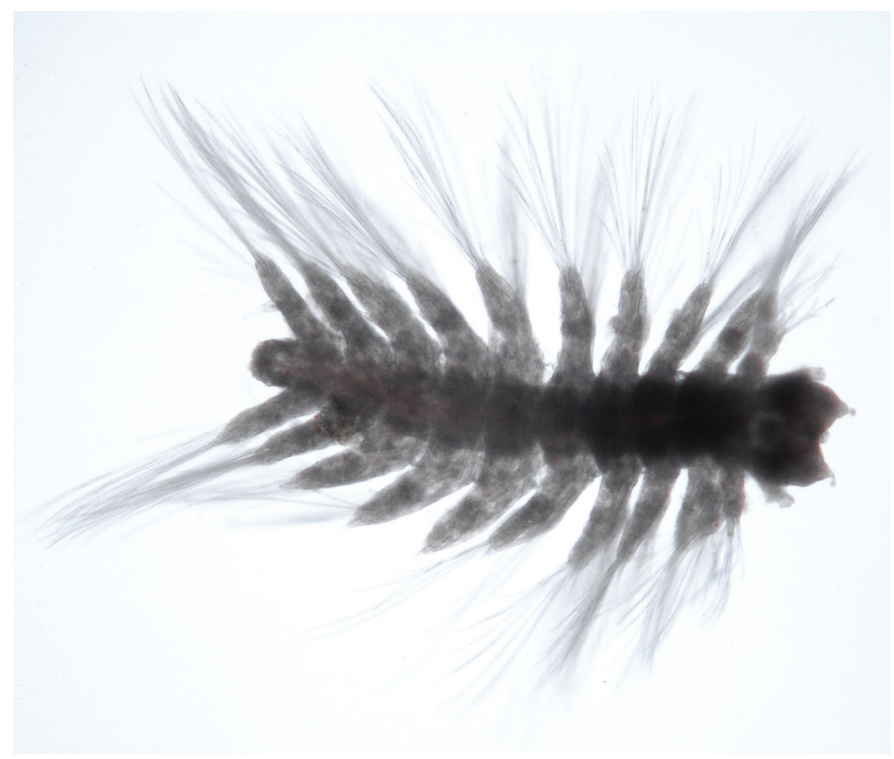

\section{Frequency:}

Pump EPR 1999-2000: Occasional

Pump EPR 2004: Frequent 
POLYCHAETA 


\section{Unknown polychaete A, Unknown Family.}

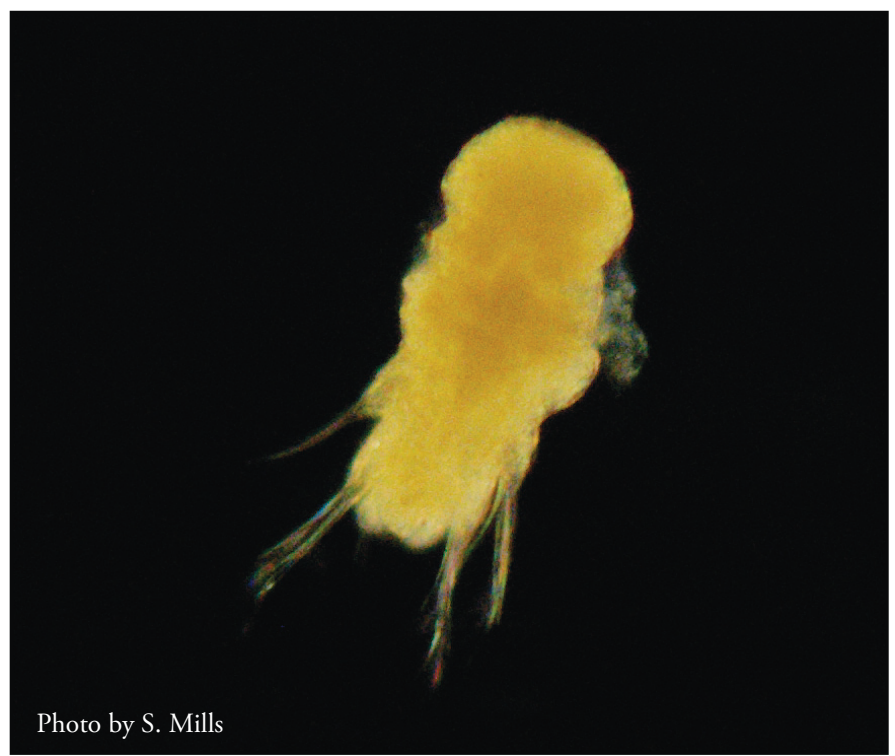

Size: $-200 \mu \mathrm{m}$

\section{Morphology:}

Small nectochaete larva, generally found at the two-chaetiger stage. Chaetae about as long as the body is wide, angled toward the posterior end. No prostomial appendages or jaws. This group has been present in sampling prior to the 2005-2006 eruptions at $9^{\circ} \mathrm{N}, \mathrm{EPR}$, but was not distinguished from other unknown polychaetes. It may be a smaller version of a member of our nectochaete group, but because of consistent differences in morphology and color, we have listed it separately.

\section{Frequency:}

Pump EPR 1999-2000: Not distinguished from other polychaete larvae Pump EPR 2004: Not distinguished from other polychaete larvae

\section{Can be confused with:}

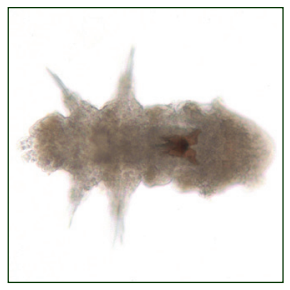

Ophryotrocha sp. is similar in general outline, but is larger (this two-chaetiger specimen is $280 \mu \mathrm{m})$. In Ophryotrocha the parapodia stick straight out to the sides rather than being angled back to the posterior and it also has a jaw apparatus visible through the body wall. Unknown polychaete A tends to be yellow or tan in color when preserved in ethanol rather than gray to white like Ophryotrocha. 
POLYCHAETA 


\section{Unknown polychaete B, Unknown Family.}
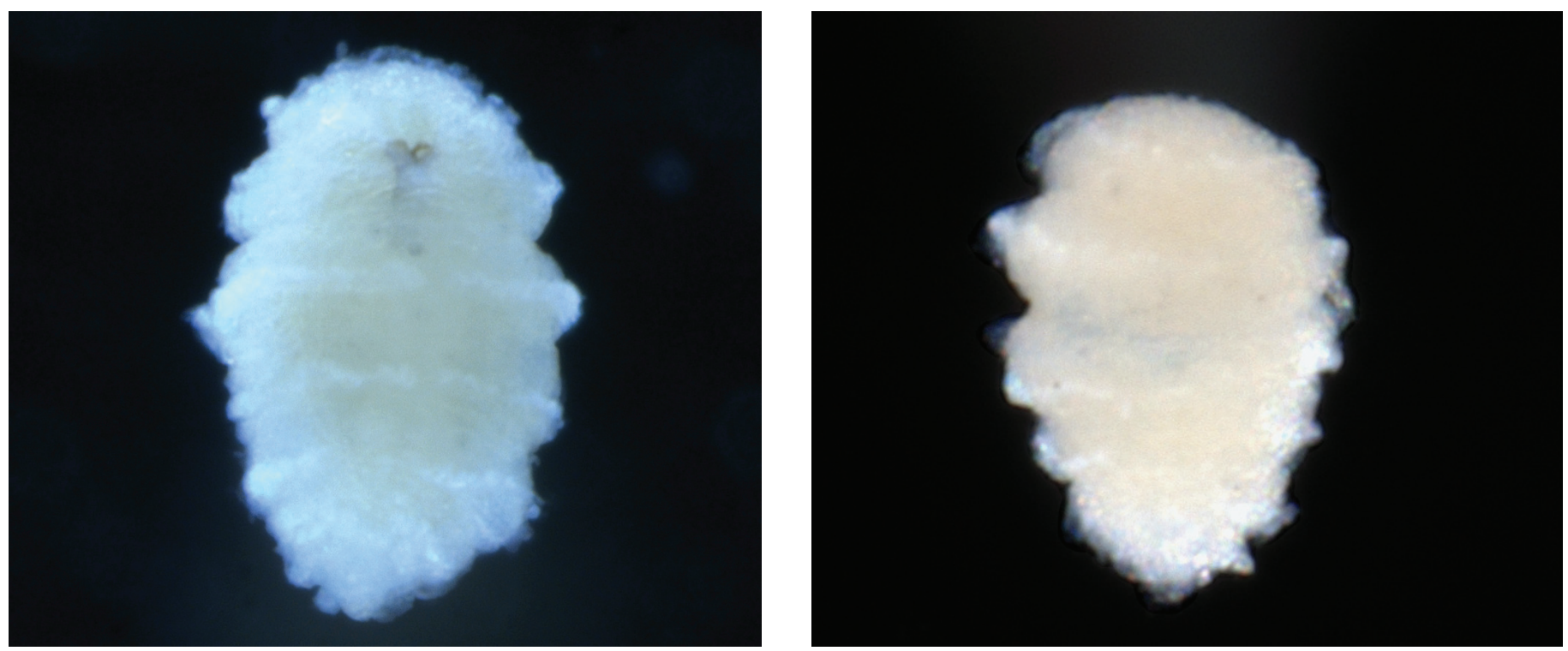

Size: $535 \mu \mathrm{m}$ (left), $340 \mu \mathrm{m}$ (right)

\section{Morphology:}

Oval-shaped larva, quite wide for its length. No chaetae visible, but four evenly spaced ciliary bands encircle the body and there appear to be patches of cilia on the anterior and posterior ends. In larger individuals, jaws can be seen through the body wall, as in the specimen on the left. This form was not collected prior to the 2005-2006 eruptions at $9^{\circ} \mathrm{N}$, EPR and we do not know if it belongs to the vent fauna.

\section{Frequency:}

Pump EPR 1999-2000: Not collected

Pump EPR 2004: Not collected

\section{Can be confused with:}

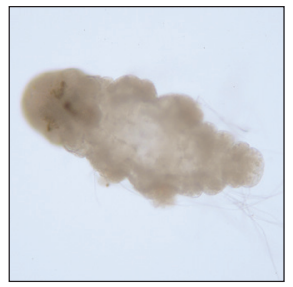

Archinome rosacea is similar in size and general outline; however, it has long, delicate chaetae, whereas Unknown polychaete B has only cilia. Archinome has dark pigmentation on its prostomium, but does not have a jaw apparatus. 
CRUSTACEA 


\section{Barnacle cyprids, Order Cirripedia.}

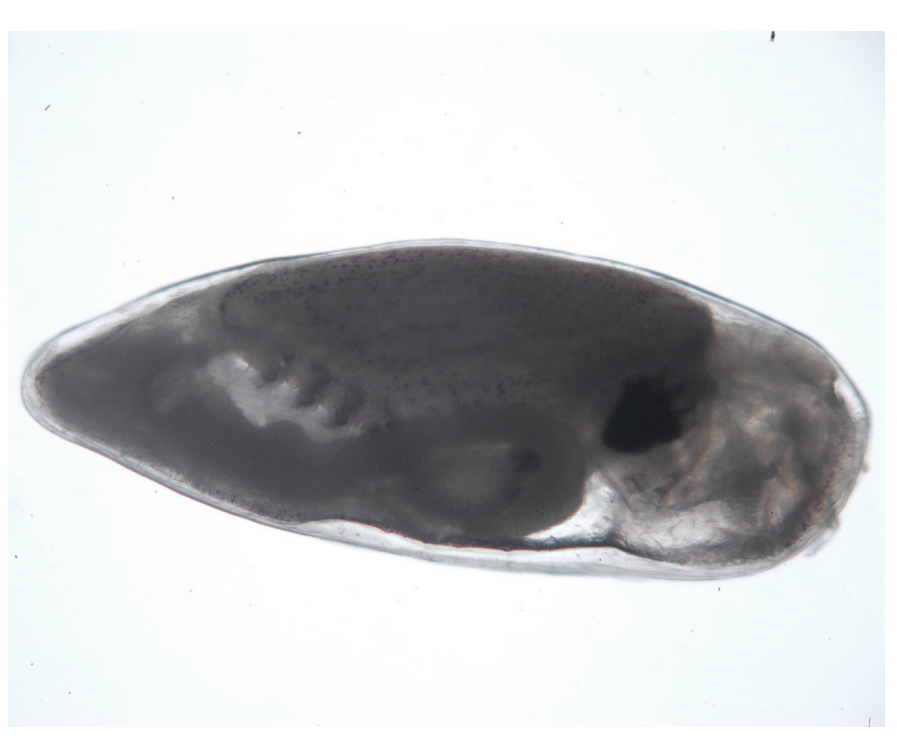

Size: various from $-600 \mu \mathrm{m}$ to $>1 \mathrm{~mm}$

\section{Morphology:}

We have found a variety of cyprids in our plankton samples, most (and perhaps all) non-vent. The only vent species at $9^{\circ} \mathrm{N}$ is Neolepas zevinae Newman, 1979; nothing is known about its larval life, but a few newly settled cyprids, approximately $800 \mu \mathrm{m}$ in length, were recovered on our settlement blocks (Mullineaux et al., 2003) which presumably belong to this species. Two of these are pictured above (right photo).

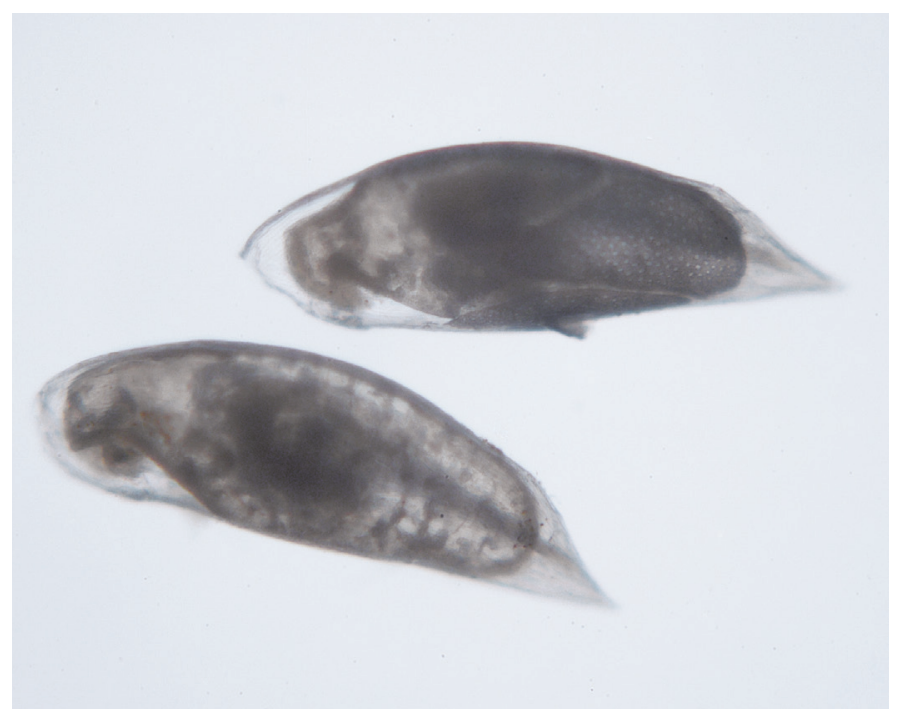

\section{Frequency:}

Pump EPR 1999-2000: Rare

Pump EPR 2004: Occasional

Trap EPR 2004-2005: Occasional 
CRUSTACEA 


\section{Bythograea microps de Saint Laurent, 1984.}

\section{Infraorder Brachyura, Family Bythograeidae.}

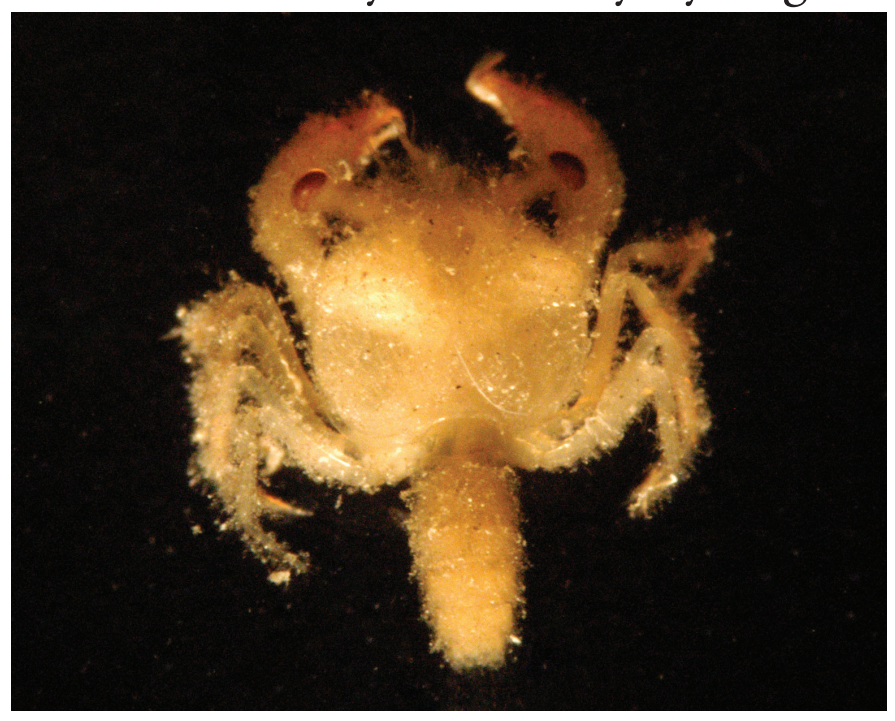

Size: megalopa $-3 \mathrm{~mm}$

\section{Morphology:}

\section{Frequency:}

This is a small megalopa with long eyestalks. It has been attributed to B. microps by de Saint Laurent (1988), who originally described the species and recent molecular work has confirmed the identification (L. Hurtado, personal Pump EPR 1999-2000: Not collected Pump EPR 2004: Not collected

Trap EPR 2004-2005: Occasional

\section{Can be confused with:}

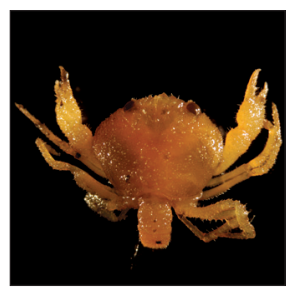

We have only collected two types of megalopae at this site, this one and a much larger one which has been attributed to Bythograea thermydron (on the left). The size difference should be sufficient to distinguish the two species. 
CRUSTACEA 


\section{Bythograea thermydron williams, 1980.}

\section{Infraorder Brachyura, Family Bythograeidae.}
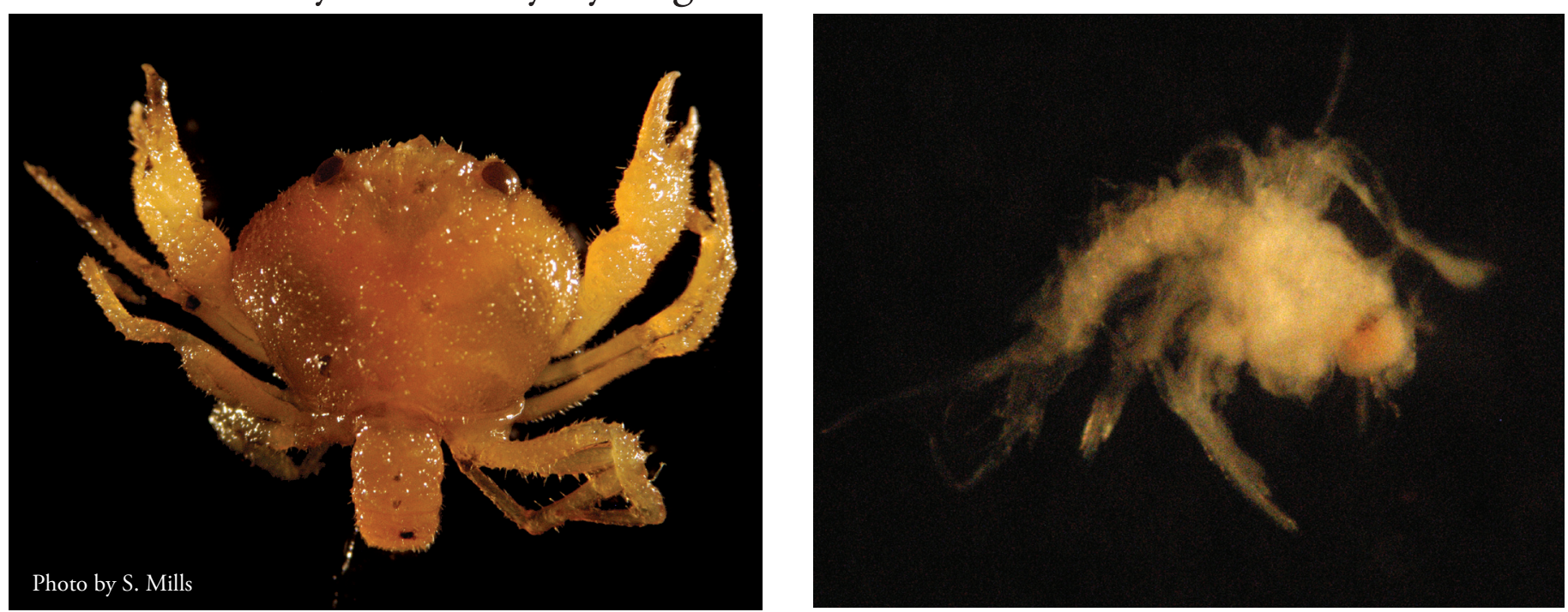

Size: megalopa $\sim 8 \mathrm{~mm}$, zoea $\sim 1.5 \mathrm{~mm}$ (right)

\section{Morphology:}

\section{Frequency:}

Typical brachyuran megalopa, reddish in life, but generally tan to whitish in preservative. The zoea is similar to those collected from B. thermydron females (A. Dittel, personal communication) and we believe it also belongs to this species.

Pump EPR 1999-2000: Rare

Pump EPR 2004: Rare

Trap EPR 2004-2005: Occasional

Can be confused with:

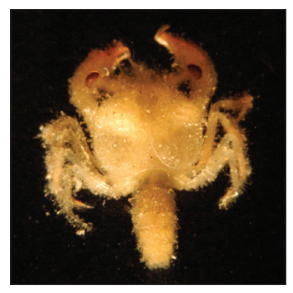

We have only collected two types of megalopae at this site, this one and a much smaller one which has been attributed to Bythograea microps. The size difference should be sufficient to distinguish the two species 


\section{FORAMINIFERA}




\section{?Tretomphalus sp. Class Foraminifera.}
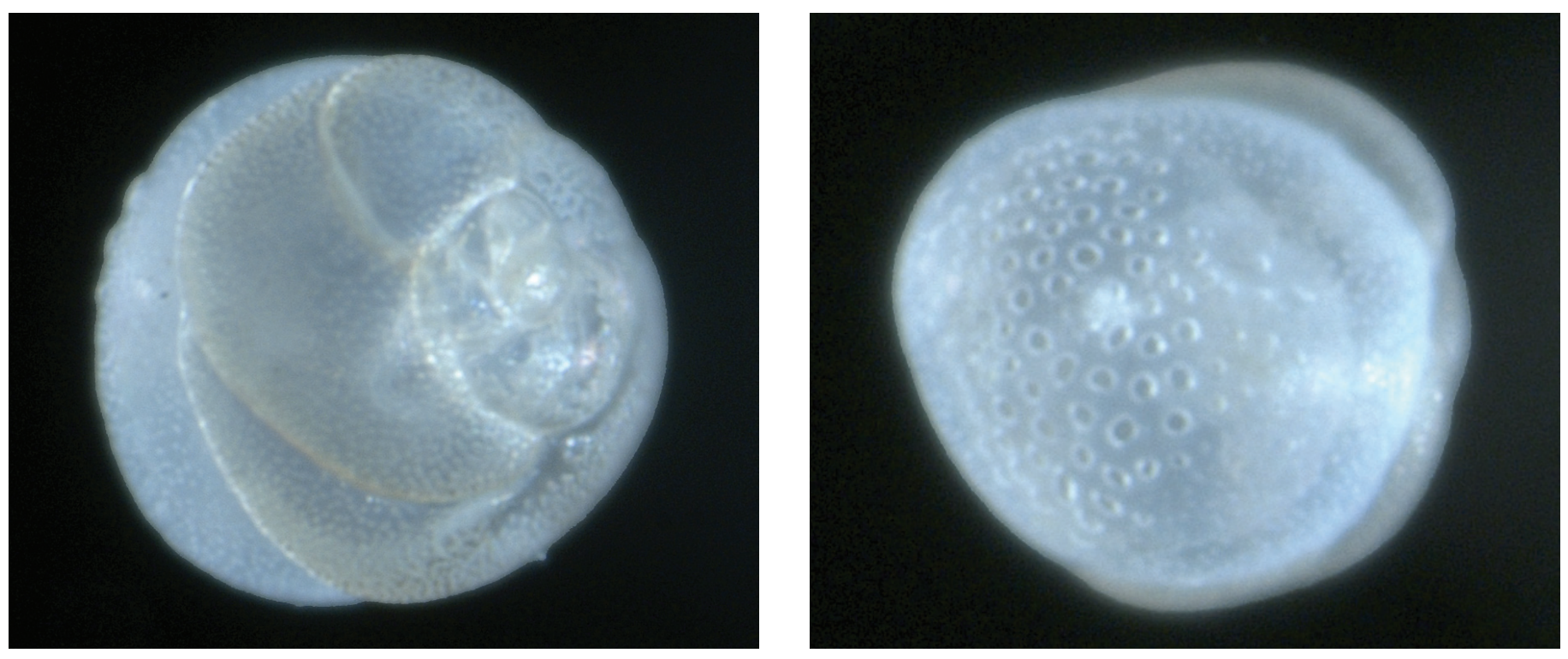

Size: $-250-300 \mu \mathrm{m}$ in diameter

\section{Morphology:}

Roughly spherical foraminiferan with coarse perforations on the ventral surface (above right). The dorsal surface is composed of a brownish spiral of increasing sized flat chambers; the whole specimen appears to be a benthic foraminiferan with an inflated chamber (similar to those in planktonic species) on the ventral side. Our specimens have been examined by an expert (S. Richardson) and appear similar to the dispersal form of the genus Tretomphalus, a shallow-water benthic group. Most, though not all, are empty shells.

\section{Frequency:}

Pump EPR 1999-2000: Occasional

Pump EPR 2004: Not collected

Trap EPR 2004-2005: Not collected

\section{Can be confused with:}

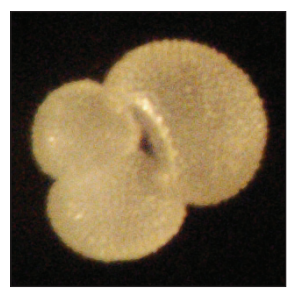

At first glance Tretomphalus might be mistaken for a chamber of a planktonic foraminiferan, such as is shown at left, but these do not have the flat-chambered spiral shown above left. 
Adams, D.K., 2007, Influence of hydrodynamics on the larval supply to hydrothermal vents on the East Pacific Rise. PhD Thesis, MIT, Cambridge, MA \& Woods Hole Oceanographic Institution, Woods Hole, MA.

Adams, D.K. \& L.S. Mullineaux, 2008, Supply of gastropod larvae to hydrothermal vents reflects transport from local larval sources. Limnol. Oceanogr. 53: 19451955.

Beaulieu, S.E., L.S. Mullineaux, D.K. Adams \& S.W. Mills, 2009, Comparison of a sediment trap and plankton pump for time-series sampling of larvae near deepsea hydrothermal vents. Limnol. Oceanogr.: Methods 7: 235-248.

Blake, J.A., 1985, Polychaeta from the vicinity of deepsea geothermal vents in the Eastern Pacific. I. Euphrosinidae, Phyllodocidae, Hesionidae, Nereididae, Glyceridae, Dorvilleidae, Orbiniidae and Maldanidae. Proc. Biol. Soc. Wash. 6: 67-102.

de Saint Laurent, M., 1984, Crustacés décapodees d'un site hydrothermal actif de la dorsale du Pacifique oriental $\left(13^{\circ} \mathrm{N}\right)$ en provenance de la campagne française Biocyatherm, C. R. Acad. Sci. Paris, Sér III, 299: 355360.

de Saint Laurent, M., 1988, Les mégalopes et jeunes stades crabe de trois espèces du genre Bythograea Williams, 1980 (Crustacea Decapoda Brachyura). Oceanol. Acta Hydrothermalism, Biology and Ecology Symposium, Paris, 4-7 November 1985, Proceedings, 99-107.

Desbruyères, D., M. Segonzac \& M. Bright, eds., 2006, Handbook of Deep-Sea Hydrothermal Vent Fauna. Second completely revised edition. Denisia 18: 544 pp.

Geiger, D.L., B.A. Marshll, W.F. Ponder, T. Sasaki \& A. Warén, 2007, Techniques for collecting, handling, preparing, storing and examining small molluscan specimens. Molluscan Res. 27: 1-50.

Gustafson, R.G. and R.A. Lutz, 1994, Molluscan life history traits and deep-sea hydrothermal vents and cold methane/sulphide seeps. Pp. 76-97 in C.M. Young and
K.J. Eckelbarger (eds.), Reproduction, Larval Biology, and Recruitment of the Deep-Sea Benthos. Columbia University Press, New York.

Hickman, C.S., 1984, A new archaeogastropod (Rhipidoglossa, Trochacea) from hydrothermal vents on the East Pacific Rise. Zool Scr. 13: 19-25.

Kenk, V.C. \& B.R. Wilson, 1985, A new mussel (Bivalvia, Mytilidae) from hydrothermal vents in the Galapagos Rift Zone. Malacologia 26: 253-271.

Kim, S.L. \& L.S. Mullineaux, 1998, Distribution and near-bottom transport of larvae and other plankton at hydrothermal vents. Deep-Sea Res. II 45: 423-440.

Lutz, R.A., D. Jablonski \& R.D. Turner, 1984, Larval development and dispersal at deep-sea hydrothermal vents. Science 226: 1451-1454.

Lutz, R.A., P. Bouchet, D. Jablonski, R.D. Turner \& A. Warén, 1986, Larval ecology of mollusks at deep-sea hydrothermal vents. Am. Malacol. Bull. 4: 49-54.

McLean, J.H., 1981, The Galapagos Rift limpet Neomphalus: relevance to understanding the evolution of a major Paleozoic-Mesozoic radiation. Malacologia 21: 291-336.

McLean, J.H., 1988, New archaeogastropod limpets from hydrothermal vents: Superfamily Lepetodrilacea. I. Systematic descriptions. Phil. Trans. Royal Soc. London B319: 1-32.

McLean, J.H., 1989, New slit limpets (Scissurellacea and Fissurellacea) from hydrothermal vents. Part 1. Systematic descriptions and comparisons based on shell and radular characters. Contributions in Science, Los Angeles County Museum of Natural History 407: $1-29$.

McLean, J.H., 1989, New archaeogastropod limpets from hydrothermal vents: new family Peltospiridae, new superfamily Peltospiracea. Zool. Scr. 18: 49-66.

McLean, J.H., 1990, Neolepetopsidae, a new docoglossate limpet family from hydrothermal vents and its relevance to patellogastropod evolution. J. Zool., Lon- 


\section{Literature Cited}

don 222: 485-528.

McLean, J.H., 1990, A new genus and species of neomphalid limpet from the Mariana vents with a review of current understanding of the relationships among Neomphalacea and Peltospiracea. Nautilus 104: 77-86.

McLean, J.H., 1993, New species and records of Lepetodrilus (Vetigastropoda: Lepetodrilidae) from hydrothermal vents. Veliger 36: 27-35.

Mullineaux, L.S., S.L. Kim, A. Pooley and R.A. Lutz, 1996, Identification of archaeogastropod larvae from a hydrothermal vent community. Mar. Biol. 124: 551560.

Mullineaux, L.S., Peterson, C.H., Micheli, F. \& S.W. Mills, 2003, Successional mechanism varies along a gradient in hydrothermal fluid flux at deep-sea vents. Ecol. Monogr. 73: 523-542.

Mullineaux, L.S., S.W. Mills, A.K. Sweetman, A.H. Beaudreau, A. Metaxas \& H.L. Hunt, 2005, Vertical, lateral and temporal structure in larval distributions at hydrothermal vents. Mar. Ecol. Prog. Ser. 293: 1-16.

Newman, W.A., 1979, A new scalpellid (Cirripedia): a Mesozoic relic living near an abyssal hydrothermal spring. Trans. San Diego Soc. Nat. Hist., 19: 153-167.

Pradillon, F., A. Schmidt, J. Peplies \& N. Dubilier, 2007, Species identification of marine invertebrate early stages by whole-larvae in situ hybridisation of $18 \mathrm{~S}$ ribosomal RNA. Mar. Ecol. Prog. Ser. 333: 103-116.

Schein-Fatton, 1985, Découverte sur la ride du Pacifique oriental à $13^{\circ} \mathrm{N}$ d'un Pectinidae (Bivalvia, Pteromorpha) d'affinitiés paléozoïques. C.R. Acad. Sci. (Paris), Série III 301: 491-496.

Turner, R.D., R.A. Lutz \& D. Jablonski, 1985, Modes of molluscan development at deep-sea hydrothermal vents. Bull. Biol. Soc. Wash. 6: 167-184.

Warén, A. \& P. Bouchet, 1989, New gastropods from East Pacific hydrothermal vents. Zool. Scr. 18: 67-102.

Warén, A. \& P. Bouchet, 1993, New records, species, genera and a new family of gastropods from hydrothermal vents and hydrocarbon seeps. Zool. Scr. 22: 1-90.

Warén, A. \& P. Bouchet, 2001, Gastropoda and Monoplacophora from hydrothermal vents and seeps; new taxa and records. Veliger 44: 116-231.

Williams, A.B., 1980, A new crab family from the vicinity of submarine thermal vents on the Galapagos Rift (Crustacea : Decapoda : Brachyura), Contribution No. 5 of the Galapagos Rift Biology Expedition. Proc. Biol. Soc. Wash. 93: 443-472.

Young, C.M., M.A. Sewell \& M.E. Rice, 2001, Atlas of Marine Invertebrate Larvae. Academic Press, San Diego, $630 \mathrm{pp}$.

Zottoli, R., 1983, Amphisamytha galapagensis, a new species of ampharetid polychaete from the vicinity of abyssal hydrothermal vents in the Galapagos Rift, and the role of this species in rift ecosystems. Proc. Biol. Soc. Wash. 96: 379-391. 


\section{Bivalvia}

Bathymodiolus thermophilus

71

Bathypecten vulcani 73

\section{Crustacea}

Barnacle cyprids $\quad 95$

Bythograea microps $\quad 97$

Bythograea thermydron

99

\section{Foraminifera}

?Tretomphalus sp. $\mathbf{1 0 1}$

\section{Gastropoda}

Bathymargarites symplector

Clypeosectus delectus

19

\section{Ctenopelta porifera $\mathbf{6 3}$}

Cyathermia naticoides

43

Echinopelta fistulosa

33

Eulepetopsis vitrea 53

Gorgoleptis emarginatus

Gorgoleptis sp. $3 \quad 23$

Gorgoleptis spiralis 9

Laeviphitus sp. $\quad \mathbf{6 7}$

Lepetodrilus-like protoconchs

27

Lepetodrilus spp. 17

Lirapex granularis 37

Melanodrymia aurantiaca

Melanodrymia ?galeronae

Neolepetopsis spp.

49

Neomphalus fretterae
Pachydermia laevis 51

Peltospira spp. 35

Phymorhynchussp. 69

Pointy apex 11

Rhynchopelta concentrica

61

Unknown 725

Unknown 89

Unknown 931

Unknown benthic sp. A 13

Unknown neomphalid $5 \quad 15$

Unknown ?neomphalid $290 \mu \mathrm{m}$

Unknown neomphalid B $\mathbf{4 1}$

Unknown neomphalid W 55

Unknown peltospirid $240 \mu \mathrm{m}$

\section{Polychaeta}

Amphisamytha galapagensis

75

Archinome rosacea 77

Chaetosphaerids $\mathbf{7 9}$

Glycera sp. $\quad \mathbf{8 1}$

Nectochaetes $\quad \mathbf{8 3}$

Nereis sp. $\quad 85$

Ophryotrocha sp. $\quad 87$

Polynoids 89

Unknown polychaete A $\quad 91$

Unknown polychaete B $\mathbf{9 3}$ 


\begin{tabular}{|c|c|c|}
\hline $\begin{array}{l}\text { REPORT DOCUMENTATION } \\
\text { PAGE }\end{array}$ & 1. REPORT NO ${ }_{\text {WHOI-2009-05 }}$ & 3. Recipient's Accession No. \\
\hline \multirow{2}{*}{\multicolumn{2}{|c|}{$\begin{array}{l}\text { 4. Title and Subtitle } \\
\text { Photographic identification guide to larvae at hydrothermal vents }\end{array}$}} & $\begin{array}{r}\text { 5. Report Date } \\
\text { June } 2009 \\
\end{array}$ \\
\hline & & 6. \\
\hline \multicolumn{2}{|c|}{$\begin{array}{l}\text { 7. Author(s) } \\
\text { Susan W. Mills, Stace E. Beaulieu and Lauren S. Mullineaux }\end{array}$} & 8. Performing Organization Rept. No. \\
\hline \multirow{2}{*}{\multicolumn{2}{|c|}{$\begin{array}{l}\text { 9. Performing Organization Name and Address } \\
\text { Woods Hole Oceanographic Institution } \\
\text { Woods Hole, Massachusetts } 02543\end{array}$}} & 10. Project/Task/Work Unit No. \\
\hline & & $\begin{array}{l}\text { 11. Contract(C) or Grant(G) No. } \\
\text { (C)OCE-9619605; OCE-9712233 } \\
\text { (G)OCE-0424593 }\end{array}$ \\
\hline \multicolumn{2}{|c|}{ 12. Sponsoring Organization Name and Address } & 13. Type of Report \& Period Covered \\
\hline \multirow{2}{*}{\multicolumn{2}{|c|}{ National Science Foundation }} & Technical Report \\
\hline & & 14. \\
\hline
\end{tabular}

15. Supplementary Notes

This report should be cited as: Woods Hole Oceanog. Inst. Tech. Rept., WHOI-2009-05.

\section{Abstract (Limit: 200 words)}

The purpose of this guide is to assist researchers in the identification of larvae of benthic invertebrates at hydrothermal vents. Our work is based on plankton sampling at the East Pacific Rise (EPR) $9-10^{\circ} \mathrm{N}$ vent field from 1991-present. We have included frequency data from large-volume plankton pump samples taken between 1999 and 2004 and time-series sediment trap samples from 2004-2005. The guide includes an "Introduction and Methods" section that details larval collection techniques, a "Terminology" section for gastropod and polychaete larvae, and "Literature Cited" for descriptions of species. Gastropod larvae are sorted by size and other larvae are sorted alphabetically within their taxonomic class. Each species information page also includes images of species that are similar in appearance. While our sampling was limited to EPR 9-10 ${ }^{\circ} \mathrm{N}$, the guide is useful to researchers working in other areas, since some species range from $21^{\circ} \mathrm{N}$ to the southern EPR, and some have congeners in other chemosynthetic environments, e.g., Lepetodrilus (Juan de Fuca Ridge, Mid-Atlantic Ridge, wood falls), and Bathymodiolus (Mid-Atlantic Ridge, seeps). We would like to expand the guide by including additional species from other areas and welcome contributions from other researchers. This guide is also available online at http://www.whoi.edu/vent-larval-id.

\section{Document Analysis a. Descriptors}

larval identification hydrothermal vents

East Pacific Rise

b. Identifiers/Open-Ended Terms

c. COSATI Field/Group

18. Availability Statement

Approved for public release; distribution unlimited.

\begin{tabular}{|c|}
$\begin{array}{c}\text { 19. Security Class (This Report) } \\
\text { UNCLASSIFIED }\end{array}$ \\
\hline 20. Security Class (This Page)
\end{tabular}

See Instructions on Reverse

\begin{tabular}{l} 
21. No. of Pages \\
$\qquad 108$ \\
\hline 22. Price
\end{tabular}

OPTIONAL FORM 272 (4-77)

(Formerly NTIS-35)

Department of Commerce 